INTERNATIONAL

ENERGY

ASSOCIATES

LIMITED

\title{
INSTITUTIONAL ARRANGEMENTS FOR THE REDUCTION \\ OF PROLIFERATION RISKS \\ FORMULATION, EVALUATION, AND IMPLEMENTATION \\ OF INSTITUTIONAL CONCEPTS
}

\author{
M. B. Kratzer \\ E. F. Wonder \\ J. E. Gray \\ S. B. Shantzis \\ N. F. Sievering \\ H. W. Paige \\ B. M. Jones \\ Report prepared by \\ INTERNATIONAL ENERGY ASSOCIATES LIMITED \\ under Subcontract Number 7605 \\ for \\ OAK RIDGE NATIONAL LABORATORY \\ Oak Ridge, Tennessee 37830 \\ Operated by \\ UNION CARBIDE CORPORATION \\ for the \\ DEPARTMENT OF ENERGY \\ Contract Number W-7405-eng-26
}




\section{DISCLAIMER}

This report was prepared as an account of work sponsored by an agency of the United States Government. Neither the United States Government nor any agency Thereof, nor any of their employees, makes any warranty, express or implied, or assumes any legal liability or responsibility for the accuracy, completeness, or usefulness of any information, apparatus, product, or process disclosed, or represents that its use would not infringe privately owned rights. Reference herein to any specific commercial product, process, or service by trade name, trademark, manufacturer, or otherwise does not necessarily constitute or imply its endorsement, recommendation, or favoring by the United States Government or any agency thereof. The views and opinions of authors expressed herein do not necessarily state or reflect those of the United States Government or any agency thereof. 


\section{DISCLAIMER}

Portions of this document may be illegible in electronic image products. Images are produced from the best available original document. 
This report was prepared as an account of work sponsored by an agency of the United States Government. Neither the United States Government nor any agency thereof, nor any of their employees, contractors, subcontractors, or their employees, makes any warranty, express or implied, nor assumes any legal liability or responsibility for any third party's use or the results of such use of any information, apparatus, product, or process disclosed in this report, nor represents that its use by such third party would not infringe privately owned rights. 


\author{
INSTITUTIONAL ARRANGEMENTS FOR THE REDUCTION \\ OF PROLIFERATION RISKS \\ FORMULATION; EVALUATION, AND IMPLEMENTATION \\ OF INSTITUTIONAL CONCEPTS
}

M. B. Kratzer

E. F. Wonder

J. E. Gray

S. B. Shantzis

N. F. Sievering

H. W. Paige

B. M. Jones

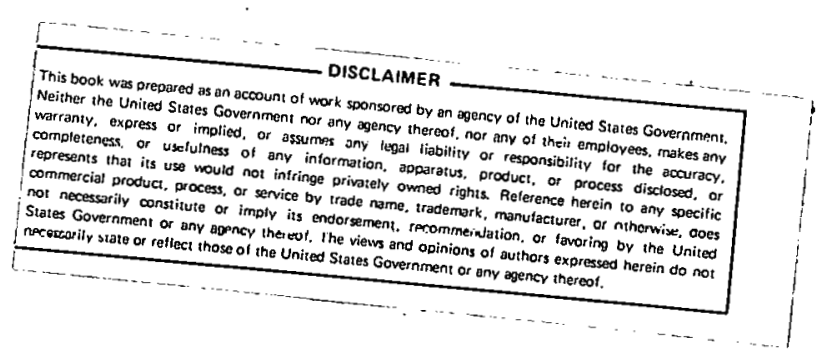

Report prepared by

INTERNATIONAL ENERGY ASSOCIATES LIMITED

600 New Hampshire Avenue, N.W.

Washington, D.C. 20037

under Subcontract Number 7605

for

OAK RIDGE NATIONAL LABORATORY

Oak Ridge, Tennessee 37830

Operated by

UNION CARBIDE CORPORATION

for the

DEPARTMENT OF ENERGY

Contract Number. $W-7405-e n g-26$

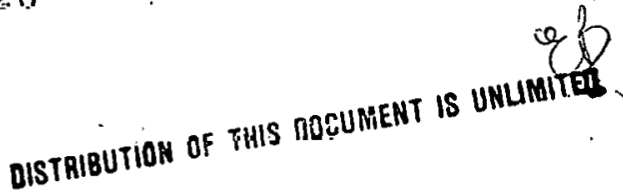


ABSTRACT

The purpose of this study was to: 1) identify alternative institutional arrangements applicable to the sensitive steps in the back-end of the fuel cycle that might reduce their associated proliferation risks; and 2) assess their advantages and disadvantages from the standpoint of nonproliferation effectiveness and political, economic, and operational acceptability. The concept of international or multinational custody of sensitive materials and facilities was found to offer a high degree of proliferation resistance and to likely be more acceptable to prospective participants than other institutional arrangements that intrude upon proprietary areas, such as facility ownership and management. 
PREFACE

In furtherance of President Carter's Nuclear Nonproliferation Policy announced on April 7, 1977, the Department of Energy initiated the Nonproliferation Alternative Systems Assessment Program (NASAP) to evaluate the proliferation risks and economic and energy security characteristics of alternative nuclear fuel cycles. Later that year, in October 1977, the International Nuclear Fuel Cycle Evaluation (INFCE) was launched on United States initiative to conduct a similar study on an international basis. Although the primary orientation of both these undertakings was technical, it was widely recognized that institutional arrangements were directly relevant to the issues of nonproliferation and energy security. Accordingly, both NASAP and INFCE included consideration of institutional arrangements in their studies.

As part of a broader effort to develop information and concepts on institutional arrangements in furtherance of NASAP and the U.S. contribution to INFCE, International Energy Associates Ltd. was requested by the Departments of state and Energy to undertake a study of "Institutional Arrangements for the Reduction of Proliferation Risks." This work, initiated in June 1978, was performed under subcontract No. 7605 with the union Carbide Corporation - Nuclear Division, with financial support from the Departments of State and Energy. The purpose of the study was to: 1) identify alternative institutional arrangements applicable to the sensitive steps in the back-end of the fuel cycle that might reduce their associated proliferation risks; and 2) assess their advantages and disadvantages from the standpoint of nonproliferation effectiveness and political, economic, and operational acceptability. 
This study was carried out in two distinct tracks. One track considered the applicability of detailed model institutions to existing facilities. The report of this track was submitted in draft form in January 1979, and was considered final by the sponsoring institutions. The other track systematically formulated and evaluated institutional concepts without constraint as to their applicability to existing facilities. This report is the culmination of that effort. Previous drafts of this report were provided to the sponsoring institutions in August 1978 , February 1979, and July 1979. Frequent briefings regarding the progress of the work, as well as consulting services requested by the sponsoring institutions, also were provided.

The study was conducted by an IEAL project team which included Myron B. Kratzer, Project Manager, Edward F. Wonder, John E. Gray, Steven B. Shantzis, Nelson F. Sievering, Hilliard W. Paige, and Blythe M. Jones. The major research on the second track study, which is the subject of this report, was conducted by Messrs. Kratzer and Wonder, who are also the principal authors of this report. Principal researchers for the first track study were John E. Gray and Steven B. Shantzis, who were also the authors of the draft main report covering that study.

A number of other individuals contributed to the study in various capacities as consultants to IEAL, and the authors are pleased to take this opportunity to acknowledge their important contributions. In particular, Lincoln Gordon, of Resources for the Future, was the principal contributor to Appendix B, an analysis of the political implications of active use denial. Lawrence $S$. Scheinman, Cornell University, was an important contributor to. the analysis of multinational ownership. Mr. Raymond Dickeman added his knowledge and expertise regarding industrial aspects of, nuclear energy and contributed importantly to the economic and operational acceptability analysis of the model institutions. 
A particularly important aspect of the study was the comprehensive review provided by a group of outside experts. In addition to the three individuals identified above, Phillip Farley, David Deese, and Mason Willrich participated in this review and offered valuable advice and comment.

Finally, IEAL wishes to acknowledge the invaluable assistance of individuals in the Department of State, the Department of Energy, and the Arms Control and Disarmament Agency, whose interest, critical review, and cooperation in providing guidance and background information were essential to the performance of this work. While many individuals played substantial parts in this way, we wish to mention with particular gratitude: Hugh Kendrick and Frederick McGoldrick of the Department of Energy; Frank Hodsoll and George Rathjens of the Department of State; and Charles Van Doren of the ACDA.

While recognizing the contributions and assistance of the individuals mentioned above, the authors accept full responsibility for the contents of the report and any errors of fact or omission.

M. B. Kratzer

E. F. Wonder

Washington, D.C.

December 1979 
TABLE OF CONTENTS

Preface

Chapter 1: INTRODUCTION

$1.1 \quad$ Background 1

1.2 Study Objective

1.3 Study Methodology 6

1.4 Proliferation Resistance Assessment 7

1.5 Results

1.6 International Auspices 19

$\begin{array}{lll}1.7 & \text { Implementation } & 10\end{array}$

Chapter 2: INSTITUTIONAL ASSESSMENT 14

$2.1 \quad$ Nonproliferation Effectiveness $\quad 15$

2.1.1 Elements of Proliferation Resistance Assessment 16

2.1.1.1 Proliferation Threats 17

2.1.1.2 Features of an International Institution 21

2.1 .1 .3

2.2

Dimensions of Proliferation Resistance 28

Political, Economic, and Operational Assessment 31

2.2.1 Criteria of Political and Economic Acceptability 33

2.2.1.1 Economic/Operational Acceptability Criteria 34

2.2.1.2 Political Acceptability Criteria 41

2.2.2 Institutional Features $\quad 47$

Chapter 3: FUEL CYCLES AND INTERNATIONAL INSTITUTIONS 61

3.1 Technical Modifications of the Fuel Cycle 62

3.2 Conclusions 72

Chapter 4: CONCEPT FORMULATION AND EVALUATION 75

4.1 Association 1.977

4.1.1 Composition $r$

4.1.2 Functional Scope $\quad 80$

$\begin{array}{lll}4.1 .3 & \text { Authority } & 82\end{array}$

4.1.4 Candidate Concept $\quad 84$

4.1.5 Concept Evaluation $\quad 85$

4.1.5.1 Nonproliferation Assessment $\quad 85$

4.1.5.2 Economic/Operational Assessment 89

4.1.5.3 Political Acceptability Assessment 91

4.2 National Facilities under Improved Safeguards 95

4.2.1 Technical Effectiveness 96

4.2.1.1 The Nature of the System 197

4.2.1.2 Restrictions on Safeguards Activities 98

4.2.1.3 Resources 100

4.2.2 Scope 101

4.2.3 Continuity 101

4.2.4 Limited Purpose . . 104

4.2.5 Candidate Concept 105 
4.2.5.1 Inspection Effort $\cdot 105$

4.2.5.2 Access Restrictions 106

4.2.5.3 Improved Funding 107

4.2.5.4 Irrevocability of Safeguards 108

4.2.6 Concept Evaluation 109

4.2.6.1 Nonproliferation Assessment 109

4.2.6.2 Economic/Operational Assessment 111

4.2.6.3 Political Acceptability Assessment 112

4.3 International Custody of Sensitive Material 115

4.3.1 Need for Custody. 115

4.3.2 Rationale for Extended Custody 125

4.3.3 Composition $\quad 128$

4.3.4 Siting $\quad 132$

4.3.5 Deposit of Material 134

4.3.6 Release Criteria 136

4.3.7 Critical Facilities and Research 137

4.3.8 Operation of the Institution 138

4.3.9 Candidate Concept 140

4.3.10 Concept Evaluation 142

4.3.10.1 Nonproliferation Assessment 142

4.3.10.2 Economic/Operational Assessment 145

4.3.10.3 Political Acceptability Assessment 146

4.4 Multinational Ownership and Management . 150

4.4.1 Iimitations of the Concept 151

4.4.2 Siting $\quad 154$

4.4.3 Composition $\quad 156$

4.4.4 Staffing and Technology Transfer 157

4.4 .5 Fuel and Service Assurances 160

4.4.6 Rights and Priviledges, Including Physical Security 161

4.4.7 Joint Management and Multinational Ownership '. 162

4.4.8 Candidate Concept $\quad 164$

4.4.9 Concept Evaluation $\quad 165$

4.4.9.1 Nonproliferation Assessment $\quad 167$

4:4.9.2 Ecunom1c/Operat1onal Assessment . 171

4.4.9.3 Political Acceptability Assessment 173

4.5 International (Global) Institution 177

4.5.1 Functions 177

4.5.2 Ownership and Management 180

4.5.3 Fuel Assurances 181

4.5.4 Candidate Concept 183

4.5.5 Concept Evaluation 183

4.5.5.1 Nonproliferation Assessment 183

4.5.5.2 Economic/Operational Assessment 185

4.5.5.3 Political Acceptability Assessment. 187

Chapter 5: IMPLEMENTATION OF INSTITUTIONAL CONCEPTS 191

5.1 Implementation Criteria 192

5.2 Evolution and Expansion $\quad 194$

5.3 Potential Participating Countries 196

5.4 Institutional Concept 198 
Additional Institutional Arrangements

APPENDIX A Institutional Precedents

APPENDIX B Political Implications and Acceptability of Active Use Denial for Sensitive Nuclear Facilities in Multinational Fuel Centers (MNFCs)

APPENDIX C References 


\section{INTRODUCTION}

\subsection{BACKGROUND}

The goal of nonproliferation policy, as it relates to the peaceful uses of nuclear energy, has been described as maintaining the greatest possible separation between peaceful uses and weapons application. To ensure this separation, a number of measures have been adopted over the years by the U.S. as weII as other nations, often collectively referred to as "the nonproliferation regime." Central to this regime are the nonproliferation undertakings: national commitments, whether given bilaterally or multilaterally, that peaceful nuclear activities, especially those which depend on assistance secured from other nations, will not be used for nuclear explosive purposes.

From the outset of cooperation in the peaceful uses of nuclear energy, these undertakings were viewed as too important to international security for their observance to be left to the conventional practices of voluntary compliance. As a consequence, another important element of the nonproliferation regime was created: the international safeguards system; a set of measures to verify compliance -- or detect noncompliance -with nonproliferation undertakings through objective technical means, including on-site inspection by international civil servents.

Inherent in the concept of safeguards is the presumption, even though usually tacit, that the detection of violations of nonproliferation undertakings will be followed by a response that, hopefully, would correct the violation and would, at a minimum, so increase the cost of noncompliance as to dissuade others from following a similar path. The mere detection of violation, unaccompanied by any. penalty, has no utility in avoiding 
proliferation. Rather, the presumption that effective counteraction will follow discovery provides safeguards with their deterrent effect.

With an increasing number of nations establishing facilities for undertaking the sensitive steps of the fuel cycle -- operations such as enrichment and reprocessing, which produce nuclear material readily usable in nuclear explosives -- the concern has grown that safeguards might not provide an adequate period of warning to allow effective diplomatic counteraction before diverted material is transformed into nuclear explosives. In response to this concern, the U.S. has adopted a domestic policy of deferral of the commercialization of reprocessing and plutonium recycle -- operations which, in their present form, involve the separation or handing of plutonium in forms readily transformable to nuclear explosive components -- and of advocating similar policies on the part of other nations. The intent of this deferral has been to permit a careful examination of the various fuel cycle options and their proliferation implications before the widespread adoption of reprocessing and plutonium recycle creates an irreversible reliance on these sensitive activities without having suitable means to avoid or to contain their proliferation risks in place. The International Nuclear Fuel Cycle Evaluation (INFCE) was established under U.S. initiative to undertake this assessment on an internatiunal basis.

While the emphasis of INFCE has been on technical means of imparting improved proliferation resistance to the nuclear power fuel cycle, the examination of institutional measures designed to accomplish this purpose was not excluded, and there has been growing interest since the establishment of INFCE in institutional approaches to improved proliferation resistance. The potential role of institutional approaches, and their relationship to technical approaches, can be readily seen by 
recalling that an important objective of nonproliferation policy is to avoid or minimize national access to sensitive facilities and sensitive materials. The examination of this objective indicates that proliferation resistance might be improved in either of two ways:

- by avoiding sensitive facilities and materials -- the domain of the so-called "technical fix"; or.

- by eliminating national access to them -- the domain of the so-called "institutional fix."

These two classes of measures are not mutually exclusive and, indeed, may be complementary. A fuel cycle which possesses proliferation resistance by, for example, avoiding the separation of pure plutonium is not an effective nonproliferation measure unless accompanied by an institutional arrangement through which countries undertake to use this fuel cycle. At the same time, there may be tradeoffs between technical and institutional measures for improved proliferation resistance. These tradeoffs arise from two considerations. The adoption of an effective technical measure may reduce the need for institutional measures to avoid national access (or vice versa). Similarly, the adoption of technical measures may reduce the practical political possibility of securing agreement on strong institutional measures for restricting national access.

\subsection{STUDY OBJECTIVE}

The objective of the present study of institutional mechanisms for the reduction of proliferation risks is to identify and assess possible institutional arrangements that might reduce the proliferation risks otherwise attendant upon the performance of sensitive back-end fuel cycle operations. It is emphasized that the performance of this study, under the sponsorship of the Department of Energy and the Department of 
State, carries with it no policy implications as to the desirability of undertaking these fuel cycle operations. The study is intended solely as an analytical tool in the consideration of policy alternatives in the context of INFCE, NASAP, or related nonproliferation assessments. The scope of the study, as specified by the Department of Energy, is the back-end of the fuel cycle, with the inclusion of reprocessing. Once again, it is emphasized that this scope is not indicative of a value judgment, either on the part of the Department of Energy or IEAL, on the desirability of including reprocessing in the light-water reactor fuel cycle, but simply a requirement by the Department of Energy for analysis of institutional mechanisms of potential applicability to such a fuel cycle, to complement and round-out other studies which have focused on the oncethrough fuel cycle and on the front-end of the fuel cycle.

While the study is confined to the back-end of the fuel cycle, it is believed that many of the results of the study and, in particular, its methodology are applicable to the front-end as well. What has not been considered is how institutional arrangements for the back-end of the fuel cycle would be affected if they incorporated front-end activities as well. Whether separate institutions for the front-end and back-end or more comprehensive arrangements covering both sets of activities are preferable is a complex question deserving explicit study.

Throughout this study, proliferation has been interpreted as the acquisition of nuclear explosives by a nation not previously in possession of them, as distinguished from the acquisition of nuclear explosives by a subnational group. This limitation is not intended to minimize the importance of the subnational threat, but it does reflect both a necessary simplification in the scope of the study and a judgment that subnational threats, almost by definition, do not call for multinational or international institutional solutions. 
An important parameter of this study has been the consideration of alternatives to conventional purex reprocessing as they might affect the nature of the institutional arrangements, which merit attention for applicability to the back-end of the fuel cycle.

As originally conceived, the study was to proceed in two somewhat independent tracks. The first would be a study of institutional arrangements that might be applicable to existing back-end fuel cycle enterprises, using these activities as building blocks toward a more universal institutional regime. The second. was to be a more unconstrained and systematic study, designed to isolate the factors that govern both the nonpro- . liferation effectiveness and the acceptability of multinational or international institutions, and on the basis of this assessment, formulate potentially attractive institutional concepts. While the methodology of the two study approaches was distinct, it was anticipated that the results could well converge on a similar conclusion.

This two-track approach was followed throughout the earlier phases of the study, and draft reports covering the results of both approaches were prepared, delivered to the sponsoring government agencies, and reviewed with a group of both government and outside experts. The conclusion of this review process was that only the "second track" -- the systematic analysis of institutional factors -- should be carried to preparation of a final draft. This judgment was based not on the conclusion that the first approach led to uninteresting results, but rather that its results were largely covered by and subsumed by some of the candidate concepts for the systematic review. This report describes the results of only the second track. 


\subsection{STUDY METHODOLOGY}

Despite considerable attention in recent years to possible international or multinational institutional arrangements for the conduct of sensitive fuel cycle operations, no genuinely systematic study of these alternatives appears to have been undertaken. An important objective of the present study, complementing and contributing to the identification and assessment of specific institutional models of possible interest, has been the development of a systematic methodology for formulating institutional models and evaluating them from the dual perspective of nonproliferation effectiveness and acceptability. This methodology, in brief, consists of the following steps :

- Identification of the several proliferation threats to which sensitive facilities and sensitive materials in the back-end of the fuel cycle are subject; for example, diversion, seizure, abrogation, and technology transfer.

- Identification of the various features of institutional arrangements; for example, composition, ownership mode, management mode, staffing, siting, and function.

- The generic assessment of the effectiveness of each of these features, i.e., their effectiveness without regard to specific institutional models in reducing the risk of each proliferation threat; for example, in what direction and to what degree does international, multinational, or national ownership of a sensitive fuel cycle facility affect the risk of diversion from that facility.

- A similar evaluation of the impact of various institutional features on the political, economic, and operational acceptability of the institution.

- A synthesis, based on these generic assessments of individual features, in the form of a set of model institutional arrangements of possible interest, and their assessment from the viewpoint of nonproliferation effectiveness and potential acceptability. 
Assessment of the nonproliferation benefits -- often referred to as the proliferation resistance -- of either technical or institutional options is central to the task of identifying improved fuel cycle or institutional measures. It has also proven to be a difficult requirement to meet; and this study is no exception to this experience. Moreover, while assessing the comparative proliferation resistance of alternative institutional schemes, although inherently more subjective, offers some chance of specific results, the inter-comparison of the proIiferation resistance of technical measures with that of institutional measures lacks any generally agreed and objective yardstick.

What is clear is that the proliferation resistance of specific technical or institutional measures. is not uniform, either for all countries or, especially, over time. A proliferationresistant fuel cycle that effectively. precludes the acquisition of weapons-usable material by countries of moderate technological capability may present only minor obstacles against such acquisition by countries of high technological capability. A country that falls into the former category today may be included in the latter category in a decade or so. In general, there appears to be agreement, for this reason and related reasons, that the nonproliferation effectiveness of technical measures is likely to decline with the passage of time.

The dependence of the nonproliferation effectivness of institutional measures on location and time is more difficult to categorize. The proliferation resistance of institutional measures appears to be less related to specific national characteristics and more dependent on the overall international climate than that of technical measures. For similar reasons, the effectiveness of institutional measures does not appear to depend on time. Their effectiveness may increase with the passage of 
time, as they gain more universal acceptance, especially if international stability is maintained or improved. The effectiveness of these measures may, on the other hand, degrade rapidly if international stability is seriously threatened. To a considerable extent, success is likély to beget success in the nonproliferation performance of institutional measures.

Uncertain as any forecast must be, it is apparent that, if only because institutional measures stand a chance of increasing in effectiveness over time against a certainty of diminishing effectiveness of technical measures, institutional alternatives merit serious consideration for inclusion within the new nonproliferation consensus now being sought.

\subsection{RESULTS}

The application of the methodology described above, in the judgment of the authors, has yielded interesting and, hopefully, significant results not heretofore derived from more intuitive assessments of institutional arrangements for sensitive fuel cycle activities. In brief, it is a conclusion of this study that the internationalization or multinationalization of such basic institutional features as ownership, management, operation, and staffing yield relatively limited benefits from the viewpoint of nonproliferation, while having significantly adverse effects on the probable acceptability of institutions incorporating these features. Rather, the nonproliferation benefits of intentional or multinational institutions flow primarily from placing responsibility for material control in international hands. As a result, the optimum institutional arrangements from the standpoint of both securing important nonproliferation benefits and maximizing prospects for acceptability may be arrangements in which sensitive facilities remain nationally owned, managed, and operated, but function under a regime of international or multinational control that we designate "custody." 


\subsection{INTERNATIONAL AUSPICES}

An important, though as yet undefined, concept in nonproliferation policy is that of "effective international auspices." The importance of this term derives from its appearance in several provisions of the Nuclear Non-Proliferation Act of 1978 (NNPA), as a necessary condition for the acceptable conduct of reprocessing or other sensitive fuel cycle activities. Section 403 of the NNPA, for example, requires the President to seek agreement to the policies that include a "prohibition against reprocessing" except "in a facility under effective international auspices and inspection" [Section 403 (b)(1)].

The legislative history of the Act stresses that flexibility in its meaning was deliberatel-y intended, since "considerable study and negotiation will be required to determine precisely what arrangements would be most desirable from the standpoint of reducing the risk of proliferation . . . and achieving widespread participation" [Senate Report No. 95-467, Page 25]. Thus, the emphasis in defining compliance with this requirement has been placed on the results achieved, including both effectiveness and acceptability, rather than on the means of achieving them. It is, of course, clear from the language of the Act that "effective international auspices" requires something more than international safeguards, and the senate Report cited above confirms this interpretation.

The Report also indicates that "there should be international participation in the operation and/or ownership of the facility." This phase appears to have ample flexibility to encompass several of the models considered in this study, including that of custody. 
It is not, of course, within the scope of the present study to seek authoritative interpretations of the statutory concept of "effective international auspices." The study, however, is believed to be in keeping with and to have contributed to the Congressionally recognized requirement that only by "considerable study and negotiations" can the most desirable arrangements be identified.

\subsection{IMPLEMENTATION}

In addition to the formulation and assessment, on a generic basis, of several institutional concepts for the back-end of the fuel cycle, consideration is given to how selected concepts developed in the conceptual portion of the study might be implemented. The examination of implementation inevitably raises questions of the real-world groupings of nations that must be dealt with in the development of institutional arrangements and the incentives and inducements to which they are most likely to respond. While implementation is discussed at length in Chapter Five, some preliminary comments are appropriate at this time.

In Chapter Two of this report, it is pointed out that the institutional arrangements for the reduction of proliferation risks may offer both intrinsic and extrinsic nonproliferation benefits. Intrinsic benefits refer to the increased proliferation resistance of an activity conducted under the institution's auspices compared with the proliferation resistance if the same activity were conducted only under national auspices and international safeguards. Extrinsic benefits refer to the ability of the institution to limit the number of and locations where sensitive fuel cycle activities are performed, both by members of the institution and by non-members.

Any limitation on the performance of such activities by members would presumably be provided for within the terms of the institution's charter itself. Limitations on non-members, on the 
other hand, would presumably be realized through indirect means, such as providing an attractive source of supply for the materials or services in question, by limiting the members' freedom to transfer technology or otherwise assist in the establishment of new facilities, and by creating an international climate in which proceeding with sensitive activities on a national basis is regarded by the world community as inappropriate.

The extrinsic benefits of any institutional arrangement are closely linked with the question of whether it can be implemented and how, since it is in the implementation process that a bargain is struck between the benefits made available to countries who become members of the institution and the acceptance of any constraints that the institution places on the freedom of action its members would otherwise enjoy. These restraints may be of two kinds:

- to accept the institution's controls on any fuel cycle activities, falling within the scope of the institution, which the member conducts; and

- to refrain from, or accept limitations in the right to engage in, particular activities.

Since participation in an institutional arrangement involves restraints, agreement to do so will normally require incentives or inducements in some form. Consideration of how institutional arrangements can be implemented is thus, in essence, an examination of the quids pro quo -- the incentives and leverage by which participation by specific countries in specific arrangements can be realized.

Just as the nonproliferation benefits of an institutional arrangement may be either intrinsic to the institution or extrinsic, so too may the considerations favoring participation 
be either intrinsic or extrinsic. Intrinsic incentives are the benefits offered by the institution to participants. These. take such forms as improved access to financing, technology, managerial skills and the like, economies of scale, and improved assurances that the materials or services offered by the institution will be available. These are examined in a generic form in this report as part of the political, operational, and economic assessment of each concept studied.

Extrinsic considerations favoring participation are those that do not flow directly from the institution itself. It is clear that they may take the form either of positive incentives or penalties. For example, one or more countries might extend technical, economic, or even defense assistance otherwise unavailable to a participant in an institutional arrangement. Conversely, failure to participate in an institution could result in the withdrawal of benefits which a country might otherwise be able to count on receiving. While these extrinsic incentives and penalties may be important in bringing about the creation of desirable institutional arrangements, it is clearly preferable that the creation of an institution and continued participation in it be based insofar as possible on intrinsic considerations. Extrinsic factors, no matter how persuasive at the moment, can change or erode as governments, policies, and circumstances change, thus greatly increasing the risk that participation that was dependent on these extrinsic factors will end when they are removed. It is for this reason that institutional design, per se, deserves the most careful analysis, with the objective of devising arrangements in which intrinsic benefits and disadvantages are at least balanced, and, preferably, clearly on the positive side.

The analysis of implementation, as carried out in this study, is distinct from the formulation of detailed bargaining tactics. Although such tactics would be devised in due course, the 
implementation analysis in Chapter Five focuses upon the selection of the specific institutional concept to be implemented, the criteria that implementation must satisfy, the approach to the composition of the institution, the selection of specific countries as potential participants, and the leverage and incentives available to establish the institution.

The institution that was selected for implementation, on the basis of the conclusions of Chapters Three and Four, is custody. Among the criteria which an implementation strategy must satisfy are getting an early start to institutional implementation, application to existing sensitive facilities, accommodation of new facilities without stimulating their construction, and appropriate composition in the membership.

Institutional expansion, which involves increasing the membership, must be kept distinct from institutional evolution, in which it is hoped that the role and responsibility of the institution may strengthen over time. An evolutionary approach to implementation is potentially dangerous if it encourages acceptance of an initially weak institution in exchange for broader membership, since the prospects of evolution actually occurring under these circumstances are not good. This consideration supports a clear preference for a multinational rather than international composition, since the diversity of interests in a group of the latter composition could make agreement on an institution that is effective from the start difficult to achieve.

Finally, Chapter Five suggests one approach to implementation entailing implementation of custody first at small and mediumsized facilities in order to get an early start and still win support for the institution from a number of important nuclear countries. This initial group could eventually expand to include large commercial facilities. 


\section{INSTITUTIONAL ASSESSMENT}

The gains in proliferation resistance afforded by an institution and the economic and operational advantages and disadvantages of the institution determine whether or not the particular institutional arrangement is desirable on nonproliferation grounds and attractive on energy and commercial grounds. The relationship between proliferation resistance and political, economic, and operational acceptability -- whether there is a tradeoff between the two or whether both can be realized with little or no expense to each other -- determines, to a major extent, whether the institution is acceptable to prospective participants.

The following analysis develops nonproliferation and acceptability criteria against which individual features of an institution can be assessed in a generic fashion. This offers a preliminary view of the advantages and disadvantages of particular institutional features. Specific institutional concepts that combine these features in, different institutional arrangements are analyzed in Chapter 4.

The first major section of this chapter identifies major proliferation risks with which an institution must deal, identifies specific institutional features, and analyzes -- in a generic way -- their impact upon each $r$ isk in terms of how they affect the difficulty, detectability, and penalties of misuse. The second major section identifies political, economic, and operational considerations that an institution must address and their implications for designing institutional concepts.

\subsection{NONPROLIFERATION EFFECTIVENESS}

The nonproliferation benefits of institutional arrangements fall into two general categories: those which are intrinsic to the activities undertaken by the institution, i.e., which reduce the 
likelihood of proliferation resulting from the multinational or international activity in comparison with a similar activity conducted under national auspices; and those which are extrinsic to these activities; i.e., which reduce proliferation risks by reducing the number or geographic spread of the sensitive activities in question.

The potential ability of institutional arrangements to reduce the proliferation risks associated with the sensitive activities taking place within the institution is not an automatic and inevitable characteristic of all such arrangements. The nonproliferation strength of any particular arrangement depends on the specific features of the arrangement in question. As discussed below, the ability of institutional arrangements to realize intrinsic benefits depends upon the organization of the institution, the functions it performs, the mutual nonproliferation obligations that it requires of its members, and the improved potential for counteraction in the event of violation that the institution makes possible.

The extrinsic nonproliferation benefits of institutional arrangements are of considerable importance as well. An institution that effectively controlled the sensitive facilities and materials under its jurisdiction, but that did little to constrain the number or location of sensitive facilities or stockpiles of sensitive maleirials in both member and non-member nations of the institution, could weaken security and international stability. Benefits of an extrinsic nature could be achieved through the existence of institutional arrangements, which themselves may impose technical handicaps, in the form of policies restricting the transfer of sensitive technology or foreclosing the construction. of sensitive facilities outside the institutional framework, or which establish a political presumption that such facilities, even if legally acceptable, are politically illegitimate and stand in contradiction of international norms. 


\subsubsection{Elements of Proliferation Resistance Assessment 3}

The approach employed in this study to the assessment of the intrinsic proliferation resistance afforded by a particular institutional arrangement focuses on the effect of a set of institutional features on a variety of proliferation risks. This approach facilitates the direct evaluation of the effectiveness of specific institutional configurations through the identification, in a qualitative fashion, of both the direction and strength of various institutional features in providing protection against each proliferation threat.

The analysis is based upon the institutional features and proliferation threats listed below:

Proliferation Threats

National Diversion

National Seizure

Abrogation or Withdrawal

Technology Transfer
Institutional Features

Composition

Ownership

Management

Staffing

siting

Functions

The following discussion defines the threats considered here, and generically assesses -- that is, without reference to any specific institutional model -- the effectiveness of each institutional feature in reducing the risk of each proliferation threat in terms of the following three questions.

- How does the feature affect the economic, technological, and political difficulty of misuse of sensitive nuclear material or production facilities in the activities under the institution?

- How does the feature affect the likelihood and timeliness of the detection of any misuse? 
- 'How does the feature affect the ability of the institution to respond effectively to violations or threatened violations?

The net assessment of the responsiveness of the institution to each type of threat yields some measure of the intrinsic proliferation resistance of the institution.

The extrinsic proliferation resistance of the institution is dependent upon the institution's ability to increase the political and economic pressures against autonomous facilities, and thereby discourage their construction, and to strengthen the response capability of the international community where misuse of autonomous facilities and materials occurs. The following discussion deals primarily with intrinsic proliferation resistance.

\subsubsection{Proliferation Threats}

The credibility of the threats to which the institution must be responsive, and the probability that these threats will occur, is a function of several factors that characterize them. The credibility of the threat may depend on whether subnational or national adversaries are involved and on the level of technical sophistication and ability of the adversary to carry it out. One may also distinguish belween threats that are simple acts or lengthy processes and those that are overt or covert. The focus of the threat -- sensitive facilities, sensitive materials in transit, know-how -- may have a considerable bearing upon which institutional feature(s) is the most relevant to reduction of the threat.

Subnational threats are excluded from the assessment of the proliferation resistance of each institutional concept for several reasons. The most serious threat posed to regional and world order may be the propsect of national proliferation, not only because of the possible size of the nuclear arsenals involved, but 
because of the likely greater skill and technical capacity of a national proliferator to develop a nuclear explosive device. This is not meant to denigrate the seriousness of a credible subnational threat, but it is meant to recognize that institutions that do little to elevate the barriers against national proliferation would constitute an insufficient and unacceptable international response to the proliferation problem. Moreover, institutional approaches to proliferation resistance almost by definition are not called for by subnational threats that are within the domain of the internal security function of the state. This reasoning leads us to set aside subnational threats for the moment and concentrate upon threats posed by national adversaries.

National Diversion has long dominated nonproliferation thinking. It is defined here as a long-term activity of a covert nature with small amounts of special nuclear materials (SNM) taken repetitively such that only cumulatively is a weapons potential posed. Sensitive facilities might be the most probable, though not exclu- sive, focus of this activity. The most likely source of the diversion threat would be the country hosting the sensitive facility. Although other members of the institution conceivably could attempt to divert, the substantial logistic problems encountered in carrying out diversion elsewhere than on home territory would reduce the attractiveness of this type of misuse, as well as the probability of its success and, if attempted, the scale of diversion that might be achieved.

Another characteristic of this risk is its relationship to the economic, political, and strategic characteristics of the country in question. Diversion of small quantities of weapons-useable material seems unlikely to be an attractive path to proliferation on the part of large politically and economically powerful nations whose strategic needs for nuclear weapons, should they decide to seek them, would be for a large sized arsenal. At the same time, while economically and politically weaker nations might perceive smaller requirements of weapons-usable material, the size of the 
nuclear complex or facility in such states from which diversion might be attempted, in general, would be smaller also. In the first case, diversion likely would not yield enough material quickly enough; in the latter, the prospects of detectability at smaller facilities may be higher.

National Seizure refers to the abrupt and, presumably, overt expropriation of sensitive material or production facilities in order to acquire an immediate weapons potential. Barring highly improbable circumstances, the only likely source of a seizure threat against sensitive facilities is the host country. Seizure of sensitive material in transit or stored at a reactor by the countries where such material is located is, however, also a credible threat. The credibility of seizure at the preferred proliferation path increases as the requirements of a militarily significant nuclear weapons program expand. The act of seizure is inherently overt and, thus, in most cases would be self-announcing. An act of seizure might, however, go unnoticed or undetected for some time if the institutional arrangements for surveillance were lax. Although an institution itself may not be capable of stopping a seizure effort using armed national force, it may increase the consequences of seizure and, thus, the deterrent effect posed by the existence of the institution.

Abrogation or withdrawal is employed here to refer to an action taken by a national to free itself from nonproliferation undertakings involving sensitive materials or facilities. It could include abrogation, as that term is usually understood as being the exercise of treaty withdrawal or termination of rights, or expropriation, and other similar actions.'

Although abrogation through denunciation or refusal to honor nonproliferation commitments, or exercising withdrawal provisions of a binding undertaking are acts of quite different legal and political standing, the end result of either could be the same -- the freeing of a sensitive facility or materials from institutional 
arrangements. Both abrogation and withdrawal would be overt actions likely to be taken only after careful deliberation and, hence, should be viewed as the manifestation of substantial resolve on the part of the abrogating or withdrawing party. Although a withdrawal confined to a specific facility is conceivable, the more probable pattern would be a general refusal to honor international commitments that encompass an entire nuclear program.

- Abrogation is a threat that could involve either the host country of a sensitive facility or any other member of the institution. The withdrawal of a non-host country would pose a proliferation threat of a limited and less immediate nature by threatening the viability of the institution and by removing the institution's restraints on the withdrawing party. Withdrawal of a host country could pose a direct proliferation threat. On the other hand, withdrawal could conceivably be occasioned by dissatisfaction with economic aspects of the institution and need not necessarily communicate an immediate intention to proliferate. Whether a worst-case assumption of an intent to develop nuclear explosives would be justified in such a situation would depend upon the specific country involved and all the circumstances surrounding the action.

Technology transfer, as a source of proliferation risk, involves the potential for misuse of information relating to sensitive facilities gained by the parties to an institutional arrangement. It could include access to scientific and engineering know-how and acquisition of hands-on operation, design, or construction experience that could be applied to the construction and operation of an out-of-system plant by either the host country or any other member. Technology transfer is a potential risk at both the corporate and government levels of an institution and broadens the possible sources of proliferation threats to include all the participants in the institution, unlike the other threats in which the host country is of primary concern. 


\subsubsection{Features of an International Institution}

Institutional arrangements derive their proliferation resistance from the way in which the various features enhance the difficulty, detectability, or penalties of each of the proliferation threats. The specific form of these features and their combination are of fundamental importance to the proliferation resistance of the institution.

The composition of the group involved with the plant has a bearing upon the level of all risks and the credibility of risk reduction in the eyes of outside observers. The group may be international in composition if it encompasses all countries utilizing sensitive facilities or materials, or multinational if some subset of such countries participates. The most significant aspect of composition is the incorporation among the partners of a genuine adversity to the possible misuse of the plant. International or multinational control of the plant would be effective only where the members, themselves, have a fundamental interest in preventing each other from utilizing the plant through diversion or seizure for military ends. At a minimum, misuse by any member must be inimical to the interests of at least one other.

The interest of regional adversaries, or better yet, members that are also nuclear weapon states, in ensuring that the others cannot misuse the plant would enhance the institution's credibility for reducing proliferation risks. Of particular importance is the extent to which composition might affect the consequences of being detected. A high degree of political, economic, or military interdependence among the group could significantly raise the consequences of being detected. The group must also be composed in such a way that sufficient technical competence to run the facility efficiently and to conduct safeguards-related and material control operations is present. 
Composition can also affect proliferation resistance in other ways. For example, a project that does not appear credible in a business sense or that fails to meet legitimate needs for the materials or services in question might encourage countries to resort to indigenous options, resulting in an aggravation of the threats associated with diversion, seizure, and abrogation.

Ownership refers to whether the facilities or materials in question are owned by the institution itself, by the host country or its nationals, or in some other mode. Ownership of a sensitive facility can be relevant to reducing the threat posed by abrogation and seizure and, possibly, diversion and technology transfer as well. The possibility of abrogation by an entire group owning a plant has low credibility to begin with and would be further reduced if the group is composed of members with adverse interests regarding proliferation. The potential for group abrogation is, thus, a very minor consideration. The more credible course of action is for the host country to attempt to misuse the facilities or materials under the institution's jurisdiction. Host country seizure is an ever present risk regardless of institutional arrangements, but group ownership could strengthen the deterrence of such an act by increasing the likelihood that a quick and direct response would be forthcoming from the remaining partners whose property was being seized. In this case, one might expect group ownership to increase the costs of any act of misuse.

International or multinational ownership is the institutional feature that usually comes to mind first when institutional arrangements for the reduction of proliferation risks are contemplated. 'l'he foregoing considerations indicate that there are nonproliferation benefits attendant on international or multinational ownership, particularly against the threat of seizure or abrogation, but there is little basis on which to concluae that these benefits are compelling or that they can be realized only through internationalization or multinationalization of ownership. On the contrary, the growing acceptance in recent years of the 
practice of expropriation or nationalization, particularly when adequate compensation is offered, leaves reason to doubt that international/multinational ownership alone offers convincing nonproliferation advantages.

Management has direct relevance to diversion threats insofar as it affects a project's operating procedures and decisions that have relevance to the effectiveness of safeguards. Additionally, joint management would provide some obstacle to the formulation and implementation of diversion scenarios by the host or other participating countries, as opposed to national management, where such decisions are the prerogative of the operator alone. Joint management could contribute to the adoption of higher nonproliferation-related operating standards than those that some members might have adopted on their own and in more rigorous adherence to: good safeguard and accountability practices. Host country abrogation or seizure of a plant under multilateral management could entail more severe penalties and, thus, have a higher decision threshold than would seizure of a plant under national management. Joint management, however, unlike its national counterpart, might create a presumption on the part of some members toward eventual technology transfer. Joint management without some access to design and engineering data could prove difficult and ineffective. Nonetheless, divided management dilutes national authority and capability to plan diversion and to operate a facility after abrogation or seizure by the host country.

Staffing could have a direct bearing on the detection of diversion. National staffing would place the full burden of surveillance upon inspection by the IAEA or other institutional authority. On the other hand, in terms of diversion risk, multinational staffing at particularly sensitive locations could provide an effective and economical means for detection of diversion by exposing any diversion attempt to observation and reporting by nationals of other countries. Achievement of this "built-in" inspection capability, however, is not an automatic consequence of 
multinational staffing. It depends on careful structuring of the staff to ensure a multinational presence at all sensitive points at all critical times, on the willingness of the staff so deployed to perform a surveillance responsibility along with their normal operating responsibilities, and on the existence of reporting channels for any information obtained by the multinational staff. On the other hand, while the risk may be small, multinational staffing at sensitive locations would create the opportunity for diversion by nationals, not only of the host country, but by all those with access to the sensitive locations.

Staffing also may have a more indirect relevance to seizure, insofar as the concealment of preparations inside the plant would be more difficult if those involved had to work in constant contact with personnel from other nations. On the other hand, multinational staffing would increase risks associated with technology transfer. The major question of multinational staffing in this regard is whether the acquired operating experience is sufficient to permit continued plant operation by a single party after abrogation or seizure.

Legitimate questions exist as to whether multinational staffing is a practical matter from an industrial operation point of view and as to whether it, in fact, can offer the inspection benefits frequently attributed to it.

Siting as an institutional feature has both qualitative (where the facilities are built) and quantitative (how many are built) aspects. The ideal qualitative arrangement from a nonproliferation standpoint would be to confine sensitive facilities to existing nuclear weapons states. But failing this, confinement of such plants to internally stable and diplomatically neutral countries with no interest in or need for nuclear weapons, or to countries incapable of resisting sanctions, even if they possessed a few newly acquired nuclear weapons, might be of interest. Less optimal siting would require correspondingly stronger institutional 
and technical arrangements to compensate. Siting arrangements that entail quantitative limitations on the total number of plants are important in their own right.

Siting is highly relevant to all threats. The credibility of seizure or abrogation by the host country is directly affected by the qualitative restrictions just discussed. National abrogation certainly would be less threatening if the potentially dangerous facilities or materials were located in another country. The likelihood that a would-be proliferator would resort to diversion would be greatly reduced if the diverted material had to be secreted out of another country. Quantitative restrictions would facilitate the concentration of surveillance resources. Furthermore, clear specification of qualitative and quantitative restrictions would make the very construction of a plant elsewhere an explicit provocation and violation of international understandings, even if no weapons motive was present.

Important as siting is, an institution or regime that relies exclusively on confining sensitive facilities to "acceptable" sites for its proliferation resistance has serious shortcomings. This is because such restrictions are inherently discriminatory and, thus, unlikely to be lasting. An institution that confines reprocessing plants, for example, to nuclear weapons states without concurrently adopting other proliferation-resistant features may, in the long run, be an institution of limited proliferation effectiveness.

The functions performed by the institution determine, in major part, the exterisiveness of the institutional arrangements, the level of collective organization they require, and, quite possibly, their nonproliferation effectiveness. The functions of an institution, in order of increasing extensiveness and complexity, include:

- adoption of common codes of conduct with regard to nonproliferation policy; 
- improved safeguards (while still confined to the traditional safeguards task of verification);

- custody of sensitive materials and facilities; and

- operation of sensitive facilities.

A particular institutional arrangement may confine itself solely to one function or combine several of them. In general, the above mentioned responsibilities could be expected to be cumulative, i.e., an institution would incorporate all of the functions that appear on the list above its most intensive role. This provides a spectrum of institutional arrangements that are discussed in greater detail in Chapter 4 .

A code of conduct for suppliers, much as already exists in the actions of the London Supplier Group, would further harmonize export or other nonproliferation policies and, thus, improve the predictability of the response of the supply system to requests for sensitive facilities, materials, or services. Such a code, while it might demand full-scope safeguards, would not improve the safeguards systems themselves. Although a code might specify the sanctions that a supplier group might take against misuse, the absence of institutional arrangements extending to sensitive facilities and materials might leave the political deterrent against seizure or abrogation unaffected. A supplier code of conduct similarly might not effectively guard against misuse by one of the participants, since a characteristic of an institution whose function is confined to the establishment of a code of conduct is the absence of an overall enforcement mechanism or entity.

Improved safeguards would directly improve the capability of present safeguards systems to detect diversion and possibly seizure as well. An institution confined to this function, however, would not measurably increase the deterrent inherent in the institution against abrogation and seizure (other than through greater assurance of detection) above that which current arrangements already 
provide. In particular, it would not crystallize the responsibility for responses to misuse that, in the current system, is diffuse. This function also does not address itself to the possible need for qualitative or quantitative restraints on sensitive facilities.

Custody means actual legal and physical control over sensitive facilities and materials for the sole purpose of guarding against their use for unauthorized purposes. If custody were the responsibility of a multinational or international institution, physical control of the sensitive materials or facilities in question would be exercised by personnel of the institution with authority over the host country itself. In particular, the institution would have full responsibility for the ingress and egress of sensitive materials and personnel and would enjoy the unqualified right to account for and control materials within the facilities under its jurisdiction. In effect, the institution would bear the same relationship to national facilities under its auspices as does a national government to private or subnational facilities within its territory. It need not own, manage, or operate them, but has ultimately unlimited power to assure their use for authorized purposes only.

An institution that exercised a custody function might also augment the safeguard resources applied towards detection of diversion. More importantly, however, it would increase the political deterrent against seizure or abrogation by making more distinct the direct interests of the members of the institution in preventing misuse. Custody represents an attempt to establish this deterrent without interfering with national operation of the facilities and without creating a presumption, one way or the other, as to how technology transfer issues will be addressed.

Operation of sensitive facilities by an institution represents the most complex and intrusive arrangement. The purpose of such an institution would be to incorporate the safeguarding and deterrent 
aspects of institutions into the actual organization and operation of the facilities themselves. It would involve management. and staffing at all times by the international/multinational entity and would ordinarily, although not necessarily, imply international/multinational ownership as well.

Nonetheless, operation of a facility by an international/multinational institution would not, in itself, ensure the nonproliferation benefits that accompany international/multinational custody. These would result only if there were a conscious effort to incorporate into the institutional arrangement both clear undertakings and accompanying arrangements to ensure that the material control/custodial function, like all other operating responsibilities, be placed in the hands of the institution.

It is even conceivable, although improbable, that an organization could be devised in which all operating responsibilities, except that for material control and custody, were vested in the international/multinational institution, while the latter responsibility would remain in national hands. In such a case, sensitive material could be transferred to unauthorized uses on the basis of national decision, without the necessity for an overt take-over of plant operations.

\subsubsection{Dimensions of Proliferation Resistance}

Finally, one must consider the effect of each institutional feature upon specific proliferation threats in terms of how it increases the difficulty of misuse, its detectability, and the consequences of being detected.

The difficulty of misuse under the institution is a function of the amount of political, economic, and technical resources that must be committed to a misuse attempt. The degree of difficulty must be assessed, not only in terms of misuse of facilities and materials under the jurisdiction of the institution, but also in 
terms of resorting to out-of-system clandestine or stand-alone facilities that might be encouraged and even facilitated by some institutions. Although accessibility is sometimes thought of as exclusively a technical attribute of the proliferation-resistant design of plants or fuel, this should not obscure the fact that the effectiveness of the technical impediments to access that such a design introduces depends upon the technical sophistication and resources of the adversary. Thus, the degree to which the organization of the institution, itself, may significantly complicate misuse is of pivotal importance.

Detectability refers to the timely discovery of misuse of sensitive nuclear materials and facilities. It includes, but is not limited to, detectability through international (IAEA) safeguards. other means of detection include national intelligence and the inherent "self-announcing" characteristic that particular violations may have. If one conceptualizes detectability as essentially a problem of information processing, the effectiveness of the institution in enhancing detectability is a function of the strength, character, and timing of the signals generated by misuse and of the speed and correctness of the authorized bodies in interpreting the signals.

The institution and its detection system must be able to prevent the "noise". generated by legitimate fuel-cycle operations from obscuring the "signals" resulting from misuse. A high signal-tonoise ratio, implying that the signals are both prominent and unambiguous, is essential to detectability, as is the ability of the institution to draw correct conclusions despite what, in reality, may be often incomplete information on a specific incident. The contribution of the institution includes the techniques and procedures used to gather, interpret, and communicate information which are part of the institution, the degree to which it enhances current safeguards systems, as well as whatever improvements in intelligence capabilities or in the visibility of misuse that the institution may make possible. 
The consequences of being detected are a function of the political, legal, economic, technological, or military responses that would result from detection of misuse. Perhaps more important than the formal specification of these responses is the degree to which the existence of the institution improves the probability of national or concerted action. The consequences of being detected at a violation are likely to be contingent upon the nature of the violation and, possibly, its degree of success as well. It would seem logical that the penalties would be more severe where misuse is successful than where it is not.

In terms of assessing the effectiveness of the institution, those penalties that might ensue regardless of the existence of the institution, such as military intervention, must be kept distinct from those that may be intrinsic to the institution itself, such as the denial of nuclear fuel. There is no reason in principle, however, why an institution's formal penalties must be confined to the nuclear field. Even more so, its potential for informal or ad hoc penalties might go far beyond the nuclear, or even the economic sphere. It must be kept in mind that the potential of the institution to deter misuse quite likely depends upon its ability to trigger a broad range of penalties that cross over the nuclear boundary.

Moreover, the institution may increase the political price of possibly legal but, nevertheless, provocative acts, such as withdrawal from the institution, refusal to join it, or research in sensitive technical areas independent of institutional control. Since these activities in themselves need not involve misuse of sensitive material or sensitive facilities, it may be useful to treat them as a separate category of implicit violations from the standpoint of the penalties that they will incur.

As with any deterrence relationship, the credibility of deterrence rests on the ability and willingness of the actors to impose penalties of sufficient magnitude. F'or this reason, the composition 
of the institution is of primary importance to the penalties and, thus, the deterrent potential associated with the institution.

As noted earlier, a composition that comprises countries engaged in broad and intense political, economic, and security relationships -- in short, countries that have a high degree of interdependence -- may be the most effective composition for proliferation resistance, so long as the indispensable element of a strong nonproliferation interest is present. Large institutions of global or international membership would, on the face of it, include members with close interdependence. However, the influence and motivation of these countries to take effective action against violation by one of their members could well be diluted by the presence of many other less interested and interdependent nations within the organization.

\subsection{POLITICAL, ECONOMIC, AND OPERATIONAL ASSESSMENT}

The acceptability of international institutions is a function of their political, economic, and operational characteristics, as well as their nonproifferation effectiveness. An institution that failed to perform its assigned task in an economically acceptable manner could make matters worse for the international control of nuclear energy than had there been no institution at all. Serious economic shortcomings, beyond those which one might tolerate in order to achieve nonproliferation goals, could be perceived as: evidence of the bankruptcy of the entire approach and, as a result, could encourage countries to build the indigenous, autonomous facilities the institution was intended to prevent.

The same institutional features that influence proliferation resistance, together with an additional feature -- market -which is relevant predominantly to acceptability rather than proliferation resistance, also have political, economic, and operational implications that affect the willingness of countries to participate in the institution. Despite the contrary 
impression, that many share, these implications of institutional features need not necessarily be negative. International institutions may offer economic and political benefits to some countries, such as access to efficient facilities or political legitimacy, which would not be obtainable in a purely national undertaking. A generally positive impact is an important factor in determining whether countries will be prepared to embrace facilities under international arrangements as an alternative to autonomous national plants, thus, limiting the overall number and location of sensitive facilities.

At the same time, a positive political, economic, and operational balance may not be essential to the adoption of a particular institutional arrangement, provided that its perceived nonproliferation benefits are adequate to overcome any negative impact in other areas. Institutional assessment involves weighing the importance of the institution's net proliferation resistance against its net political, economic, and operational acceptability. This yields a composite judgement that provides a foundation for rejecting or endorsing a particular institutional concept. Proliferation resistance is an absolute prerequisite for any concept to deserve further attention. Although the institutional assessment along each of the two dimensions -nonproliferation effectiveness and acceptability -- is carried out independently, the two dimeneione are not accorded equal weight in the overall assessment. ;

The considerations that guide acceptability assessment can be divided into two broad categories: those related to economics and operation; and those related to political acceptability. Although energy security is a prominent consideration in both economic and political terms, in this study it is categorized as a political factor, since political considerations predominate in its impact. This view recognizes that energy security entails both economic and political components that are not easily separable. An institution that appear to be deficient 
in terms of security of energy supply might, for example, have such important economic impacts as discouraging investment in energy intensive industries, even without an actual supply interruption. If interruption did occur, the economic impacts could clearly be of great importance. Nevertheless, the political aspects of energy security, in particular its implications for national security and political independence, are the dominant features of energy security.

It is also evident that agreement to participate in an institutional arrangement may be brought about by factors extraneous to the intrinsic merits of the institutional arrangement. The detailed evaluation of this possibility is outside the scope of this section of the study, but some general remarks. are appropriate at this point. Such extrinsic factors might take the form of additional incentives or benefits, for example, security guarantees or technical and economic assistance beyond the field covered by the institution, or of penalties or disincentives, such as withholding otherwise available military or economic assistance. While such extrinsic "sweeteners" or clubs may bring about agreement to an arrangement that a particular nation might otherwise be unwilling to join, it seems clear that participation that is not, in the participant's judgement, justified by the overall intrinsic merits of the institution, itself, is far more likely to be jeopardized when the 'extrinsic benefits or penalties are discontinued.

\subsubsection{Criteria of Political and Economic Acceptability Assessment}

The following Iist, which is similar to that used in the assessment of nonproliferation effectiveness, presents the institutional features and various acceptability criteria: 
Acceptability Criteria

Economic/Operational

Economics

Domestic Economic Impact

Economies of Scale

Financing

Operations

Construction \& Procurement

Operating Efficiency

Health, Safety, \& Environment
Institutional Features

Composition

Ownership

Market

Management

Staffing

Siting

Functions

Political

Energy Security \& Self-Determination

Domestic Policies \& Politics

Foreign Policy

Institutional politics and Leadership

The net result of judging institutional features according to these criteria offers some measure of the acceptability of the institution. Balancing the results of this evaluation with those for nonproliferation effectiveness enables one to draw preliminary conclusions as to what kinds of institutional arrangements can optimize both nonproliferation and colitical, operational, and economic interests.

\subsubsection{Economic/Operational Acceptability Criteria}

Economic

The economics of the institution can be analyzed in two distinct categories: those related to the economic impact of the institution on its members; and those related to the economics of the institution itself, such as the impact upon the economics of its. facilities and upon that segment of the overall fuel cycle under its jurisdiction, and the financing of the institution. The first category encompasses such considerations as domestic 
economic impacts, for example, foreign exchange costs incurred or saved through participation, and access to improved financing, better technology, or greater technical competence. The second includes such matters as the institution's potential for affecting the cost of the services or materials it provides by, for example, offering greater economies of scale, reduced transportation requirements, or more economic (or more costly) solutions to the waste disposal needs of the institution.

Domestic Economic Impact: Reliance on a foreign alternative to indigenous production inevitably entails economic disadvantages of some sort, even if the foreign alternative produces the materials or services in question at lower cost. Thus, for a participant other than the host country, reliance on a multinational or international institution for a particular fuel cycle operation would entail a negative impact on the balance of trade, fewer domestic jobs, and a possible sacrifice of opportunities to obtain hands-on experience in a technology of potential economic importance.

The actual significance of these considerations depends upon the characteristics of the country in question and the extent to which they are offset by other economic factors, including the possible availability of the material or service in question at lower direct cost. Factors to be considered are the importance of the export sector to GNP, the significance of the technologyintensive industries to the structure of the economy, and the overall sectoral mix of exports, particularly the proportion of high value-added items. There may also be adverse impacts on domestic employment in the construction and scientific skill segments of the manpower pool, although the seriousness of these impacts depends upon the availability of alternative sources of employment. The significance of these considerations to industrialized and developing countries other than the U.S., which have traditionally attached far greater importance to the conservation of foreign exchange and to protection of domestic 
economic interests than has the U.S., should not be underestimated. On the other hand, some countries may place a high value upon access to superior technology and competence through the institution, offsetting some of these potentially negative impacts.

Economies of Scale: The fact that high fixed costs of capitalintensive projects can be spread across a larger output to reduce unit'costs has supported arguments that the resulting increase of scale economies with growing plant size is a distinct advantage encouraging construction of a small number of large projects. Economies of scale for reprocessing are generally acknowledged to be particularly important, with facilities serving at least 20-30 GWe usually regarding as the minimum economic size. A possible disadvantage of large-scale facilities, however, is the premium that they place on high capacity factors; failure to achieve such capacity factors can substantially offset hoped-for economies of scale or turn them into a negative factor.

Scale effects also may vary with the technology employed and with the regulatory environment governing operating practices. While economies of scale can provide a substantial advantage for an institution offering its services to a market broader than simply the domestic one, it is sometimes overlooked that it is simply the size of the facilities in question, and not the multinational character per se, which results in the economies of scale. Thus, the factor is likely to be more advantageous for participating countries whose domestic market is small. In a number of realistic situations, it is only through participation in an institution offering such economies of scale that particular countries could overcome prohibitive economic penalties of small-scale fuel cycle facilities. 
Financing: Reprocessing projects rank high in risk, cost, and uncertainty, complicating the acquisition of sufficient capital on terms acceptable to the project sponsors. Reasons for the numerous financial and technological uncertainties involve failure of demand to meet design estimates, increased construction time, escalation, and regulatory requirements in excess of those anticipated. The final costs of research and development may be far from trivial; for many countries, the resources absorbed in a back-end undertaking may dwarf those of other technological projects. The relative unpredictability of the successful outcome of a project, especially for the first-of-a-kind, may be high. The magnitude of these effects obviously varies with the financial and technical resources at the disposal of particular countries.

A combination of high risk and high cost can aggravate the problem of attracting financial support and could well exceed the financial capabilities of a given country, regardless of whether the project is to be financed and undertaken by the private sector, by the public sector, or by some mixed mode. For virtually any country, the undertaking of a full-scale reprocessing enterprise would rank as an exceptionally large project that would place a substantial demand on sources of capital, whether public or private. Long amortization periods and delayed payback schedules would further complicate the financing of the project. Risks to the marketability of the product or services also may be serious if nonproliferation conditions foreclose part of the prospective market. As a result, institutional arrangements that provide access to capital markets, prospective guarantors of debt, and other means of reducing the risks investors must bear could prove particularly attractive.

Despite the importance of these considerations, the capital cost of reprocessing would, if conducted on an adequate scale, represent only a relatively small fraction of the investment required for the nuclear power generation facilities that the reprocessing 
plant would be designed to serve. There is, however, an important qualitative difference, at least under present circumstances, in the kind of capital required for reprocessing. In contract with power plants, reprocessing involves technical and entrepreneurial risks calling for a far higher proportion of "risk" capital than is customarily required for power generation facilities. This is a difference that might be obscured, but by no means overcome, by full or partial government financing.

The specific means by which financing is arranged can have a marked impact upon the stability of the institution. Joint financing may be an advantage if a single nation's capital market is inadequate to cover investment needs, but it can also be seriously counterproductive if each member's contribution is subject to uncertainties, such as the need for periodic parliamentary approval. Financial difficulties of this nature frequently threatened the viability of Eurochemic and ultimately led to its inability to continue operation. Thus, as in the case of economies of scale, the advantages of joint financing are likely to be most attractive to small countries without strong national financial capabilities, while the potential disadvantages are likely to loom largest to countries that could finance such a facility on a national basis.

Operations

The operational impact of the institution is felt most keenly in the design, construction, management, and business/industrial operation of the institution, and in decision making related to those areas. (This level of decision making is to be kept quite distinct from policy and political areas, such as export policy, safeguards, and technology transfer.) of major concern is how the actual performance of the design, construction, management, and operational functions within the institution compares to that in its autonomous national alternatives. The degree to which such matters become politicized, the organizational 
complexity and delineation of responsibility in the institution, and, thus, the cumbersomeness of its administrative machinery are in major part functions of the institutional features. The problems in this area, whether real or perceived, constitute the most frequent basis for objections to multinationally or internationally' managed institutions.

Construction and Procurement: Sourcing of components, allocation of R\&D money, and siting decisions can become easily politicized where the organization functions through constant negotiations and where the concept of "fair return" animates government perceptions of distributing contracts and decision-making positions within the enterprise. Two-tier management structures can mask but not eliminate national preferences, as the history of URENCO demonstrates. The URENCO experience with making choices between the competing technologies of the members and in determining the level and rate of capacity expansion is evidence that even among politico-military allies, serious disagreements culminating in reorganization can occur. (See Appendix A on Institutional Precedents for further discussion of the URENCO case.) Leaving construction and procurement decisions in national hands, perhaps subject to some competitive bidding that would be open to all members, would offer an alternative with lower potential for politicization.

Operating Efficiency: The technical competence of the staff and the smoothness of its functioning may have a discernible impact on plant safety and operating efficiency and on the assurances of plant operability that may loom large in the eyes of the participants. The achievement and maintenance of high-capacity factors, minimizing unscheduled interruption of operation, may have a major positive effect on the willingness of prospective participants to rely upon the institution instead of indigenous undertakings. This effect could be particularly prominent for countries otherwise lacking substantial domestic technical skills, since in the short run participation in the institution 
could compensate for domestic deficiencies by providing access to a better designed and run plant and over the longer term, could offer a means of gradually improving national technical sophistication. Concern that staff qualifications might be prejudiced by political pressures to hire personnel on a national quota rather than on a merit basis would be most pronounced among participants from countries with high levels of technological advancement.

Health, Safety, and Environment: The setting of health, safety, and environmental standards might entail the reconciliation of divergent national philosophies in these areas and satisfaction of the host country in particular. The issues might include safety design of the plant, insurance against accident liability, and procedures to handle high-level waste and toxic materials. Although some members may see advantages in the opportunity to escape rigid national regulation by operating in a host country with relatively looser standards, a more likely outcome is that some members may press for health and safety standards which at least match their own. Lower standards could arouse domestic political opposition to participation. Multinational staffing, in particular, would force governments to become involved in setting exposure standards at facilities where their nationals would be employed.

At the same time, multinational participation could be unattractive to potential host countries. The disposal of high-level waste originating from other countries is a prominent example of safety and environmental issues that cause domestic political problems which can complicate the acceptability of an institution to the potential host. The presence of operational or managerial personnel who might, correctly or incorrectly, be regarded as less competent than domestic citizens and the inherent complexities of international management could also prejudice acceptability to the host country, especially in facilities with a substantial potential for accidents or environmental damage. 


\subsubsection{Political Acceptability Criteria}

The political acceptability of international institutions is frequently equated with their impact on the sovereignty of the participants. The term "sovereignty" generally refers to the possession by the state of full authority over its internal affairs, independent from outside coercion. Despite the frequent use of the term sovereignty in international relations, the utility of this concept as the benchmark for analysis of political acceptability is limited. Any compromise of full internal authority involves a loss of sovereignty. What really matters is not the loss. of sovereignty in the abstract, but the overall nature of the undertaking and how agreement to it is achieved.

Rather than focus upon sovereignty, it is more profitable to isolate more specific factors which affect political acceptability. These are: .

- Energy Security and Self-Determination

- Domestic Policies and Politics

- Foreign Policy

- Institutional politics and Leadership

The first three factors are related to the impact of the institution on individual participants; the fourth factor is related to the impact of all the members on the institution.

Energy Security and Self-Determination: The impact of the institution on the energy security of both members and non-members will be, perhaps, the central determinant of political acceptability. Not only must the assurance of supply offered by the institution to its participants be acceptable, participation must confer clearly discernable advantages on participants vis$a-v i s$ non-participants for there to be positive inducements to join. 
In this discussion, the term "energy security" is used to designate the entire complex of factors that affect a country's perception that its energy requirements (or at least those in the particular sector under consideration) will be met without undue sacrifice of national integrity and political independence. Energy security includes, but involves broader consideraations than, fuel assurance, however important fuel assurances may be to the viability of nuclear energy and to consumer willingness to tolerate dependence upon foreign sources of supply. Fuel assurance, in turn, has two separate components that often are not distinguished to the extent necessary for accurate assessment of differing institutional arrangements. These two components are: 1) the probability that supply undertakings will be honored; and 2) the probability that new ones will be offered as the need arises.

Energy security, as it relates to nuclear fuel cycle activities, involves the following considerations:

- The extent to which the institution circumscribes the national prerogative to unilateraily determine the size, scope, and structure of the national fuel cycle.

- The extent to which the institution establishes national, regional, or multilateral arrangements for continued access to energy supplies that are compatible with the foreign policy objectives and interests of the participants, particularly freedom from manipulation of energy supply for political purposes.

- The extent to which the supply system functions in a coherent and predictable manner in meeting the actual physical fuel needs of the members and, at a minimum, fulfills the criteria of fuel assurance as defined above.

The limiting case of energy security is complete self-supply through well-designed and run plants. Where multinational or international institutions are relied upon in whole or in part, 
a high degree of fuel cycle interdependence may replace selfsufficiency as the means by which energy security can be achieved.

The above conception of energy security makes clear that fuel assurances, although necessary, are not a sufficient condition for energy security to be satisfied. An institution that offers strong assurances of supply, in terms of both the performance of existing contracts and the availability of resources, but that permanently precludes fuel cycle options that participants may see as desirable, or that is perceived as capable of imposing political pressure on participants through the ability to withhold supplies, might still fail to pass the test of energy security. The strong pressures for self-supply, even in the context of multinational arrangements, are visible in such actions as the recently announced URENCO decision to establish enrichment facilities in the F.R.G., as well as in the U.K. and in the Netherlands.

Domestic Policies and Politics: The willingness of countries to participate in an institution is not solely a function of its impact on energy security. Institutional arrangements may generate domestic controversy in several ways. They may appear to sacrifice projects or policy objectives which rightly or wrongly have acquired high symbolic importance in the domestic political system, such as rapid economic modernization. They may adversely affect the interests of powerful domestic factions or groups. Finally, the issue of participation may be manipulated by the government and opposition for political purposes completely unrelated to energy.

A major aspect of the domestic political acceptability of an institution is the degree to which it interferes with or promotes policies to which particularly high priority or political significance has been attached. Many countries tend to regard 
the energy industry, and especially high-technology energy industries, as "leading sectors" of the economy and as significant determinants of domestic economic welfare through job and capital formation as well as more obvious price effects. This perception may increase the political sensitivity of the institution's impact on the development of back-end industries, on the utilization of technical manpower, and on regional and national economic development. Government policies designed to promote such objectives may establish parameters that limit government and public receptivity to institutional concepts. The constraining effect of such parameters on the ability, and willingness of governments to participate in institutions would be all the more strong where the popular legitimacy and political power of the government rested upon its ability to achieve those objectives. This is particularly the case in many industrializing countries, where belief in the modernizing effects of high technology industries is especially strong.

A coalition supporting membership may incorporate interests that are sufficiently diverse as to render its cohesion very tenuous. Among the interest groups most likely to actively attempt to influence official positions and the issues most likely to concern those groups, are:

- The supporters and opponents of nuclear power: The supporters may favor proposed concepts if they remove debilitating bottlenecks in the industry; the opponents may attack proposals as legitimizing or favoring nuclear power, or they may oppose proposals ostensibly on other grounds if they believe the proposals will promote nuclear power;

- Environmental and safety-oriented groups: The debate among such interests may center on whether international institutions weaken or enhance their ability to influence and improve environmental and safety standards;

- Industry: Companies in the fuel cycle industry may support measures that both bring a level of certainty to the market and protect their market shares; utilities will.look for supply assurances and stability in the political conditions governing supply availability; 
- Government bureaucracy: Government agencies may lend the strongest support to proposals that elevate their influence in the governmental structure and oppose those that threaten their influence;

- Political parties: In countries where party competition exists, opposition parties may be tempted to seize upon any area where they perceive the government to be vulnerable -- institutions that demand highly visible concessions may weaken the domestic influence of the government and invite partisan conflict;

- Major financial institutions: Major banks and commercial investors will pay close attention to the impact of institutions on investment risks and on the advanced technological sectors of the economy where they possess a direct economic stake.

Domestic politicization may be a substantial obstacle to acceptability where participation involves a restructuring of the aomestic balance of influence between these groups.

Foreign Policy: Foreign policy considerations offer both opportunities and constraints for political acceptability. On the positive or opportunity side, participation may be valued as a means of acquiring international legitimacy for the use of sensitive materials and for alleviating foreign pressure against national nuclear policies. Participation also offers an opportunity to demonstrate to regional neighbors the peaceful nature of one's nuclear projects. This could be a particularly powerful incentlve in cases where continued suspicion of a country's motives could otherwise lead its neighbors to take pre-emptive action against a project or respond in kind with their own. This latter consideration, of course, relates directly to the nonproliferation effectiveness of the institution.

On the constraint side, fuel cycle policy may be symbolically associated with regional politico-economic leadership or with independence from the hegemonial pretentions of other countries. 
The political attractiveness of an institution that appeared to impose a visibly subordinate status upon a participant attaching such symbolic importance to fuel cycle policy, consequently, could suffer considerably.

The acceptability of the institution, when viewed from this perspective, rests on its ability to accommodate foreign policy motives within arrangements that assure greater proliferation resistance. At a minimum, the institution must compensate any sacrifice of objectives. This places a particular emphasis upon voting provisions, avenues for technological development, and the institution's impact on the country's political stature visa-vis its neighbors and regional rivals.

Institutional Politics and Leadership: The politics of the institution -- which countries, interests, and politico-economic perspectives dominate the institution -- have a direct bearing upon whether it will promote both proliferation resistance and energy security. Whereas the previous criteria of political acceptability measure the impact of the institution on its members, that of institutional politics measures the impact of the members on the institution. Individual national perceptions of this impact become, in turn, criteria that influence the acceptability of the institution to prospective members.

The assessment of political acceptability in terms of institutional politics has two parts. The first is whether the membership presents a sufficient commitment to nonproliferation for the institution to fulfill its fundamental purposes. The second is whether it is possible to fashion the necessary majorities for action to be taken despite the range of political, economic, military, and energy circumstances represented in the membership, or whether conflict will cripple the institution.

Questions of institutional politics may affect the perception of the institution by key governments. For example, an institution in which a combination of developing countries and several 
industrial states can block actions desired by more industrialized members may be unacceptable to this latter group of countries. By the same token, other countries might expressly desire such an arrangement. A pivotal question is whether the institution can minimize the intrusion of outside factors, such as conflicts over matters unrelated to nuclear energy, which would interfere with its effective functioning.

\subsubsection{Institutional Features}

The institutional features -- composition, ownership, market, management, staffing, siting, functions -- frequently exert opposite effects on the economic, operational, and political acceptability considerations just described. An institutional feature that may be perceived as advantageous from the viewpoint of energy security might have a negative impact on operational efficiency. Moreover, as noted in the preceding discussion, features that are viewed as advantageous by one class of participants may be viewed as disadvantageous by others.

Composition: The political, economic, and operational impacts of composition reflect not only what assets the members bring to the enterprise but what benefits they demand of it as well. An institution with a membership comprising major nuclear markets or combining a number of small markets into a large one, as in a regional approach, might enjoy a considerable economic advantage if these markets are combined to support larger facilities with greater economies of scale. Composition may have a major impact on financing where inclusion of major economic powers might improve access to capital markets.

If the institution incorporates multinational management, staffing, or operation in its design, the operational effects of composition are likely to be strong. A wide diversity of economic and energy circumstances among the membership could be detrimental to decision making on policy matters. Attempts to maximize individual economic gains may adversely affect the efficiency of construction and procurement. Uneven levels of 
technical skill and expertise may detract from operating efficiency and contribute to dissension among the members, while divergent approaches to safety and environmental regulation and design could complicate standard-setting in this area. On the other hand, if the function of the institution is limited to that of custody over materials and facilities, diversity of membership would have far less impact.

Politically, composition can have a major bearing on what kind of claims and interests are given the strongest weight. The actual energy circumstances of the members, and the manner in which they define energy security -- their individual attitudes towards dependence on outside sources, the links they make between energy and foreign policy, and the resulting orientations toward closing the national fuel cycle -- directly affect the prominence of energy security in determining political acceptability. Here, again, the effects of composition are magnified as the operational role of the institution is increased. The inclusion or exclusion of particular countries, such as regional or ideological rivals, may so affect foreign policy interests as to have a significant impact upon acceptability. Institutional politics are preeminently a product of composition. Unless potential members are both able and willing to cooperate and share a firm commitment to nonproliferation, the effectiveness of the institution may be hampered by internal dissension over the manner in which its nonproliferation responsibilities are performed. However, this consideration should not be given such weight that the countries whose nonproliferation credentials are suspect are rejected, since it is these countries in particular whose ambitions one would hope to restrain.

Ownership: Ownership may affect the scale of a facility insofar as the ownership arrangements influence the size of the market available to the project. An arrangement in which group ownership entails a pooling of markets could be a considerable advantage. Ownership has a direct and obvious relationship to financing, as it determines how many and which countries bear the 
financial risks and supply the capital pool to which the institution might have access. Ownership also may have an impact upon operational considerations to the extent that it incorporates a diversity of interests and skills in the decisionmaking structures of the institution. Whether or not this becomes a problem obviously depends upon the levels of group involvement and the kinds of decisions -- policy or management and industrial, or both -- left for group determination.

Ownership can figure prominently in the political acceptability of the institution. A share in the ownership of a facility may alleviate, while not entirely eliminate, energy security concerns by giving the country in question a direct stake and voice in the facility, and also may address some of the concerns likely to be raised in the domestic political arena. While certain1y not of the same symbolic significance on foreign policy grounds as a national plant, an ownership share offers a potential means of reconciling national political interests that emphasize some measure of self-reliance, the economic interest in having access to a well-run facility, and nonproliferation interests. It may also have a salutory effect on the politics of the institution insofar as it provides the members with an actual financial stake in the orderly functioning of the institution and a vested interest in preventing the nationalization of a jointly-owned facility by the host country. Joint ownership, however, as opposed to national, curtails national control over fuel cycle policy, involves foreign participation in proprietary matters, and demands political sacrifices, particularly by the owners of present facilities, which both foreign and domestic policy interests may not tolerate.

Market: The market of a fuel cycle institution with at least some international or multinational attributes could, in principle, be either national, that is, confined to the host country, or multinational. An institution whose multinational characteristic is confined to the adoption of a code of conduct by its 
national participants would not necessarily impose a responsibility on those members to offer their services either to other members of the institution or to outsiders. United Reprocessors Group (URG) is an example of such an institution, in that reprocessing services are made available to foreign customers strictly as a commercial proposition and not as part of a political obligation assumed by the members.

On the other hand, the extension of the services performed by facilities participating in the institution to at least all members of the institution would be a normal and expected feature, and would be an essential one if the facilities are to benefit from the economic advantages of scale beyond that possible by supplying their national markets alone. More importantly, extension of institutional services to all participating members would also be an essential feature of an institution that planned to restrict the siting of the facilities in question to one or a few of the participating member countries.

The feature of providing the fuel cycle service in question to all participants clearly constitutes for the host country not only an opportunity but an obligation. The tendency of some countries to give priority to domestic needs in the event of shortages of particular materials or services is inconsistent with the obligations of a host country of a sensitive fuel cycle facility to other participants in the institution.

Multinational institutions could also market their materials or services to non-members, provided this could be done in accordance with the institutions' nonproliferation ground rules. such a broader market could have both economic benefits and nonproliferation advantages by reducing the incentives for the establishment of sensitive fuel cycle facilities by the nonmember countries it served. Both URENCO and Eurodif are examples of fuel cycle institutions that are prepared to offer their services to non-member customers, while giving priority to the needs of their members. 
Management: Although the arrangement for management of the institution's facilities and operations may have little relevance to the achievement of economies of scale, minimization of domestic economic costs, or the availability of, financing, as these considerations have been defined, management arrangements are likely to have considerable impact on other economic/operational assessment criteria. In general, extension of institutional responsibility to the operational level, whether it be of a reprocessing plant or a plutonium storage facility, can raise serious questions regarding functional efficiency and the management's freedom from political interference.

If management is to be internationalized at all, manag along lead-country lines offers the simplest decision ing structure and the one least prone to politicization through the competing demands of the institution's members. The lead-country approach, in which managerial and operational responsibility is vested in a single party, has found increasing favor as an effective way of organizing technical and commercial collaboration. It should be noted that, in this approach, the lead country may associate other participants in subordinate roles.

On the other hand, in practice management control of joint projects is often apportioned among the participating nations; creating potentially serious problems. Because the managers come from assorted national, organizational, and technical backgrounds, they often work in varied ways and, more importantly, perceive different commercial and technological interests and needs. Project managers are tempted to settle disagreements by seeking compromises that are not necessarily. compatible with economic optimization, operational efficiency, or perhaps even sound safety practices. The result can be a complicated, expensive, and inefficient operation in which political bargaining as much as, or even more so than, sound business practice determines the outcome of business and managerial decision making. 
Procurement anā construction decisions can also be affected by managerial arrangements. The sourcing of components, allocation of $R \& D$ money, and siting decisions can become easily politicized where the organization functions through constant negotiations and where the concept of "fair return," which emphasizes national quotas, animates government perceptions of aistributing contracts. Two-tier management structures can mask but not eliminate national preferences. Vesting management in one party, coupled with provision for a competitive bidding process open to the institution's members, might reduce the potential for politicization.

Management arrangements may also affect, the intensity with which health and safety regulations are enforced. Where national philosophies arnong the members on such matters are quite diverse, joint management might simply incorporate this diversity into not only the setting but also the implementation of regulations. This coula become a source of discord within the group, particularly vis-a-vis the host country.

Management arrangements that lead to inefficient operation 'and frequent conflict over business matters may have a serious adverse impact upon the members' confidence in the ability of the institution to enhance their energy security. This negative impact must be weighed against potential gains in the visibility of participation that may be valued by some countries for foreign policy or domestic political reasons. The political calculation that countries must make -- whether or not confining direct participation to ownership creates a politically undesirable impression at home and abroad that they have done little more than finance someone else's plant -- is of fundamental importance to how extensive a role in the institution is necessary for participation to satisfy the political needs of prospective members. 
Institutional cohesiveness inay suffer if management arrangements generate conflict among the members or result in operational problems that are unacceptable to some members. There would be fewer opportunities to compartmentalize conflict or to limit it to levels within the institution where it cannot easily disrupt the conduct of the enterprise.

If management is to be international, efforts are usually made to insulate the management, in some degree, from the airect political influence or interference of member states. This can be accomplished by establishing multi-tiered arrangements in which political decisions are made by a senior political body, while management is exercised by a professional staff chosen on merit and left free to make commercial and operational decisions. Examples of institutions that function in this way are included in Appenaix A. While experience has been mixed, and there are examples of efficiently managed institutions with a management of international composition, there appears to be a strong trend, at least in institutions that deal with activities particulariy susceptible to political influence, to organize along lines such as the lead-country arrangement, in which at least operating management is predominantly of a single nationality.

Staffing: The same remarks about the relationship of management to economic, operational, and political acceptability are applicable to staffing. The impact of staffing is most apparent for operational efficiency and, possibly, for the importance accorded health and safety. Language barriers, differences in the quality of training and habits, and cultural differences may render a multinational operating staff less cohesive and efficient than a well-trained work force of the same nationality or background. Although close political, economic, or social linkages among the participating countries may constrain the divisive impact of such differences, the resources expended to overcome any obstacles posed by multinational staffing represent 
a cost not encountered in a national plant. Moreover, the technical competence of the staff and the smoothness of its functioning may have a aiscernible impact on plant safety and operating procedures and on the assurances of plant operability. The strength of safety standards also may become a more important issue for the members if their own nationals are to be employed in the facility.

Multinational staffing may be important for political acceptability if the training and utilization of skilled manpower is a pressing issue. In general, however, who staffs the plant may be a less significant issue for acceptability than who owns a sensitive facility or material and decides basic matters such as the timing or scope of capacity expansion. These issues go more directly to the heart of the energy security ano foreign policy interests of the members than does the less significant question of staffing. By the same calculation, staffing is less significant for the politics of the institution than is the composition of the institutional group.

Siting: The economic impact of siting measures is felt primarily in two areas: domestic economic costs; and health and safety. The relevance of siting to other economic and operational considerations is more remote. Although quantitative siting measures -- how many sensitive facilities are actually built -- will influence the level of economic benefits, qualitative measures -- where facilities are built -- may prove to be more controversial for acceptability. The number of facilities needed can be determined by objective economic criteria, such as demand levels, minimum efficient plant sizes, and scaling effects. The determination of where facilities can be built may involve more arbitrary criteria regarding the nonproliferation credentials of the host country and raises the politically sensitive question of who decides whether the prospective host country meets the nonproliferation standards. 
Whether participation in the institution entails substantial foreign exchange costs, loss of direct employment opportunities as well as opportunities for development of component industries, and higher transportation costs obviously is determined by where a facility is sited. In the absence of any compensating benefits, such as access to fuel cycle technology of potential future use to the participating country, domestic economic costs may be unacceptably high to a country intending to develop a complete fuel cycle industry. Just as the status of a non-host country participant implies certain economic disadvantages, host country status bestows economic and commercial benefits in the form of jobs and foreign exchange earnings that may be perceived as being very large. The benefits of host country status can encourage vigorous competition for such status.

The geological and sociological characteristics (population density, etc.) of a particular site also may have a bearing upon the strictness of health, safety, and environmental standards. However, these features of the site by themselves may have less impact on the acceptability of siting restrictions than other institutional features already discussed, such as whether standards are set jointly or by the host country. The characteristics of a particular site, moreover, may be less important to the acceptability of the institution to a particular country than is the question of siting. itself.

The political consequences of siting may be even more pronounced than the economic. If the facility is expected to be the sole source of supply for a particular fuel cycle service for its members, the consequent dependence on outside supply places a heavy burden on the institutional arrangements for satisfying energy security needs. The terms and conditions of access to supply, the reliability of the host country and of any others involved in the supply chain, the types of supply guarantees offered by the institution, and, above all, who decides such 
matters, become pre-eminent features of the institution where siting restrictions enforce a high degree of supply dependency.

Rigid siting measures that restrict sensitive facilities to a small number of countries also may seriously detract from political acceptability, measured in foreign policy terms, if uncompensated for by the arrangements for ownership, etc. This effect would be particularly pronounced if the acceptable host countries also happened to be all nuclear weapons states (NWSs) or advanced industrial countries. In such circumstances, the institution would appear to superimpose an additional layer of politico-economic discrimination over existing ones.

From a domestic policy point of view, siting also could be a prominent factor in acceptability, as siting provisions may have significant consequences for job formation, industrial and local economic development, etc. The political symbolism of siting measures -- whether or not they appear to place the country in a subordinate status in the institution -- also may become a factor in the domestic debate, particularly if nationalism or a "dependencia"-type ideology is a prominent political force. While the status of host would normally be expected to be sought after, it may, however, become an obstacle if the populace of the host country perceives the facility as benefiting mainly foreign parties, while resulting in safety or environmental hazards or in local socio-economic dislocations out of proportion to the expected economic benefits. The difficulties of siting international spent fuel storage or radioactive waste disposal sites are obvious examples of this effect.

The political repercussions of siting may affect the politics of the institution as well. Siting restrictions may reinforce the divisions among the membership, which are important aspects of its composition, and further complicate the ability of the institution to attract and retain the support of its members. 
It is evident from the above that siting constitutes one of the most aifficult aspects to resolve in the development of institutional arrangements, and that this difficulty increases as the exclusivity of siting the institution's facilities is increased. Where exclusive siting is to be the rule, determination of an acceptable host country may be dependent on the existence of a compelling circumstance which leaves little scope for disagreement, such as the formation of an institution around an existing facility or the possession by a single member of technology indispensible to the success of the enterprise, as in the case of Eurodif. Where this compelling circumstance is absent, as in the case of URENCO, the only viable solution may be multiple siting, even at some sacrifice in economies of scale.

Function: The functions performed by the institution can have a major and immediate impact upon its acceptability.

A code of conduct, which involves some siting limits, controls over technology transfer, standards for export policies, and possibly measures for the management or custody of sensitive material, would have greater economic impact, particularly in the area of domestic economic costs if the siting limits are inflexible, but might minimize any additional costs in the areas of operation, financing, decision making, etc., by leaving ownership, management, and operations in national hands.

A code of conduct may have considerable impact on political acceptability to the extent that it appears to discriminate against some countries, even with obligations on members to honor fuel commitments and to desist from any arbitrary conduct. The prospects for expansion of those participating in the code, and thus mitigating its discriminatory nature, would be one of the politically most visible aspects, in the eyes of customer states, of an institution performing this sort of function. With the prospect of attracting recipient states to participate in all institution, one of whose main functions is to impose 
restrictions on the recipient's access to sensitive technology, materials, or facilities, the combination of this function. with others perceived to be more advantageous by recipients could well overcome this obstacle. The NPT, itself, is both a suppliers' undertaking not to export without safeguards and to engage in nuclear commerce with countries honoring their nonproliferation commitments.

Improved Safeguards constitute the least economically obtrusive institutional feature, as they are largely neutral to the economic and operational criteria considered here, with the possible linited exception of operational efficiency. Improved safeguards represent added costs of sufficiently small magnitude such that they can be passed along to the consumer without necessarily jeopardizing the competitive position of nuclear power.

Although they may prove controversial, the political repercussions of improved safeguards are likely to prove far less substantital a factor in determining political acceptability than measures that impose multinational control over a plant or rigid siting limitations.

An institution with custody as its primary function would not necessariiy require international or multinational ownership, management, and staffing. By avoiding such a requirement, it could avoid many of the disadvantages associated with multinational configurations of these features. By the same token, custody would not confer the economic advantages of multinationalization where these exist, although there is nothing in the concept of custody which precludes multinational ownership, management, and staffing where the parties prefer such arrangements.

The fact that custody entails international or multinational control of sensitive material in a regime under which the host 
country has no greater right of access to the material than any other country inevitably will affect the host country's perception, and that of the other members, of energy security under such an institution. Custody, rowever, by not necessarily imposing arrangements for ownership, etc., avoids restrictions that might further aggravate these perceptions. The nature of any accompanying siting restrictions would be particularly important to government responsiveness to custody based upon its energy security effects. The siting restrictions, more so than the custody concept itself, would have greater impact upon the foreign policy aspects of acceptability. Assignment of the export licensing function to the custody agency, though, could evoke domestic opposition. Host countries may be reluctant to assign to another body the responsibility of determining who can be supplied by the host country's facilities.

Finally, an institution with direct responsibility for facility operation would represent the most intensive form of international or multinational arrangement. It would, almost of necessity, be an institution whose ownership, management, and staffing were also jointly shared by the participants. It would thus encounter the economic advantages and disadvantages associated with the international or multinational configurations of those features. An institution with operational responsibility, likewise, would impose constraints upon national prerogatives which affect political acceptability. The burden upon institutional politics, leadership and cohesion also would increase, since the institution would be more centrally linked to the actual physical functioning of the fuel cycle system and, as a result, more demands for meeting individual interests and needs would be made of it.

It is not a foregone conclusion that operation by the international or multinational institution would be unacceptably less 
efficient than a national undertaking, or that whatever inefficiencies did result would be serious. In fact, for some countries participation would be advantageous if it includes access to a facility better designed and operated than they could on their own. There likely exists some threshold of tolerance that determines how much additional cost is acceptable as the necessary price for political or economic benefits that otherwise might not be obtainable. 
The objective of nonproliferation policy -- the reduction, if not total elimination, of national access to sensitive facilities and materials -- suggests there are two basic approaches to the reduction of proliferation risks. One can:

\footnotetext{
- reduce or eliminate the national access;

- reduce or eliminate the sensitivity of facilities or materials.
}

The first approach -- Iimit national access -- relies upon institutional arrangements. The second approach -- reduce the sensitivity of facilities and materials -- relies upon technical modifications in those facilities and materials.

of direct importance to the assessment of the institutional approach is whether there exist any tradeoffs between institutional arrangements and technical modifications; that is, whether the incorporation of technical modifications reduces the need for institutional arrangements on nonproliferation grounds or, if in marshalling broad-based acceptance of technical measures, the political tolerance for extensive institutional arrangements to be applied in addition to technical measures is reduced. Furthermore, some, or all, technical measures may pose institutional requirements, creating the possibility for hybrids of the two approaches. The allocation of resources within such hybrid arrangements, between the two approaches, and within the institutional approach, between arrangements for sensitive facilities and arrangements for sensitive material, will reflect the relative magnitudes and probabilities of specific proliferation threats, as affected not only by the sophistication and resources of the adversary, but also by the technical characteristics of different fuel cycles. 
In principle, improved proliferation resistance can be achieved through the incorporation of technical measures in the design and operation of reprocessing plants and in the form in which sensitive material is present in the fuel cycle. Quantitative, even qualitative, assessment of the size of this increment is very difficult. Nevertheless, the question of whether and to what extent technical measures can substitute for institutions, and vice versa, can be discussed and is of particular importance to this study.

While there are a large number of technical modifications to improve the proliferation resistance of plutonium-using fuel cycles, these concepts can be reduced to three general classes in terms of their inplications for institutional approaches for reduction of proliferation risks. These classes are:

- technical modifications to sensitive nuclear material which make it more proliferation resistant;

- technical modifications to the processes or facilities processing, handling, and using sensitive material that. make such facilities themselves, as well as the material they produce, less sensitive from a proliferation standpoint; and

- active use denial measures that, while not making materials and facilities less sensitive, prevent or interfere with their misuse once such an attempt is deiected.

Which of these avenues is given emphasis depends in large measure, upon what the perceived threat is and who poses it. For example, confining sensitive facilities to NWSs only might shift the technical effort to making sensitive materials in transit less accessible. On the other hand, if the likelihood of reprocessing facilities in non-nuclear weapons states, especially those of high proliferation risk, is foreseen, greater emphasis should be placed on the development of proliferation-resistant processes and plant designs. Active use denial techniques fall in the latter category along with process and equipment design. 
Material Modifications: Material modifications can be achieved through measures to leave or incorporate highiy radioactive materials in plutonium to create a radiation barrier, and isotopic dilution to establish an isotopic barrier. In general, the addition of gamma spikes can achieve no greater levels of protection than that imparted to spent fuel by its inherent.radioactivity. In practice, the barrier is more likely to be considerably less effective and durable than that of spent fuel. Isotopic dilution, while immune to chemical purification, provides protection at the expense of greater impact on the overall fuel cycle. Whether this protection is more or less effective than that imparted by radiation is a matter of some debate and will depend on the capabilities of the countries concerned. In general, however, it is believed that at the present state of capabilities, isotope separation presents a greater obstacle to more countries than does chemical separation. It is also worth noting that once the isotope separation barrier is overcome by a country, it would be able to prepare weapons usable material from natural or slightly enriched uranium without recourse to specially denatured fuels, such as $U-233 / U-238$ mixtures.

Radiation barriers to reduce accessibility would require extra shielding of handling equipment to utilize the material. Ruthenium (Ru-106) and cerium (Ce-144) are formed directly as fission products and, hence, require no separate production process. However, as they are recycled, stable isotopes of these elements increase in concentration until, if high dose levels $\left(1 \times 10^{3}\right.$ $\mathrm{R} / \mathrm{hr}$ ) are required, they occupy a significant fraction of the fuel volume. Cobalt requires only trace amounts to yield a substantial dose $(10,000 \mathrm{R} / \mathrm{hr}$ at $\mathrm{I} \mathrm{ft}$. from an LWR element). Cobalt, however, cannot be coprocessed with the fuel and must be produced separately (but potentially in the same reactors from which the spent fuel is derived) to be added to the refabricated fuel. The cost of such measures would be in the range of $0.4-0.7 \mathrm{mills} / \mathrm{kwh}$. [Reference 1, page 74] 
Pre-irradiation of fresh MOX prior to shipment could produce gamma activity on the order of $500 \mathrm{R} / \mathrm{hr}$ per element. This would require a special facility at the fabrication site and would entail the irradiation of fresh LMFBR fuel to approximately $1 \%$ of its total burnup. Pre-irradiation of fresh fuel in an especially constructed reactor might add from 0.9 to $1.5 \mathrm{mills} / \mathrm{kwh}$ to the cost of nuclear power. Average nuclear power costs in 1978 were about 15 mills/kwh. [Reference 1, page 74]

The approach of diluting U-233 with U-238 to create an isotopic barrier to accessibility involves major changes to nuclear fuel cycles and probably the introduction of new reactor types. Under present conditions of isotope separation capabilities, diluted U233 is more proliferation resistant than spiked plutonium fuel elements because its extraction requires technically more demanding and less readily available physical rather than chemical separation techniques. Additionally, the natural radioactivity of U233 daughter products would make attempts to steal or divert it dangerous. The key assumption as to its proliferation resistance is that of limited distribution of isotope separation capabilities. Detracting from the attractiveness of $\mathrm{U}-233$ is the fact that plutonium-fueled reactors are more efficient breeders than those on a thorium/U-233 cycle, and thus are more attractive from a resource-conservation viewpoint.

Facility Modifications: The traditional reprocessing approach of yielding two separate product streams, plutonium and uranium in the form of nitrate solutions or oxide powders, can be modified to combine the two streams (coprecipitation) or, in addition, to leave a portion of the fission products in the product stream to create a radiation barrier. A process and plant design to accomplish this, designated CIVEX, has been described in recent literature. 
Coprecipitation, which modifies the conventional PUREX process to carry some uranium along in the plutonium stream, protects the material only by chemical dilution. The product, a mixture of $\mathrm{PuO}_{2}$ and $\mathrm{UO}_{2}$ or their nitrate solutions, presents only minor impediments to a sophisticated national adversary, since a group capable of constructing a nuclear weapon also would possess the competence to extract plutonium from the mixture. Coprecipitation might pose a more substantial barrier to subnational groups that must divert larger amounts of material and take extra time to separate out the plutonium.

The CIVEX approach couples coprecipitation with partial decontamination. The resulting material retains a number of moderately long-lived fission products in order to present impediments to the proliferator approximating those encountered in extracting plutonium from spent fuel elements. To be effective, simple modifications to yield a pure plutonium stream must not be possible. CIVEx also would include facility modifications in the form of colocated reprocessing and fabrication, as well as locating sensitive equipment in high radiation areas. Not all aspects of the CIVEX approach have been pilot-plant tested.

Active Use Denial: Active use denial measures could be applied sensitive facilities. Neither the facility nor its product would be inherently less proliferation sensitive as a result, but, theoretically, timely implementation of denial steps would prevent misuse of the facility. A fundamental assumption of active use denial is that detection would be real time or sufficiently close to permit disabling before an actual weapon threat is posed.

Applied to a facility, active use denial, employing a command, control, and communication system for the remote initiation of a sequence of graded responses when misuse, particularly host country takeover, is detected, would deny access to critical areas or shut down or destroy the facility. Not all of the technology for such a system exists yet, and the concept itself is very demand- 
ing. Fulfilling the requirements of such a system -- noninterference with normal plant operations, extreme reliability, operability from a remote command center, and immunity from tampering by people familiar with its workings -- may be inachievable.

Each of the three foregoing classes of technical measures for increased proliferation resistance has different implications for the kind of multinational measures that might be required to accompany the technical approach.

Case 1: Conventional Reprocessing and Proliferation-Resistant Fuel

This configuration of the fuel cycle has as its purpose the elimination, or at least minimization, of vulnerabilities associated with sensitive fuel. It would not significantly reduce those vulnerabilities associated with the reprocessing plant. Due to the existence of a pure plutonium or U-233 process stream and the potential for removal of plutonium or U-233 from plant waste streams, the dangers of undetected diversion at the plant would remain unchanged. In the absence of any use denial measures or institutional features that confined the plants to acceptable countries or that imposed other forms of international arrangements upon the plant, risks of plant or material seizure would remain unaffected as well.

Technical modifications of sensitive materials would be sufficiently effective to permit their conventional distribution, without any accompanying institutional arrangements, only if the material were no longer accessible for weapons purposes or if the larger amounts of material that would have to be taken in the case of dilution or the handling problems caused by radiation ensure either prompt detection or a warning time so long that even late detection would still be acceptable. Any failure to fully meet these requirements, correspondingly, would decrease the proliferation resistance afforded by the technical modifications and increase the need for institutional arrangements for the material. 
Some institutional measures are necessary despite the proliferation resistance of the fuel. For there to be a high degree of confidence in such technical measures, there must be an institution in place to mandate and monitor their utilization. Otherwise, their use would be at the discretion of individual countries. The conventional reprocessing facilities themselves would require a maximum of institutional protection or siting in nuclear weapons states or other locations deemed to present no appreciable proliferation risk. The proliferation resistance of material leaving a fuel cycle facility in this case would have no bearing upon diversion or seizure risk at the facility itself or upon the deterrence of host country abrogation. Risks associated with technology transfer similarly would be unaddressed in the absence of institutional arrangements. Moreover, technical modifications of sensitive material may deal with the less directly dangerous segment of the fuel cycle. Whereas chemical or physical processing of modified materials would be necessary to extract weapons-grade material, the conventional reprocessing in this case leaves unconstrained a direct capability to obtain weapons material. Thus, proliferation-resistant fuel does not avoid, but, indeed, presumes substantial institutional arrangements to cover reprocessing facilities, comparable to those that would be called for in the absence of the steps taken to render the product more proliferation resistant.

The proliferation benefit of an effective means of making fresh fuel essentially as proliferation resistant as spent fuel would, nevertheless, be substantial. Detailed evaluation of the feasibility of accomplishing this, and the cost of doing so (including substantial costs throughout the fuel cycle, is beyond the scope of this study, but a number of reviews conducted under NASAP and INFCE auspices suggest that proliferation resistance equivalent to that of spent fuel cannot be achieved, that the costs of achieving significant protection are high, and that the added health, safety, and operational problems of fabricating and using such fuel are formidable. 
It follows from this that, while the potential for the development of proliferation resistant fuel desires further study, its promise is not sufficently clear to justify any reduction or change in direction in efforts denoted to the understanding and development of proliferation resistant institutions.

Case 2. Proliferation-Resistant Reprocessing and Proliferation-Resistant Fuel

Proliferation-resistant design and operation might relieve the pressures upon institutional protection and restraints only if certain conditions are met. Regardless of how it is accomplished, a proliferation-resistant design would ideally have to ensure that the operator would have great difficulty in altering it to produce pure plutonium, that this attempted misuse could be detected on a timely basis in all cases, and that the fresh fuel produced would be as nearly inaccessible a source of plutonium as spent fuel. Key factors in assessing such designs are the degree of difficulty in modifying the plant to produce a pure plutonium or $\mathrm{U}-233$ process stream, in removing plutonium or $U-233$ from the waste stream, or in stripping plutonium or U-233 from the output.

A facility that possesses a very high degree of proliferation resistance as measured in these terms and that produces material that meets the qualifications identified in the previous case would minimize the need for institutional arrangements at all points in the fuel cycle. Primary, if not total, reliance would be placed upon the technical modifications.

The possibility of developing proliferation resistant reprocessing plant designs has been studied in several places. In particular, a conceptual design designated CIVEX has been examined in some detail. This concept departs significantly from the ideal criteria. cited above. Specifically:

- The process is still essentially based on PUREX process principles, with the flow-sheet designed to leave a 
portion of the fission products in the plutonium, or mixed plutonium-uranium product stream, and with engineering designed to make it difficult to modify the flow sheet or plant for complete decontamination.

- Even if this is accomplished affectively, however, the CIVEX process product represents a substantially easier starting material for the production of a fully decontaminated product than does spent fuel.

- A CIVEX plant would provide any country with access to it with extensive design and operating knowledge on which to base a far simpler auxiliary facility designed to decontaminate the CIVEX product. This could be located at an unsafeguarded site remote from the declared and safeguarded CIVEX facility.

- The radiation barrier provided by the CIVEx process is considerably lower and much shorter lived than is that of spent fuel. After a few years, the CIVEx product could be handled essentially with conventional contact means.

- The CIVEX process will require major development effor.t that would place it at least a decade farther away from application than conventional reprocessing. It would also entail essentially the same costs and penalties elsewhere in the fuel cycle, as do other measures for the incorporating of a radiation protection barrier in fresh mixed oxide fuel.

Thus, institutional requirements are not fully eliminated, and it is not clear that the degree of any reduction is as great as the concept of proliferation-resistant reprocessing implies. As was the case with proliferation-resistant fuel, there would remain a very important need to ensure that the intended proliferationresistant designs are, in fact, employed and that operators are not developing measures to defeat them. It seems doubtful that any of the approaches suggested offer proliferation resistance that would justify construction of such plants regardless of location or circumstances. Even if the specified design itself cannot be misused, the experience gained in building and operating a reprocessing plant capable of complete decontamination could be utilized in the construction of a clandestine plant. Potentialiy serious risks associated with technology transfer would thus 
remain present. Although there may be a reduction in the obtrusiveness of institutional arrangements in force at technically modified facilities, there is likely to remain a permanent institutional requirement to deal with the problems just identified.

In this case, as in the preceding one, it appears that, while the concept of proliferation-resistant facilities merit detailed examination, it does not allow any relaxation in effort on institutional approaches.

Case 3. Active Use Denial and Proliferation-Resistant Fuel

Starting from the premise that timely warning affords insufficient protection without rapid response, active use denial holds out the potential of automatically shutting down a plant and denying access to sensitive facilities or materials. The principal threat to which denial techniques have been addressed is plant seizure, but this does not limit their relevance to other threats, such as diversion or abrogation. In any case, high reliability and a low false alarm rate would be demanded of the system. [A more detailed analysis of active use denial can be found in Appendix $B$ of this report.]

The implicit premise of active use denial is that if a highly reliable capability to render a facility unusable before a weapon threat can be posed is possible. Then the sensitivicy of the facilities, as well as the need for institutions that infringe upon national ownership, etc., becomes less central to proliferation resistance. Any weakness in the system, however, would create serious vulnerabilities against which technical or institutional measures, or both, could otherwise form a second line of defense. Even assuming a sufficiently strong capability to deal with diversion, seizure, or abrogation, the likely situations in which use denial measures could be triggered, use denial would fail to deal directly with the risks of technology transfer and clandestine plants built with know-how gained from a plant subject 
to use denial. In this case, disabling of the in-system plant could be a deterrent or penalty but would not prevent the building of a clandestine plant.

Another shortcoming in the concept of active use denial is that it is principally applicable (if at all) to facilities, and not to the materials that they produce. It is difficult to conceive of a fuel cycle regime in which there was sufficient concern over the proliferation risk of a reprocessing plant to justify the application of active use denial measures, but no corresponding concern over the proliferation risk of the product of the plant, sizeable stocks of which would, almost of necessity, be accumulated in the country in which the plant itself was located. Thus, if the objective of active use denial is to eliminate or reduce the need for institutional means of proliferation resistance, it would make little sense unless all plants and all significant stocks were placed under the same form of protection -a difficult task -- or if the reprocessing plants produced a product of high intense proliferation resistance.

Even assuming very high technical reliability, the principal factors governing the nonproliferation effectiveness of active use denial are institutional in nature. The concept, itself, presumes the existence of some authority responsible for interpreting signals and reports and for determining the appropriate response. The degree of multinationality of the facility, the nature and dependability of the host country, and the scope of the affected facility's operations may have a substantial impact on the political acceptability of active use denial arrangements and on the complexity of the necessary technical and decision-making apparatus. Political acceptability appears very doubtful where the multinational staff associated with use denial are in an essentially adversary relationship with national plant operators (although this would be necessary for nonproliferation reasons) or where a substantial part of the country's power supply depends upon the affected plant. The use denial arrangements might be 
more complex in so-called proliferation threshold countries as compared to existing nuclear weapon states and stable neutral: countries.

Major liabilities and weaknesses in the concept are also institutional. Recruitment and maintaining morale of the use denial teams on-site at the plant could be problematic, especially if non-interference with operators would be the norm. The legitimate concern of the host country with the risks that false alarm poses to continuity of energy supplies could lead to cumbersome group decision-making arrangements incorporating appeal procedures, despite the fact that the magnitude of the risk associated with accessible sensitive facilities and materials seemingly would necessitate a well-integrated command system responsive to unified, fast-acting authority. Decision making by committee might be incompatible with these needs.

Despite these difficulities, the concept of active use denial remains an interesting one. While its technical problems are formidable political ones may be controlling. In view of this, a political analysis of the concept has been undertaken as part of this study, and is attached as Appendix B. This study concludes that the most realistic application for active use denial is as a means by which an international or multinational institution can disable a plant under its own auspices in the event of an impending national takeover.

\subsection{CONCLUSION}

The technical measures discussed here might increase the levels of protection, but what is not yet evident at the present stage of their development is whether the incremental costs of technical measures are matched by commensurate gains in proliferation resistance, and whether these gains materially change the magnitude of proliferation risks. Moreover, the realization of these gains presumes institutional structures for enforcement of standards, 
monitoring of compliance, and decision-making leading to appropriate response when abuse occurs. Some measures that are portrayed as technical changes in the fuel cycle in fact may be more institutional in character.

A final, major point about technical fuel-cycle measures is that they do not advance proliferation resistance on all fronts. They essentially change the parameters of accessibility, possibly increasing the cost of abuse if measured in terms of resources expended in the effort to misuse the material. They may have less relevance to problems of detectability and technology transfer and to the ability of the international community to respond in a timely fashion. Only active use denial has any bearing upon the consequences which would follow detection of abuse.

The relationship between the fuel cycle and international institutions is not a simple one. Although there may be trade-offs between the technical and institutional approaches to reducing national access to sensitive materials and facilities, there may exist a minimum level of institutional measures that must be implemented, regardless of the degree or success of. technical modifications in the fuel cycle. 


\section{REFERENCES}

1. DOE Assistant Secretary for Energy Technology, office of Nuclear Energy Programs, Nuclear Proliferation and Civilian Nuclear Power, Report of the Nonproliferation Alternative Systems Assessment Program, DOE/NE-000I Vol. 5. 


\section{CONCEPT FORMULATION AND EVALUATION}

The analysis in the preceding chapters supports the conclusion that institutional approaches to the reduction of proliferation risks are promising and perhaps the pre-eminent means of reducing the potential for using the civil fuel cycle for weapons purposes. The discussion of specific proliferation risks and institutional features indicates that an institutional approach is highly relevant to the reduction of these risks. The chapter on fuel cycles demonstrates that technical modifications of fuel cycles, or of sensitive facilities and materials, do not obviate and, in fact, presume the need for institutions. Consequently, there are no alternatives to an institutional approach. Moreover, the amount of political tolerance for both extensive technical modifications and for extensive new institutional arrangements may be limited, dictating that choices made among the two approaches be firmly grounded in an understanding of the effectiveness of each.

There exists a spectrum of institutional arrangements that, combining the individual institutional features described in Chapter II in different configurations, could be established to strengthen the proliferation resistance of both sensitive facilities and materials. The following concepts within this spectrum can be regarded as major candidates for an. institutional approach to proliferation resistance:

\footnotetext{
$\therefore \quad$ association of national facilities;

- national facilities under improved safeguards;

- international custody of sensitive facilities and materials;

- facilities under multinational ownership and management; and

- Eacilities under international ownership and management.
} 
The individual points in this spectrum afford different degrees of institutional protection and acceptability.

This chapter first develops the nonproliferation rationale of each concept. On the basis of this analysis, the structure of each candidate institutional concept is presented. Finally, each concept is assessed against the nonproliferation threats and. acceptability elements identified in Chapter II.

For the sake of definitional clarity, national facilities are those in which ownership, managerial, and operational responsibilities are retained in national hands. These responsibilities extend to such matters as investment, choice and development of technology, and capacity expansion. Institutional concepts consistent with this character would not compromise national managerial and operational authority. Multinational and global facilities involve joint ownership and management arrangements in which governments are the principal parties. National authority in this case would be subordinate to group determination. The term "multinational" refers to institutions with a relatively small number of member nations, joined together by some common interest or regional relationship. Thus, there could be several multinational institutions engages in the same field of fuel cycle activities. The term "international" is applied to an institution that is eventually global in scope, encompassing all or nearly all the countries engaged in a particular activity. 


\subsection{ASSOCIATION}

Institutional arrangements that involve some form of association establish a formal organizational relationship among the participants, together with legally binding rules and guidelines governing policy matters relevant to nonproliferation, while leaving the ownership, management, and operation of sensitive facilities in either national hands or the hands of multinational institutions charged with these responsibilities. Precedent already exists for supplier arrangements. A loose association -- United Reprocessors Group (URG) -- already links the existing reprocessing facilities in the U.K., France, and West Germany. URG was not created to promote a nonproliferation objective; it is principally a market-sharing mechanism, with some aspects of technology sharing and, at least so far, has had limited commercial importance. Since its purposes are basically promotional and commercial, it can be argued that it has encouraged the performance of reprocessing before adequate restraints on separated plutonium have been established. Nevertheless, the existence of URG does demonstrate the capacity of reprocessors to concert their policies.

An association offers an opportunity to advance nonproliferation objectives by providing a mechanism that can limit or avoid competition that undercuts safeguards and other controls and that can ensure the application of nonproliferation controls that might not otherwise be applied. The association structure can provide the organizational foundation for the harmonizing of export and safeguard policies, the determination and implementation of other nonproliferation-related standards, including restraints on the dissemination of sensitive technology, the establishment of fuel assurance mechanisms, and the coordination of policies pursued by other regional or multinational institutions. The major shortcoming of the association approach, as that term is applied in this study, is that it provides no additional assurances against unauthorized use of sensitive materials or facilities by the members of the association itself. 
The existing London Suppliers Group already serves, in limited respects, as an association of existing and some potential reprocessors. The London Group provides for restraint on the export of reprocessing technology and encourages, but does not mandate, supplier veto rights over reprocessing. It also requires safeguards and physical security óver all exports, thus, including any products returned from reprocessing operations. It does not, however, impose any additional controls on the members in their own use of the reprocessing plants that they possess or of their products, beyond those already called for by their existing nonproliferation and safeguard undertakings.

The London Group, while it establishes a precedent for supplier agreement on a code of conduct, does not provide the sole model for an association, nor does it limit the range of responsibilities and purposes for an association. A spectrum of association-type arrangements can be developed from different permutations of several core features of the association concept. The structure of the association, as well as its intrinsic importance to the overall nonproliferation regime, can vary according to:

- who belongs (composition)

- its functions

- nature of its authority

The London Group is only one point in this spectrum. Although the central purpose of an association may continue to be to establish binding "rules of the game," how it does this, and for whom, may be just as significant as the substance of the rules themselves.

\section{1 .1 Composition}

The status of the association in the overall nonproliferation regime depends to a major extent upon what kinds of entities 
participate. An association of essentially regional, multinational organizations that have primary responsibility for operation of sensitive facilities or management of sensitive materials would provide a mechanism for the harmonization of regulations and coordination of policies, while allowing for some tailoring of the regional arrangements to the specific needs and interests of individual countries. In such an approach, however, the regional institutions would have much more immediate relevance and importance to proliferation risks and to energy security than the association itself.

An association in which national suppliers and customers participated directly, on the other hand, might be the central institution of the regime. In this approach primary nonproliferation responsibility would reside in the association itself, unlike in the first approach where it resides in the constituent parts of the association.

The identity of the initial membership is particularly crucial to the political acceptability and long-term effectiveness of an association consisting of nation-states. Confining the initial membership to the existing reprocessor states imparts a strongly discriminatory character to the association, creating serious acceptability problems. Against this liability is balanced the possibility of the greater deterrent power that such an institution may possess and the likelihood that it can adopt stricter controls and restraints than those on which an organization that includes recipient countries could agree. The establishment of a limited membership association would constitute a major advance in the development of a consensus on nonproliferation strategy among the major participarits in INFCE, whose positive cooperation is essential to the strengthening of the inter- 0 national nonproliferation regime. On the other hand, to many less advanced countries it would appear to superimpose a new axis of discrimination upon the existing economic and military ones in the international system. 
Closely related to the discrimination issue is the long-term viability of the association. Not only would the foundation of a limited membership association be eroded by political opposition to it, the expansion of markets for reprocessing services and the gradual diffusion of technical capabilities inevitably will place the issues of expansion of membership and the extension of institutional arrangements to new plants on the agenda. Although an association of a limited number of countries is perhaps the least time-consuming institution to establish, problems of long-term institutional viability and relevance may become serious unless provision is made for expansion.

\subsubsection{Functional Scope}

The value of the association to the international nonproliferation regime, its nonproliferation effectiveness, and its political and economic acceptability are to a considerable extent related to its functional scope. In its simplest form, the association's responsibility could be limited to the establishment and enforcement of a code of conduct. Additional responsibilities could include arrangements to reinforce the assurances of supply of the services offered by each member of the association.

Code of Conduct: In addition to requiring uniform application of safeguards and physical security measures over all exports, including any retransfers, a code of conduct could include the following additional features:

- The association could undertake not to export to additional parties the technology jointly or individually held by the members, unless such export clearly promotes a nonproliferation objective.

- The association could offer reprocessing services only upon the understanding that all recovered plutonium will be submitted to an effective international custody scheme. 
- The association members could consult each other in connection with any request to provide reprocessing services to particularly sensitive countries or regions and could agree not to undercut any of the agreed safeguard and control requirements for competitive reasons.

A number of additional features that could provide increased proliferation protection, but that might be less acceptable to some reprocessors or customers, are considered below:

- The association members could employ only proliferationresistant technology either in the reprocessing operation itself or in connection with the distribution of any product.

- The association might confine reprocessing services only to those nations that agree not to engage in reprocessing activities themselves, at least for a certain minimum number of years or until a certain set of conditions were met, such as the amount of installed nuclear capacity that establishes a genuine economic rationale for reprocessing.

The viability of such a code, which incorporates politically sensitive restrictions on the flow of technology, would be particularly dependent upon the identity of the association's members. The potentially discriminatory character of such arrangements, and the controversial question of who decides.such matters, place considerable weight upon the composition of the association and also upon whether it directly unites reprocessor states, offers room for expansion, or provides a framework for a federation of regional institutions.

The association concept itself could be flawed if it encouraged exclusive reliance upon such a code. Such a code alone would afford insufficient proliferation resistance for reprocessing plants located in more sensitive countries and regions. The association is insufficient from the outset, if the plutonium returned to the customers is subject only to safeguards. The composition of the membership cannot compensate for this defect. 
Fuel Assurances: A second functional area in which the association can make a direct contribution is that of assurances of supply. The association offers ways to strengthen a fuel assurance scheme based primarily upon à competitive market, supported by various undertakings among suppliers to make fuel or fuel cycle services available on an emergency basis where, for reasons unrelated to nonproliferation concerns, supply is not forthcoming. The primary contribution of the association to the functioning of the market would be a firm prohibition against any restraint of competition, thus, reducing the pressure for independent capacity that the potential for cartelization inherent in an association that restricts the number of reprocessors would create. Such a prohibition could create a dilemma for the association, since the economic benefits of cartelization, real or perceived, could be an incentive in ensuring supplier compliance with the code of conduct contemplated here. Any evidence of self-serving policies, however, could drive customers to acquire independent capabilities.

Credible assurances of supply are essential to both restraining the spread of reprocessing and promoting customer satisfaction with the association arrangements. The association structure provides a mechanism at the plant operator level through which back-up arrangements and emergency stockpiles can be established to protect the customer against interruption in the supply of back-end services and products. This can be accomplished through agreements among suppliers establishing commitments to honor each other's arrangements, while not interfering with the competitiveness of the market.

\subsubsection{Authority}

The question of what kind of authority the association possesses goes beyond the binding character of its obligations, which in any permutation of the concept would be a minimum prerequisite for its proliferation effectiveness, to more politically sensitive issues of what kinds of decisions are reserved to the association and how they are made. Of particular significance is 
whether decisions identified in the code of conduct -- on technology transfer, sales to sensitive countries -- are made collectively or nationally, following only group consultation in the latter case.

Reserving such decisions to the association, following the precedent established by URENCO would necessitate the establishment of a permanent central policy committee and would make significant political demands of the members. The second approach, retention of national decision-making power within a framework of rules and guidelines, could somewhat lessen these demands by leaving to the individual supplier determinations of whether transfer advances nonproliferation interests, but would introduce the potential for serious strains among the members if one or more members were to make decisions perceived as imprudent or self-serving by the others.

Collective decision making on matters related to the code of conduct raises the question of whether unanimity or some form of majority voting is to be the basis for action. The composition of the group is particularly relevant to this point, since parity of technological competence and political influence in nonproliferation would be two prominent factors governing the allocation of power within the organization. Although URENCO offers an example of decision making by unanimity, the precedent it offers may be limited by the circumstances of its founding (each party initially felt it had rough technical parity with the others, the Dutch perceived a political need to hold a veto power over West Germany's centrifuge program) and the potential for one reluctant partner to prevent action that might otherwise be beneficial for nonproliferation reasons, such as expand the membership or to offer fuel assurances to countrics that otherwise might build their own plant. A majority voting scheme, with votes weighted by some objective index, such as installed nuclear capacity, would alleviate this potential for blockage and would better tailor the voting power of individual members to their actual weight in the nuclear market. 


\subsubsection{Candidate Concept}

Several candidate concepts based upon the preceeding discussion can be developed. These concepts are:

I. Association of Suppliers

- The initial membership would consist of the countries that already have reprocessing capabilities, supplemented perhaps by those with a sufficiently large nuclear power complex to justify such facilities.

- The primary function of such an association would be to implement a code of nonproliferation conduct, among whose major provisions would be restraint of technology transfer and sales of services to sensitive countries. Services would be provided only to countries which forego the establishment of their own reprocessing facilities, unless these are accepted as economically justified by the members of the association.

- In the interests of promoting the wide-scale acceptability of an arrangement based upon restraints, the association could establish supply assurance mechanisms of the sort identified in the preceeding section in order to offer advantages offsetting membership provisions which otherwise might discourage customer support.

- The primary mechanism for implementing the code would be a set of rules and guidelines without any formally centralized policy committee. Alternatively, such a committee could be established, with significant implications for the scope of national authority.

II. Association of Suppliers and Customers

- The membership would consist of those both supplying and utilizing reprocessing services.

- The same code of conduct as in \#I would be established.

- Supply assurances, possibly made available on an exclusive basis to customer-participants, would 
be an integral part of the institution as the primary benefit to attract customer participation.

III. Association of Multinational/Regional Institutions

- Multinational/regional institutions operating facilities or performing custody-type operations would compromise the membership.

- A code of conduct defining various "rules of the game" would harmonize the standards and regulations of the constituent institutions.

- Each member institution presumably would exercise direct fuel assurance responsibilities, although the association could provide an additional level of mutual back-up guarantees.

\subsubsection{Concept Evaluation}

\subsubsection{Nonproliferation Assessment}

From the nonproliferation viewpoint, the concept of an association of suppliers has much in common with suppliers' arrangements, which have long been a tool of nonproliferation policy. The concepts of an association of both suppliers and customers or of other institutions do not have the same base in precedent. The latter concept in particular would be a more novel institutional step and, because the level of proliferation resistance it affords is primarily that attributable to its member institutions (custody, multinational facilities), would not bear the same direct and immediate relationship to nonproliferation as would associations of nations. As a result, the evaluation of the nonproliferation effectiveness of this sort of association must be carried out principally at the level of these institutional concepts (see sections $4.3,4.4$, this chapter).

The approach of developing a code of conduct of the sort envisaged here, and institutionalizing it in the form of the 
association, has the advantage of favoring the restriction of plants to those nuclear weapon states and advanced industrialized nations where reprocessing will have the least potential for contributing to proliferation. If endorsed as an appropriate framework for the conduct of reprocessing, it would remove a source of controversy among the industrialized countries in nonproliferation policy. The arrangements also could receive support from a number of recipient countries, since acceptance of such a regime as an appropriate basis for reprocessing to take place would presumably be accompanied by a policy on the part of those countries, such as the U.S., which exercise approval rights over fuel that they supply to normally grant approval for reprocessing. Although recipient countries would be concerned by the restrictions on their access to the separated plutonium, the assured availability of reprocessing services under such an arrangement could prove very persuasive when compared to the economically risky current situation.

On the negative side, establishment of this arrangement would constitute a step -- although a conditional one -- toward the legitimization of plutonium recycle, and would undoubtedly intensify pressures from other nations to enter the reprocessing field. Even without preclusive conditions, such as a requirement that customers of the association forego reprocessing on their own, the overall thrust of the arrangement would be viewed as discriminatory. Confinement of supplier approvals for reprocessing to services performed by association members would reinforce this. Negative reactions, particularly by the more industrialized developing countries, are predictable. The concept of an association of both suppliers and customers addresses the issue of restrictive membership and discrimination, even though it does not necessarily entail a dilution of restraints on technology.

National Diversion: The principal bulwarks in this concept against diversion of sensitive materials from the reprocessing plant are IAEA safeguards and the composition of the group. The 
major contribution of the association to the proliferation resistance of the plants, themselves, is the restriction of such facilities to countries with little or no incentive to misuse them. The risk of national diversion by the plant operator would be directly influenced by the siting criteria. The composition and siting criteria could prove to be more important in alleviating this risk than the organizational format of the association itself. Limiting reprocessing plants to nuclear weapon states or to stable countries with no real need or interest in nuclear weapons might reduce the probability of diversion or plant seizure. In the absence of any restrictions on the distribution of sensitive material or of an arrangement for custody of such material, however, the association concept fails to address national diversion risks that would occur away from the reprocessing plant.

Since the association itself does not undertake any safeguards responsibility, it does not materially strengthen the detection capabilities of the nuclear regime. Whatever monitoring function the association performs would be to ensure compliance with its rules. The code of conduct does not itself improve either the difficulty or detectability of diversion. The siting restrictions and restraints on technology transfer integral to the code, which rely upon the trustworthiness of the host countries, would constitute the major addition to resistance against diversion attributable to the association itself. As in other major respects, particularly in the safeguards area, the international nuclear regime would be unchanged.

Seizure: Diversion is not the only problem at the reprocessing plant itself. While there is nothing inherent in the association concept that would prevent ovcrt use of reprocessing plants for direct employment in a weapons program, the deterrence against such an act may be considerable, although the association lacks the trigger for response in case of seizure that custody provides. The strength of deterrence would reside 
in the willingness and ability of the membership to take retaliatory measures and in the hoped-for disinclination of the host states to provoke such a response. This raises the issue of motives and incentives, and emphasizes the pivotal importance of composition. Motives and incentives may be very much a function of political and military circumstances having little relation to the association itself. As in the case of national diversion, any absence of restrictions on the distribution of sensitive material would be a serious liability in the face of seizure risks associated with material in transit or in the hands of potential users. This risk would argue strongiy for establishment of a custody arrangement, in which case the association's code of conduct would supplement the more direct nonproliferation contribution of the custody institution.

Abrogation: An abrogation in the context of the association could take one of two forms: a renunciation of safeguards by a recipient; or a violation of the code, such as an unapproved transfer of sensitive technology by a supplier-member of the association. The major deterrent against abrogation by a member of the association is that the other members would exact economic and political penalties on the violating members. Diluting this deterrence, however, is the fact that the association is little more than a code of conduct that lacks reinforcement by any other more extensive form of multinational involvement or explicit set of sanctions that could be taken against a member.

This weakness might not be as apparent where a customer-country is guilty of abrogation. The association in such an instance would offer a mechanism for total cessation of the flow of ser-. vices, sensitive material, or technology from the supplier members of the group. However, as a trigger for sanctions, abrogation by a customer of undertakings made to the association may be only incrementally different from abrogation under the current regime, and certainly may not appear comparable to abrogation by a country hosting a multinational reprocessing plant 
where the de facto expropriation of foreign property might unleash a quicker and stronger reaction.

Technology Transfer: Technology transfer in this concept is the risk that is most effectively dealt with, since the purpose of the association is to minimize it. The association members would transfer reprocessing technology in rare circumstances, and then only where it enhanced proliferation objectives. The contractual, rather than investment arrangements, upon which supply assurances would rest, would not create a presumption on the part of customers that they eventually would have access to technology. At the same time, while indigenous development would be more difficult in the absence of technical assistance, it would not in most cases be rendered impossible.

\subsubsection{Economic/Operational Assessment}

The principle economic and operational advantages of the association lie in its minimal interference with national decision making and conventional financial, ownership, and managerial practices. In this regard, individual plants could avoid some of the inefficiencies of multinational plants. The association also would not impose foreign exchange costs upon customer countries any greater than those they would experience if the current situation of having to contract with reprocessing facilities in a few industrialized states were to continue. As a result, both suppliers and customers would be no worse off economically than they would be if the present situation continued indefinitely.

The association, on the other hand, does not necessarily improve the economics of reprocessing. It would not involve the spreading of investment risks over a number of parties or the attainment of scale economies. Voluntarily built joint plants would be possible, but they would not be mandated under this concept. Each investor would bear his own investment and technological 
risk. On the other hand, the operator would be able to operate within a normal national, rather than a negotiated, multinational framework.

The geographical confinement of reprocessing for proliferation reasons also would provide a constraint upon new competitive threats, which existing reprocessors might see as a benefit. This, of course, could have negative implications for fuel assurances and acceptability in the eyes of customers, but this constraining effect could provide the glue to hold the suppliers together. How much competition would be necessary for assurances, and whether competition and diversity of supply or the strength of contracts would be the more important determinant of customer perceptions of assurance, are particularly important considerations, but it must be borne in mind that the inclusion of all current and potential near-term reprocessors would offer several potential sources of supply.

The proscription of any sort of economic collusion renders the economics of reprocessing 1 ittle different from those of the present situation. What the association does, by impeding the spread of reprocessing to new countries, is favor the retention of most of the market by the current reprocessors. Such a de facto market assurance could be a very valuable incentive for participation by suppliers, especially where potential new market entrants, together with reactor cancellations and postponements, could otherwise create substantial fluctuations in both the demand and supply curves. The extent to which the benefits of stabilizing the supply side of the reprocessing market is attainable solely through the association is not abundantly clear, especially since that market. for some time to come may, even in the absence of a formal association, be dominated by a few reprocessors with large amounts of capacity at their disposal, and since the economic barriers to market entry are not insignificant. 
What differentiates the association concept from multinational or global institutions is that it does not introduce inefficiencies that some consider to be inherent in jointly owned and managed plants. It might not be unfair to characterize the association concept as at least economically neutral in this regard.

\subsubsection{Political Acceptability Assessment}

The sharp differentiation that the association makes between supplier and customer-states, as it is institutionalized in a code of conduct that is highly restrictive towards technology transfer and consequently the ability of countries to build commerical reprocessing plants, has a fundamental impact upon the political acceptability of the concept. The differential advantages and benefits that an association of suppliers, or suppliers and consumers, confers parallel existing divisions among states based upon economic and military status. Although the association offers some offsetting benefits to customers, these may be insufficient to overcome the inherently discriminatory character of the association.

The following discussion of political acceptability is confined to associations in which states participate directly. Because of the more immediate presence of the regional/multinational institutions in the association of institutions concept, the political acceptability of that arrangement will be much more a function of the characteristics of the constituent institutions. The association in that instance is both more remote from the nation-states and quite likely of less priority to their immediate fuel needs and political interests. As a result, there is little that can be said of the acceptability of such an association independently of the analysis of the constitutent institutions.

From the standpoint of supplier-participants, the association imposes relatively few constraints that might detract from its 
political acceptability. By taking national ownership, management, and staffing as a given, the association would minimize interference with decision-making authority over the fuel cycle for supplier countries. The constraints that it does impose are limited to export policy and, in fact, can be seen as economically, advantageous if they minimize the expansion of reprocessing operations into potential competitor countries. From an energy security point of view, therefore, the association likely would be a relatively satisfactory institutional outcome in the eyes of suppliers.

More explicitly political considerations might lead to a more mixed outlook. By keeping the reprocessing industry home, the suppliers' association would be more likely to be compatible with domestic economic policies. Although expansion of capacity to service largely foreign needs could encounter opposition from environmentalist and anti-nuclear quarters, this opposition would likely differ only' in degree, not kind, from that against building reprocessing plants of any sort. The more serious misgivings could arise from concern for foreign policy interests, which participation in what many customers could construe as a discriminatory arrangement might damage. The reluctance of the original London Suppliers Group to have it publicly known they were participating in that organization is evidence that such concerns could be significant, though not necessarily insurmountable, obstacles to the negotiability of an association.

The politics of the institution also would be more satisfactory to suppliers, as their dominance would be assured by their control of the reprocessing plants. Customer participation would not mitigate this asymmetry of power.

The political acceptability of the association to customer countries, on the other hand, in all probability would be very low, with the result that the association's political legitimacy would be very tenuous. The association effectively would substantially curtail the customer's authority to determine its 
fuel cycle policy and would institutionalize long-term, if not permanent, dependence on outside sources of supply: Although the association offers a mechanism for potentially credible fuel assurances by encouraging competition, supplemented by supplier back-up guarantees, the political price -- postponement of the indigenous plant option - - would be seen as high. On balance, with no demands of similar magnitude made of suppliers, could lead to overall negative conclusions about the association where energy security is the criterion.

The association might fail the other political tests as well. In restricting an industrial development, the association likely would arouse domestic political opposition. It, likewise, would visibly reinforce the diplomatic subordination of customer countries. This need not be the result in all cases; reprocessing abroad may be preferable where its domestic political sensitivity is high, as in some West European countries. These countries, however, are not in most cases the object of the nonproliferation concerns that give rise to the association. A similar willingness to tolerate long-term dependence cannot be expected of more nationalistic industrializing countries now expanding their nuclear power programs.

Finally, the politics of the instltution may be unacceptable as well for many customer-states, since they would lack any decisive influence within the association. This is the exact reverse of what may make the association attractive to suppliers.

On balance, the association may appeal politically and economically to some supplier countries. To others, especially customer-countries, it represents an unacceptable abridgement of their authority and freedom to determine their own fuel cycle policies and would be seen as institutionalizing discrimination. The most serious consequence of this would be that it inadvertently could encourage development and construction of the indigneous facilities it is intended to prevent. Its economic consequences, however, might be less onerous and might not, as a 
result, play as significant a role in determining its acceptability as its political ramifications.

Against this very mixed evaluation of acceptability must be weighed its potentially limited nonproliferation effectiveness if all that is established is a code of conduct. Other institutional arrangements, especially for control of sensitive material, appear necessary. Such arrangements, however, if estabIished, would be of more direct relevance to proliferation resistance than the association, as described here. A code of. conduct may in any case be necessary to implement siting restrictions and to address problems of technology transfer. It is evident, however, that such a code can be incorporated in the undertakings established by other more ambitious institutional arrangements. 
From the outset of international nuclear cooperation, international safeguards have been the principal institutional mechanism for the separation of peaceful from military utilization of nuclear energy. This role, first given prominence in the statute of the IAEA, was further emphasized in the NPT, which requires the acceptance of safeguards' on all their peaceful nuclear activities by all non-nuclear weapon states. (NNwSs) party to the treaty and the application of safeguards to nuclear exports by treaty parties, whether destined for parties or non-parties. Despite the role accorded safeguards in nonproliferation policy in the past, much of the rising concern over increased risks of proliferation stems from doubts as to the adequacy of safeguards in ensuring a proper separation of peaceful and military uses, at least insofar as the sensitive fuel cycle facilities and sensitive nuclear materials are concerned.

Any comprehensive analysis of possible institutional arrangements to provide improved proliferation resistance for sensitive fuel cycle operations must include consideration of whether and to what extent improvements in the safeguard system and arrangements as now understood can contribute to this end. This examination, in turn, calls for a clear delineation of the limitations, whether real or perceived, of current safeyuards as a means for insuring that peaceful nuclear activities and materials are not misused. Only through such an understanding can improvements be systematically identified and their effectiveness assessed.

In undertaking this examination, it is important to record that international safeguards remain widely accepted and strongly supported as a valuable obstacle to further proliferation. The concern is not whether safeguards are necessary, but whether they are sufficient. This reservation involves, in varying degrees on the part of different observers, concern over the following factors: 
- Technical effectiveness. Whether safeguards can detect significant diversions of sensitive materials promptly, unambiguously, and with a high degree of assurance.

- Scope. The fact that safeguards are not applied to all facilities and materials in all non-nuclear weapon states engaged in peaceful uses of nuclear energy and, in particular, that sensitive facilities in several states of principal concern remain outside the safeguard system.

- Continuity. The possibility that safeguards, even when in place, can be renounced or terminated by the state, leaving sensitive facilities or materials transferred in reliance on safeguards no longer subject to this protection.

Limited purpose. Closely related to the problem of continuity, and most important of all, the fact that safeguards are designed in the first instance only to detect diversion, and that their role in preventing proliferation, thus, depends on their ability to deter misuse through fear of prompt detection or to increase the chance of effective counteraction by providing timely warning.

These concerns differ considerably in their validity, in how seriously they detract from the adequacy of safeguards as a principal nonproliferation mechanism and in the extent to which improvements are conceptually and practically possible. Each of these separate concerns is examined below, in terms of each of the three factors -- validity, seriousness, and potential for improvement -just cited.

\subsubsection{Technical Effectiveness}

Early U.S. Studies of the effectiveness of safeguards at sensitive nuclear facilities such as enrichment and reprocessing plants concluded that the effectiveness of safeguards in detecting diversion was a function of the inspection effort, and that efforts that, while substantial, remained at a reasonable level in relation to the economic value of the safeguarded material could provide a high degree of assurance of the detection of diversions of quantities above a quite small percentage of the throughput or 
inventory of a sensitive facility. There is no reason to doubt the validity of these early studies, on which much of the early effort in the development of international safeguards was based. Nevertheless, valid concern remains as to whether safeguards as practiced will prove adequate to the technical task of prompt detection with a high degree of assurance of any significant diversion. (The term "prompt detection" has been chosen to mean detection in real-time, or within a very short time after the occurrence of a significant diversion, while avoiding any implications as to whether such prompt detection affords sufficient or timely warning in the policy sense of allowing adequate time for corrective action to be taken.) The basis for concern as to technical effectiveness of safeguards derives from: the nature of the system; restrictions of safeguards activities; and limitations on resources for safeguards.

4.2.1.1 The Nature of the System

Two basically different kinds of measures are available for detecting diversion or verifying compliance with nonproliferation undertakings :

- accountability measures, which are designed to ascertain through objective technical measurements that safeguarded material is in authorized locations; and

- containment and surveillance measures, which are designed to increase the difficulty of unauthorized removal and to discover such removal by direct observation, elther through human or instrumental means.

While accountability measures have the advantage of technical objectivity, they have important limitations. They are characterized by unavoidable limitations on accuracy, within which diversions, even if suspected, would be difficult or impossible to establish with certainty on the basis of the accountability results alone. These limits of error, even if quite narrow in percentage terms, can correspond to strategically important quantities of sensitive material when applied to the throughputs of large 
fuel cycle facilities. Additionally, and of particular importance in the case of sensitive materials, accountability measures yield Ehèit findings afier the fact, that is, after diversion has occurred, and the time lag in the case of small diversions may be considerable.

Containment and surveillance measures, on the other hand, have the advantage of being able to provide information on diversion in real-time, to be less subject to ambiguity, and to be capable of detecting even very small diversions if these make use of one of the pathways that are subjeat to the containment or surveillance. measures. On the other hand, containment and surveillance measures provide no assurance, as do accountability measures, that diversion - possibly on a substantial scale -- has not occurred through some undiscovered pathway.

In light of these differing characteristics, a practical, effective safeguards system must incorporate a mix of accountability, containment, and surveillance measures, and the IAEA system has this characteristic. Nevertheless, the emphasis in the IAEA system throughout. most of its development has been on accountability, a perhaps inevitable development in light of the similar emphasis of national maierials control systems that provided the major experience base for the development of Agency safeguards. Recently, there has been a growing realization that increased emphasis must be given to containment and surveillance measures in the IAEA safeguards system if it is to reach its maximum potential for the prompt, reliable, and unambiguous detection of diversion.

\subsubsection{Restrictions on Safequards Activities}

The basic right of the IAEA to conduct safeguards is expressed in Article XII, A(6) of the IAEA Stature, which provides for the Agency "to send into the territory of the recipient state or states, inspectors... who shall have access at all times to all places and data and to any person...necessary to account for source and 
special fissionable materials... and to determine whether there is compliance..." This right, along with other IAEA safequard riahts expressed in Article XII of the Agency Statute are, however, qualified by the introductory sentences of Article.XII, which states that "the Agency shall have the following right and responsibilities to the extent relevant to the project or arrangement." [underlining added].

These provisions, coupled with the political circumstances that surrounded the development of the IAEA safeguards system, led to a situation in which Agency safeguards could be given practical implementation only by the adoption by the IAEA of a relatively detailed set of guidelines governing how these rights, and especially the crucial right of inspection, would normally be implemented. This specification appears in two Agency documents, INFCIRC 66 and INFCIRC 153, which prescribe the Agency safeguards systems for non-NPT parties and for NPT parties, respectively.

While every effort was made in the development of both of these documents not to divest the Agency of its ultimate right of "access at all times to all places...,". it is clear that any limitation on or specification of the manner in which inspection will normally be conducted has the potential for diminishing the probability that a given diversion will be detected. Here, too strong efforts were exerted by the U.S. to ensure that these $1 \mathrm{im-}$ itations left the Agency the capability of prompt detection of diversion with a high degree of assurance. There is no evidence that if fully and effectively implemented the system fails to meet this objective. At the same time, there can be no denial that greater assurance of this capability would be present if the Agency were free to exercise its maximum statutory safeguards responsibilities without restraint. It is relevant that the U.S., in implementing the almost identical safeguards rights of its bilateral agreements, was never pressed to limit or specify the way in which it would implement these rights. 


\subsubsection{Resources}

Superimposed on the limitations on the Agency's normal safeguards procedures are limitations on the financial and personnel resources available to the IAEA to perform safeguards. These resources are allocated to the Agency staff by its Board of Governors, the majority of those members are countries that experience the application of IAEA safeguards at least in some measure, with an ultimate but limited approval authority vested in the Agency's full membership, the vast majority of which either have no safeguarded nuclear activities at all, or are predominantly recipients, rather than donors of nuclear assistance. Given these circumstances, there are predictable political objections that manifest themselves in the form of constraints on the resources made available to the Agency by its membership for the application of safeguards. To date, it has been these constraints. rather than those incorporated in the IAEA's safeguard systems, that have constituted the controliing factor in the intensity of application of IAEA safeguards. Once again, however, there is no reason to believe that the intensity of application has, so far, been inadequate for the accomplishment of the Agency's safeguards objective.

In summary, there is every reason to believe that safeguards can possess a high level of technical effectiveness for the prompt, reliable, and unambiguous detection of diversion, even of sensitive materials from sensitive bulk handling facilities. While there are grounds for concern that the present IAEA system may not be optimized for the accomplishment of this objective, there is little evidence that the system, as conceived, is seriously deficient in its detection capabilities. A greater emphasis on containment and surveillance, even without formal changes in the system, is possible and would appear to be beneficial. There is more reason for concern that the resources allocated to its implementation may be inadequate, particularly as sensitive facilities demanding more intensive inspection come increasingly under 
the Agency system. It may be useful to reconsider the basis on which the IAEA's safeguards are financed, including approaches which shift some or all of these costs to the users of nuclear power, in light of apparent Iimitations on the ability of the current assessment approach to generate resources which allow unconstrained application of the system.

\section{4 .2 Scope}

Although the importance of full-scope safeguards in ensuring that all civilian nuclear facilities and material in a given country are subject to the safeguards system is self-evident, the achievement of full-scope safeguards per se does not address the question of whether safeguards, as presently constituted, adequately deal with proliferation risks associated with sensitive fuel cycle facilities, except the risk attached to an unsafeguarded facility. The adequacy of safeguards with reference to the proliferation risks at a particular facility is primarily a function of the accounting, containment, and surveillance measures in force at that facility, not the scope of their application across a country's entire fuel cycle. Thus, of more basic importance to the improvement of the safeguards system than simply full-scope application is the strengthening of those measures which constitute the safeguards themselves.

\section{2 .3 Continuity}

Concern that IAEA safeguards lack permanence, or at least the assurance of permanence, is unquestionably a significant factor in the overall reservations as to the adequacy of safeguards as the principal proliferation obstacle for sensitive fuel cycle activities. The assumption to which this concern is directed, that a country can without qualification terminate safeguards applied within its borders, appears to be based, at least in part, on misconceptions as to the nature of the Agency's safeguard system and agreements, as well as the withdrawal provision (Article $x$ ) of 
the NPT. Related but quite different international activities, such as the removal of the U.N. peace-keeping force from the Middle East in 1967, have probably also played a part in the perception of many that inspected countries have the right to dismiss IAEA inspectors at will.

The issue of continuity has two components:

- Eirst, whether a country has the right or power to terminate the application of safeguards as such, either in whole or with respect to specific parts of its nuclear program; and

- second, whether it has the right to dismiss individual inspectors, which, de facto, could achieve a similar result with respect to a particular sensitive activity.

A definite answer to these two questions can be ascertained only by a comprehensive review of a variety of Agency and bilateral agreements and related legal precedents. The NPT, itself, and Agency safeguard agreements under the NPT are of particular importance. The withdrawal provision of the NPT (Article $\mathrm{X}$ ), while frequently described as giving parties an unqualified right of withdrawal on 90-days notice, clearly incorporates a standard against which any withdrawal must be judged, with the clear implication that if circumstances do not meet this standard, the withdrawal will hardly be regarded by the world community as proper, justified, and acceptable.

Agency safeguards agreements concluded, pursuant to the NPT, do not include a provision requiring continuing application of safeguards in the event of withdrawal to materials and equipment brought under safeguards while the country was a treaty member. In this respect, continuity of NPT safeguards is less assured than recent aqreements with non-NPT parties that, since the adoption of Gov. 1621 in 1973, must meet the requirement that safeguards remain in effect indefinitely with respect to materials subject to the system while the Agreement was in force, even after termination of the Agreement. The London Suppliers Group Guidelines call for the 
application of this provision of Gov 1621 with respect to materials and facilities supplied by the London Suppliers Group, regardless of whether the recipient country is or is not an NPT party. Section 123 of the Nuclear Non-Proliferation Act of 1978 calls for incorporation of a similar provision in new or amended U.S. Agreements for Cooperation, and the U.S. has always interpreted its Agreements to have this effect, even though explicit language is absent.

The above facts suggest that the common, if not universal, perception that IAEA safeguards can be terminated and inspectors dismissed at will is, at best, overstated. Moreover, the consequence of such an action, whether legally permissable or not, in the case of U.S.-supplied materials or equipment (and perhaps in the case of other suppliers with similar Agreements) would be to revive bilateral safeguard rights; a result that would not be entirely without its attractions in the case of an apparent move toward proliferation.

While these comments indicate that the continuity or desirability of Agency safeguards may not, even at present, be subject to as much doubt as commonly supposed, the issue is one that clearly deserves consideration. One obvious area is NPT-type safeguard agreements, which currently lack any provision for continued application of safeguards, following treaty withdrawal, to nuclear activities initiated while the Treaty was in force. Another area of consideration is the ability of states to frustrate safeguards by the dismissal of individual inspectors, even if safeguards themselves are not explicitly renounced.

While termination of safeguards by an inspected nation, whether accomplished as a matter of right or simply by exercise of sovereign power, would clearly be an event of major significance, it is perhaps incorrect to vlew it as a deficiency of the safeguards system. In light of the objective of safeguards as a means for the detection of diversion, the arbitrary termination of safeguards by an inspected nation would constitute an unambiguous 
signal of impending misuse. Thus, the safeguards systems would have fulfilled its basic purpose in the very process of being discontinued.

\subsubsection{Iimited Purpose}

The most serious issue concerning safeguards as a means for avoiding proliferation from the misuse of sensitive facilities and materials is their limited purpose as a mechanism for the detection, rather than the prevention, of diversion. Even technically infallible safeguards capable of giving immediate warning of any significant diversion would not, in themselves, overcome the concern that, when weapons-useable material is diverted, insufficient time might be available for effective diplomatic or other counteraction. Seizure of an entire sensitive facility or stocks of sensitive material, an event that with even reasonably effective safeguards would clearly trigger a prompt and unambiguous warning, would be subject to the same or greater concern as to the adequacy of warning time. Clearly, this concern, to the extent that it is justified, cannot be overcome by any improvement in the technical effectiveness of safeguards.

On the other hand, there are aspects of the safeguard system that bear. on the likelihood that such an event would take place, and on the possible counteraction that might be feasible if it should take place. It has always been presumed that an act of proliferation initiated by the violation of an international verification system would invest that act with a character that could enhance the possibility of an effective international response, as compared with a similar act undertaken without violation of such an undertaking. It is reasonable to assume, moreover, that the prospects for effective international action will be greater if the signal provided by the safeguard system is a strong and unambiguous one. Thus, there is a substantial incentive for improvements in the safeguard system that will improve its tech- 
nical effectiveness and strengthen and clarify its permanent and irrevocable character. Specific possibilities for improvements are identified and discussed in the remainder of this section.

\subsubsection{Candidate Concept}

The following specific provisions. could be adopted to enhance the effectiveness of safeguards in force at sensitive facilities and upon sensitive materials:

- Relaxation or elimination of limitations contained in IAEA safeguards system and agreements on the maximum routine inspection frequency and intensity at the most sensitive facilities. Decisions as to inspection effort would be the prerogative of the Agency.

- Lifting of access restrictions for ad hoc and special inspection, and elimination of the requirements for prior consultation in the case of special inspections.

- Improved funding of safeguards including, if necessary, direct assessment of nuclear power generating countries.

- Clear establishment of the irrevocability of safeguards, both under NPT [INFCIRC 153] agreements and non-NPT [INFCIRC 66] agreements, at least with respect to materials and facilities transferred or others acquired while the relevant agreement remained in force; and the accompanying understanding that inspectors are present as a matter of right and cannot be expelled individually or collectively unless Agency designated replacements are on duty.

\subsubsection{Inspection Effort}

Specification of the maximum frequency and intensity of routine inspections for defined categories of facilities [INFCIRC/153 para. 78-80], as well as the general principle that inspections be kept to a minimum consistent with the Agency's responsibilities, as provided for in the NPT agreements, are similarly incompatible with the principles of XII.A.6 of the Agency statute. Furthermore, the state, itself, may have considerable influence in the Agency's determination of the frequency of inspection, thus, further diluting the implication of XII.A.6 that the Agency alone should determine this point. 
Where sensitive facilities and sensitive materials present outside reactors are concerned, the frequency, and schedule of all inspec-. tions, including routine, should be determined by the Agency itself, based upon its assessment of what is necessary to effectively safeguard such. facilities and materials. Moreover, prior notification of an inspection would no longer be required of the Agency. The short warning times encountered where diversion from a reprocessing or fabrication plant occurs make prior notice incompatible with effective safeguarding.

\subsubsection{Access Restrictions}

A potential constraint on the effectiveness of safeguards is the limitations on access imposed upon inspectors by the provisions of subsidiary arrangements. Ordinarily, the Agency must provide advance notice for routine, ad hoc, and special inspections.

Moreover, access in the case of ad hoc and routine inspections is specified in advance in the safeguards agreement, and even special inspections require that the additional locations to be inspected be subject to prior consultation and agreement.

These Iimitations on access in the NPT safeguards agreements may severely compromise the intent of Article XII.A.6 of the Agency Statute. At a minimum, access limitations, as well as prior notification for special inspections, could be removed, since the circumstances of such special inspections - reports of unusual activities or unexpected changes in the containment of nuclear materials - render both requirements unwarranted and undesirable. The rationale for these steps is that constraints upon inspection are unacceptable where sensitive facilities or materials are present. 
Limitations on funding and personnel are currently the controlling factor in the intensity of IAEA safeguards implementation. Safeguàrds funding can, in principle, be derived from either or both of two different sources:

- from the Agency's own budget, derived from assessments on its members; or

- from the countries that use and, therefore, benefit from nuclear power. (Such countries can, of course, recover all or some portion of any such costs borne by them from the generating enterprises; but the Agency, as an intergovernmental organization, could not realistically assess utilities directly.)

The U.S. Government decided a number of years ago, without prejudice to the future, to support funding from the Agency's budget, although a special formula was developed to minimize the impact on LDCs, thus shifting the burden more to the industrialized states most likely to use nuclear power. While the Agency's assessment formula is based largely on GNP, this is not a direct measure of nuclear power use, and the current financing system has thus always been susceptible to the criticism that it fails to place the burden of safeguards costs on those who enjoy the benefits of nuclear power, and, by resulting in financial constraints upon safeguards implementation, gives rise to its proliferation risks.

Without regard to the philosophical merits of the alternative sources of safeguards financing, there is pragmatic evidence that the current approach cannot generate significantly greater revenues without serious political repercussions, despite the fact that the total IAEA safeguards budget continues to be a very minor cost in relation to the value of the nuclear power being generated. It seems appropriate, therefore, to consider once again raising at least a portion of safeguard costs from those who benefit from the use of nuclear power, including engaging in fuel cycle operations which absorb a disproportionate share of safeguard resources. 
An objection to this approach in the past has been the concern that direct financing would place the inspected countries in a position to limit safeguards application by their control over financing. This objection, however, would not appear to be relevant if the Agency is able to assess inspected countries in accordance with a uniform scale of charges established by the membership as a whole. Article XIV.C of the IAEA Statute explicitly provides for the recovery of all or a portion of safeguard costs from safeguarded parties.

\subsubsection{Irrevocability of Safeguards}

As discussed earlier, the IAEA has already endorsed the principle of irrevocability of safeguards and has provided for the application of this principle in all non-NPT safequard agreements. In the concept under discussion here, this requirement would be extended to NPT-tỵpe safeguard agreements, as well. The principle of irrevocability could, in principle, be further extended to provide that countries not only be required to agree to indefinite safeguards on all activities initiated while a safeguards agreement is in torce, but to agree that the agreements, themselves, be irrevocable. The effect of this would be to make a country's pledge to put all of its facilities under safeguards irrevocable and of unlimited duration. While obviously desirable from the nonproliferation point of view, such an approach would be in conflict with the withdrawal provision of the NPT, and would, on its face, be of particularly doubtful negotiability.

Under this concept, countries would also be required to accept restrictions on their right to expel inspectors, once these have been accepted. Under the Agreement on the priveleges and Immunities [INFCIRC/ 9/Rev. 2] of the Agency inspectors, inspectors enjoy the rights attributed to "experts on mission" for the Agency, including absolute immunity from arrest and detention and the right to communicate with the Agency. Unlike diplomats, inspectors cannot be declared persona non grata and may be expelled 
only after a formal procedure in which the Director General may intervene [INFCIRC/9/Rev. 2/Section $27(\mathrm{~g})$ ]. The troubling possibility is the possible interpretation of Para 85 (d) of INFCIRC 153 that a state may demand at amy time the immediate withdrawl of the designation on which rests the inspector's right to enter and remain in its territory. This interpretation, if it were to prevail, would largely vitiate the technically governing expulsion just mentioned, and creates an unwarranted assumption that a state can de facto expel an inspector, regardless of the consequence of this action for effective safeguarding.

The possibility that a state might be able to reject an inspector's designation, once accepted, would, in this concept, be restricted. Instead, an inspector on duty in a country could be removed only through a formal expulsion process, requiring a decision by the Director General that due cause had been demonstrated. The inspector in such a case would continue to serve until an authorized replacement arrived, thus, ensuring continuity of inspection.

\subsubsection{Concept Evaluation}

\subsubsection{Nonproliferation Assessment}

The improvement of safeguards identified in this concept contributes to the proliferation resistance of the fuel cycle by materially strengthening the role of the Agency vis-a-vis the states and correcting the principal weaknesses in existing safeguards practices and arrangements. Nevertheless, they are not directly responsive to the ooncern that nations that divert or seize sensitive materials or facilities might be able, notwithstanding prompt and certain detection, to produce nuclear explosives before effective countermeasures could be applied. As discussed below, however, improvements in proliferation resistance against the risks of diversion and seizure could, nevertheless, be achieved through improvements in safeguard practices. 
National diversion: Removal of limitations on access and frequency of inspection may increase the probability that diversion would be detected. While the steps contemplated remain consistent with the underlying rationale of safeguards as a system to detect but not necessarily prevent diversion, improvement in detection capability would strengthen the deterrent effect. Limitation on the right to reject designated inspectors would prevent a would-be diverter from first expelling an inspector prior to engaging in diversion, but would not improve the effectiveness of inspection per se.

Seizure: Current nonproliferation thinking has tended to discount the effectiveness of safeguards as a deterrent to national seizure or takeover of sensitive facilities and materials. In this view, the deterrent effect of safeguards derives largely from their ability to provide sufficient warning of impending proliferation to enable an effective response to be taken before the manufacture of nuclear explosives is achieved. If this warning time is substantially reduced, as it could be in the case of sensitive facilities or materials, the deterrent effect could be greatly diminished.

Safeguards, however, may exert a deterrent effect on violation of nonproliferation undertakings which goes beyond the fact of detection per se. This is the possibility that a violation of international undertakings that has involved the deception or the summary ejection of an international inspection force could trigger a more effective international response than would a similar violation in the absence of such an international inspection system. In short, the involvement of international inspection could well change, in political terms, the quality of the act of violation.

There is, fortunately, no directly applicable body of experience on which to evaluate these two differing, but not mutually exclisive, views of the deterrent effects of safequards, nor would.past 
experience necessarily be a guide to the behavior of a would-be proliferator in the future. Nevertheless, since safeguards may under either hypothesis provide some deterrence against seizure, measures that strengthen safeguards both technicaliy and poiliically can only be beneficial to the reduction of the proliferation risk of national seizure.

Abrogation: Similar and perhaps stronger conclusions can be reached with regard to the risk of abrogation. To the extent that abrogation reflects a less certain intent to embark on a proliferative course than does seizure, countries would presumably be less willing to accept the penalties of deliberate defiance of an international verification system.

Technology transfer: There is legitimate concern that international safeguards themselves may be a pathway to unwanted transfer of sensitive technology to countries not already in possession of it. To the extent that strengthened safeguards might increase inspectors' access to sensitive technology, this problem would be intensified. The difficulty of devising inspection procedures for uranium enrichment that are at the same time effective and avoid undesirable access to sensitive technology is one manifestation of the problem. One avenue worth exploring is the limitation of the inspectorate to nationals of countries that already have substantial capability in the technology in question. Another approach is to devise considerably more intensive forms of perimeter inspection, with strong surveillance and containment capabilities, as opposed to relying principally on accountability. While the problem is a difficult one, it seems apparent that the general degradation of the technical effectiveness of safeguards in order to avoid access problems is not a preferred or sound approach.

\subsubsection{Economic/Operational Assessment}

Intensified inspection of sensitive facilities and materials could entail increased costs of two kinds: 
- Those incurred by the inspectorate; and

- Those incurred by the inspected facility or state.

It is predictable that objections will be raised on both counts, and that the objections of inspected facilities or states to the payment of costs that they, themselves, incur by reason of safeguards will be increased if they are called upon to bear all or some portion of the Agency's costs. Despite these predictable objections, there is convincing evidence that technically effective safeguards involve costs that do not significantly affect nuclear power economics. One estimate places such costs at no more than $1 \%$ of the total cost of nuclear power. [Reference 1 , Page 114]

\subsubsection{Political Acceptability Assessment}

Any movement in the direction of intensified safeguards or increased freedom of the Agency to decide independently on the intensity and scope of inspection activities will meet with opposition. At the same time, such measures clearly involve a far smaller departure from the present nonproliferation regime than would either more extreme forms of institutional arrangements or the imposition of new and significantly modified fuel cycles. It is tempting, and perhaps not incorrect, to conclude that, if the current turmoil in nonproliferation policy could be resolved by no more than some intensification of the long-accepted concept of international safeguards, the path to a new consensus would be relatively quick and easy. Such acceptance would be facilitated even more by the fact that unlike proposals that would restrict the siting of sensitive facilities, measures to strengthen safeguards need not and should not be discriminatory in their application. At the same time, the problem of tradeoffs can be anticipated; that is, if there is pressure on countries to accept more extreme institutional or technical measures to reduce proliferation risks, their willingness to accept more intensive safeguards as well will be reduced. 
Although the analysis centers on safeguards applied by the International Atomic Energy Agency, much of it would be applicable to safeguards conducted by any other multinational or international institution. The creation of new institutions for the sole purpose of applying verification-type would seriously undermine the IAEA, whose safeguards role is called for by the NPR and would, in all likeilihood, be internationally unacceptable. On the other hand, institutions that are created primarily for other purposes, such as the ownership, management, operation or custody over sensitive fuel cycle facilities, would almost certainly find it necessary to undertake measures to assure themselves of the proper use of materials and facilities under their auspices. For facilities under international or multinational auspices, this function would be analogous to the national system of material, accountancy and control, which are not only encouraged but required by the IAEA safeguards system. The analysis of this section provides a basis for considering the value of the systems that such organizations might establish. 


\section{REFERENCES}

1. NRC, Office of Nuclear Material Safety and Safeguards, Safeguarding a Domestic Mixed Oxice Industry Against a Hypothetical Subnational Threat, NUREG-0414, May 1978. 
An institutional arrangement that involves more extensive institutional responsibilities with respect to sensitive facilities and materials than improved safeguards, but which leaves ownership, managerial, and operational responsibilities in national hands, has been given extensive consideration in this study. In this concept, designated international or multinational "custody," an international or multinational organization would possess full authority over ingress and egress of sensitive material to and from sensitive facilities and would have control of sensitive material within the perimeter of the facility site, itself. Such an arrangement, in effect, would extend the concept of international control contemplated in the international plutonium storage system now under discussion in the IAEA to all sensitive materials and to sensitive facilities themselves in a regime in which sensitive material is "born into custody." The organization might also possess similar authority over sensitive materials while in transit from a facility under its jurisdiction to a using site, up to the point of insertion in the reactor.

\subsubsection{Need for Custody}

The rationale of the custody concept rests on the following principles:

- That it is the responsibility for material control in a sensitive fuel cycle enterprise that has direct relevance to the proliferation resistance of the activity, rather than responsibility for such proprietary matters as ownership, management, staffing, and most importantly, decision-making authority over the amount, timing, and nature of the fuel cycle capacity to be provided.

- That the assignment of these proprietary responsibilities to an international or multinational authority is the most serious obstacle to the acceptability of multinational or international fuel cycle institutional arrangements. 
- That, accordingly, most of the nonproliferation benefits of such arrangements can be secured, while greatly enhancing the acceptability of the arrangements, by confining the international or multinational responsibility to the directly relevant area of material control, while leaving all operational or proprietary responsibilities in national hands.

The nature of the institution's material control responsibilities is the crucial feature of the concept. While these responsibilities would include (although not to the exclusion of the IAEA's verification authority) full authority to account for material in possession of the national enterprise and to verify compliance with nonproliferation undertakings, custody would go beyond verification safeguards in fundamental ways. In particular, the institution would:

- have full control over the ingress and egress of material to and from the sites under its jurisdiction;

- exercise this control through institution personnel to the exclusion of any other authority, including that of the host country itself, although this need not preclude a concurrent control by the host country if exercised in a way that does not dilute the veto power of the authority, such as in a "two-key" arrangement;

- have unrestricted right to account for, observe, and control material and the use of facilities within sites under its furisdiction.

The totality of these rights is designated "custody." They presume responsibilities and functions that are to be performed by the custody agency and that define the structure of the institution. These responsibilities and functions are described in subsequent sections.

While the concept may appear to be a rigorous one, it is closely related to and can be viewed as an extension of the concept of IAEA storage of reactor products, which appears in Article XII.A.5 of the Agency Statute and which is currently attracting widespread international support. Its fundamental characteristic is 
the extension of the same kind of international or multinational control over the movement and use of material, as applied to stored plutonium in the proposed IAEA International Plutonium Storage (IPS) concept, to all sensitive materials in the nuclear power fuel cycle and to the sensitive facilities themselves. This control would be in force at a sensitive facility regardless of whether or not sensitive material is present at any particular time. In this regard, a sensitive facility is one capable of producing weapons-useable materials with little or no warning time or technical modification. For the purpose of this study of back-end fuel cycle activities, the facilities of principal concern, in addition to the plutonium storage sites themselves, are reprocessing plants, mixed oxide fuel fabrication plants, and those portions of reactor facilities in which unirradiated fresh Mox fuel is stored.

The extension of institutional control to all sensitive materials and facilities is central to the custody concept, and the rationale for and practicality of such extension is dealt with in detail in a subsequent sction of this chapter. It is, however, of importance to consider first the contribution that custody can make to proliferation resistance, its basic elements, and the kinds of authority on which it can rest.

Custody can contribute to the proliferation resistance of sensitive fuel cycle activities in several important waya:

- It can, if exercised with sufficient intensity, provide a nearly complete solution to the problem of undetected diversion by foreclosing the unauthorized egress of sensitive material from facilities under the institution's control.

- It can interpose a direct, although by no means absolute, obstacle to the forcible seizure or diversion of the facilities and materials under its control.

- It can be expected to change fundamentally the political nature of seizure or other violation of the institution's integrity, thus, deterring any such attempt and 
making an effective response more probable and credible should a violation occur.

At the same time, there are evident limitations on the ability of custody to ensure that no violation of nonproliferation undertakings will occur. The institution would be physically incapable of withstanding national seizure and would depend upon the police power or, where required by the level of the attempt, the armed forces of the host country to prevent subnational seizure. Custody, furthermore, would not address risks emanating from the misuse of a transferred technology or of technical access gained through a multinational project. Thus, other barriers against proliferation risks, such as appropriate qualitative and quantitative limitations on the siting of sensitive facilities, would remain highly important even if custody were established.

The ability of custody to contribute to improved proliferation resistance in the ways suggested above depends upon investing the international or multinational custodial institution with authority and responsibility which include, but go clearly beyond, that of "verification," which is the domain of international safeguards, as this term has been understood to date. The exact nature of these new rights and responsibilities, as well as the practical arrangements required to discharge them, are not simple to describe and delineate, yet there is an emerging understanding as well as a gratifying growth in international acceptance of the concept. This is clearly evident in the discussions of INFCE Working Group 4 and the IAEA Experts Group on International Plutonium storage, even though a convenient term by which to designate this new package of rights and responsibilities has not been adopted, and no strong brief is held for the term "custody" chosen for this purpose in this study.

However designated, it is clear that the rights must include a. degree of physical control exercised by personnel of the 
custodial authority and not simply a documentary or paper function. The essential element is that sensitive material would not be transferred without the consent and physical release of the custodial authority. Thus, a degree of physical control is implied in the custodial arrangement. The movement of material without personal release by a custodian would require his physical displacement and, depending on the detailed arrangements adopted, might also include the breaching of physical barriers under the control of the authority.

The incorporation of an element of physical control in the custodial arrangement potentially could result in confusion of this function with a state's responsibility for "physical security" over nuclear material and facilities. The principle that physical security is clearly a state, and not an international, responsibility is strongly established, and arrangements that conflict with this principle are not likely to be widely acceptable. In fact, there is no conflict between the concept of custody as developed in this study and that of "physical security," as this term is properly understood. As discussions over a number of years make clear, the "physical security" for which individual states are properly responsible comprises protection of nuclear installations and materials against unauthorized acts by the state's own citizens or other parties acting in derogation of the state's rights with respect to such installations and materials.

The concept that the state must be responsible for physical security reflects the principle that the state is the only proper authority to exercise a police power over the actions of its own citizens. The physical control envisioned in the custody arrangement is one that would not be exercised against citizens of the state seeking access, whether authorized or not, to a controlled facility or material, but in relation to the state itself in controlling movements of material that the state intends to carry out under its own authority. Under the custody 
arrangements, such movements, if not authorized by the agreed regulations of the institution, could not take place without the defeat of the personal and, perhaps, physical barriers to such movement established by the custodial authority under its agreements with the host state.

Viewed in physical terms, the security responsibility at and beyond the perimeter of a controlled site would be exclusively that of the host state. The barriers established to preclude unauthorized removal of material by the host state from the site could, accordingly, lie immediately within the perimeter. In view of the host country physical control from the perimeter outward, there would be a conclusive presumption that any host country personnel within the perimeter would be present with host-country authorization and acting on its behalf. The barriers to removal by the host country could take a number of forms, and much effort will be required to establish forms which are both acceptable and effective. It is a conclusion of this study, however, that an essential element of the barrier established by custody is the personal presence of and action by a custodial official when an authorized release takes place. While means could clearly be devised to enable release to take place through instructions conveyed electronically or by similar means, human involvement would appear to be necessary to invest any violation with the fullest possible political consequences.

The requirement of international or multinational control over material movements does not preclude the possibility of concurrent control by the host country. In physical terms, this is often referred to as a "two-key" system, in which an approval, and an accompanying physical action to allow release to take place, are required on the part of both authorities. Thus, if this approach were adopted, each party -- the international or multinatioal custodial institution and the host country -would have a veto over release or other movement requiring authorization. 
Procedurally and mechanically, such a concurrent control or twokey arrangement presents no particular difficulties. Whether it is desirable as a matter of policy, however, raises important issues.

Such an approach would retain an authoritative voice for the host country in licensing exports and could provide it with some check against unwitting interference with plant operations. At the same time, the power of the agency to block material movements to which it objected would remain undiluted. The major objection to such a two-key scheme would be that it constitutes a form of double-licensing in which the customer must satisfy two reviewers -- the institution and the host country -- each having the ability to block the transcaction. Since the concept of a double-key is an accommodation to the possibility of disagreement between the host country and the custody agency, the potential exists for dislocation in the continuity of supply should differences in the interpretation of release criteria lead to the exercise by one party of its veto. From the customer point of view, institutional autonomy would be preferable if only because it requires satisfaction of only a single body.

While the right and responsibility to exercise control over material movement is central to the custody concept, another important component is the right to verify, through materials accountancy, surveillance, and containment, the presence of material within facilities controlled by the institution. The effective exercise of this right is an essential back-up to the institution's control function, since it provides needed assurance against the risk that unknown pathways for the unauthorized exit of material from controlled sites or facilities might exist. Since the IAEA also has the responsibility for verification of the whereabouts of material through its safeguard system, performance of this function by a custody institution could lead to duplication unless the IAEA itself is the institution selected for the custody role. If it is not, close coordination 
and cooperation between the Agency and the custody organization will be required to avoid unnecessary duplication. In principle, however, the verification aspect of custody must be performed without restraint on the ability of the institution to satisfy itself that no material subject to its control is removed without its authorization. To the extent that the ability of the IAEA to function in this manner is limited by restrictions on its degree of access, the custody institution will be required to fill the gap.

The rationale for the applicatio of the custody regime to sensitive facilities, as well as materials, is discussed later in this section. The means for doing so do not differ in principle from the means applied to sensitive materials themselves. Just as IAEA verification procedures apply to materials, even though the Agency safeguard system recognizes that materials are customarily located in facilities, so too would the focus of the custody regime be on materials themselves, rather than the facilities in which they may be located. Of particular importance in the effective functioning of the regime are reprocessing facilities, since these can quickly produce significant quantities of separated plutonium from spent fuel. Thus, even if all products of a particular reprocessing plant are immediately deposited in international storage, the plant itself, absent the controls of a similar regime, could be readily converted to unauthorlzed use.

The application of the custodial regime to a reprocessing facility would not, however, involve any interference in the management and operation of the plant while it is in use for authorized purposes. The sole function of the custody arrangement, and the test of whether the undertakings that it entailed were being fulfilled, would be the transfer of all products to the designated storage facility or facilities under the same regime. To ensure compliance, the custodial authority would have the same rights of accounting, surveillance, containment, and release as it has at a storage site. In effect, the application 
of custody to a reprocessing facility is required to ensure that the principle that all plutonium separated in the plant is in fact "born into custody."

In contrast to a reprocessing plant, a Mox fabrication facility is incapable of producing sensitive material; that is, of separating plutonium from an otherwise unusable form. On the contrary, a fabrication plant converts an easily accountable material, such as MOX powders, to the at least somewhat less accessible form of fabricated fuel: Thus, a custodial regime need be applied to a MOX. plant only when an inventory of sensitive material is present, except to verify the original design and any changes in design that might facilitate diversion. As frequently observed, the colocation of fabrication with reprocessing facilities would simplify the application of protective arrangements. This principle is applicable to custody, as well as to safeguards. Nevertheless, there is no reason in principle why the same custodial arrangements to be applied to plutonium storage sites cannot be applied to Mox fabrication plants, or other facilities, even if these are not colocated. Such facilities are likely, because of economies of scale and other considerations, to be relatively few in number, and, as a result, the burden of expenditures to the regime should be manageable.

The application of the regime to reactors that utilize plutonium involves special considerations. While the specific measures that would be applied at such facilities would not differ from those at other sites subject to a custodial regime, reactors will, in general, not be colocated with reprocessing facilities. They will be far more numerous (probably by a factor of 20 or more) and more dispersed geographically. While the continuous presence of custodial personnel would not constitute a major economic burden in relation to the value of the electrical output of a full-scale power reactor, it would be desirable to minimize the expense and other aspects of such an extensive deployment of international custodians. 
The fact that the custodial arrangement would be in force at reactors only when significant quantitites of sensitive fresh fuel are present suggests several ways in which the economic and, to some degree, the political impact of their extension can be limited. The objective is to have stocks of unirradiated Mox fuel at as few reactors as possible, for the shortest time possible. The operation of reactors, such as LMFBRs or LWRS employing plutonium recycle, without a continous inventory of plutonium-bearing fuel, appears to be feasible in light of the following considerations:

- Refuelling of these reactors is a scheduled event, taking place at roughly yearly intervals. Moreover, fresh fuel cannot be changed until irradiated fuel is removed. This provides a minimum notice period of several weeks, in current practice, even if shutdown for fuel discharge and reloading occurs unexpectedly.

- Fresh fuel can be (and often is) air freighted without significant added expense. Moreover, this can be accomplished in time periods that are generally within the time required for fuel discharge and reloading.

- A working inventory of unirradiated fuel will still be required to ensure that requirements can be readily fulfilled under the "delivery as needed" approach described above, but this working stock can be kept at one or a few places, rather than at every operating reactor. The logical place for this working stock is at the fuel fabrication facility, but maintenance of a stock in a single location in countries that do not have their own MOX fuel fabrication plant could still represent a considerable reduction of custodial effort in comparison with the extension of the custodial regime to a number of reactors on a continous basis.

When plutonium-bearing fresh fuel is delivered to a reactor site, the custodians would remain at the facility until such time as this material is charged and has rece'ived sufficient radiation to reduce its accessibility to levels that would ensure adequate warning times in the event of removal and attempted diversion. 
The extension of custody to material in transit would require resolution of a jurisdictional problem. This problem can be divided into two phases: coverage of material while in transit in a member state of the custodial organization; and coverage of material while in transit in other states, or in vessels or aircraft of non-member states. In principle, there would appear to be no basis for objection by a member state of a custodial institution to allowing custodians to accompany shipments of sensitive materials while in transit within the state to or from a facility under the institution's custodial control. Coverage of the same material while in transit through non-member states, or upon or over the high seas in vessels of a non-member, could present obvious difficulties. These difficulties are probably best resolved by avoiding such shipments insofar as possible. Where this is absolutely unavoidable, confining individual shipments to amounts less than strategic quantities of sensitive material could provide adequate protection.

\subsubsection{Rationale for Extended Custody}

Consideration of the quantities of weapons-useable material that are or might be present in the nuclear power fuel cycle make it evident why the extension of the international or multinational control authority is of critical importance in minimizing the proliferation resistance of fuel cycles in which plutonium is produced or utilized. The present emphasis being placed on the application of international control to plutonium in storage is a rational and desirable development for a number of reasons, including:

- Plutonium in storage can represent the most easily accessible material in the fuel cycle, since it would not be "protected" by physical barriers such as those afforded by fuel elements in which plutonium might be present or process equipment in which it might be contained elsewhere in the fuel cycle.

- Particularly in fuel cycles in which plutonium is recovered but not utilized, plutonium will accumulate in 
storage in quantities that may exceed those characteristic of fuel cycles involving plutonium utilization.

- The maintenence of plutonium in storage entails much smaller expenditures and simpler operational problems than activities that involve its recovery or fabrication, and, thus, storage may lend itself more readily to some form of international control.

- Perhaps most importantly, a legal and institutional framework already exists for the application of international custody to plutonium in storage, in the form of Article XII A.5 of the IAEA statute, which provides for ". - deposit with the agency of any excess of any special fissionable materials recovered or produced. . . ."

Important and constructive as the development of international plutonium storage may be, international or multinational control arrangements that are limited in their application solely to plutonium in storage would fall well short of the scope of international control that is desirable if plutonium is to be recovered and utilized in the nuclear fuel cycle. The conclusion is evident from the fact that the average daily plutonium output corresponding to a 1000 ton/year reprocessing plant (3.3 tons/day of heavy metal throughput) is of the order of $20 \mathrm{~kg}$. (60\% Pu-239). This quantity, in turn, corresponds to the operation of an LWR system of some 33,000 MWe. The significance of this fact is that, even if all plutonium recovered from the reprocessing of spent fuel in this complex is promptly transferred to international plutonium storage, a single day's output of. plutonium from the corresponding reprocessing facility could provide a strategic quantity of plutonium. Even if the deposit - under a custody arrangement of all plutonium separated in such a reprocessing facility were subject to verification, the failure to place the plant itself under the same regime means that the vital step of transfer to custody would be under less effective control than that applicable thereafter. This step would, in effect, become the weakest link in the chain.

If plutonium produced from this complex is also utilized, either through recycle in LWRs or to fliel breeder reactors, the plutonium 
working stock and inventory present in the MOX fabrication facility could be expected to be of the order of six months throughput, or some $3,000 \mathrm{~kg}$. Storage of fresh mox fuel at reactor sites might correspond to an additional six months throughput on the average, although potential for reducing this value to considerably lower levels would appear to be present. The rationale of maintaining these sizeable stocks of plutonium under a regime as effective as that applicable to central stocks is self-evident. To the extent that material in fabrication plants, at reactors or in secondary buffer storage may be in locations of greater proliferation risk than those whose central stores are located, the need for custodial control would be correspondingly greater.

In addition to application of the custody regime to all fuel cycle facilities in which plutonium is present, there are important reasons why this regime should be extended to the plutonium located in the transportation links between these facilities as well. Application of the custody arrangements to storage sites alone does not ensure that all plutonium produced in the corresponding reprocesssing plants reaches the storage facility, nor does it extend to the plutonium in transit a level of protection against seizure by the countries through which transit occurs commensurate with that which prevails at the storage site. The application of effective containment, surveillance, and verification measures at reprocessing facilities whose output is destined for international plutonium stores could largely overcome the objection that not all the plutonium scheduled for such delivery is in fact transferred, but these measures would still not provide the protection of the considerable quantities of material in transit which plutonium's strategic value justifies. An alternative response to this problem, which merits careful evaluation, is the adoption of rules that would limit the amounts of separated plutonium allowed to be in transit in a given country at any time to levels that are not of weapons significance, unless the material is given protection through international or 
multinational custody comparable to that in force at facilities themselves. The economic implications of this restraint on shipment could, however, be substantial, and require detailed study.

The concept of extending international or multinational custody from plutonium storage sites to all facilities in which separated plutonium is present, as well as to the transportation links between them, is shown graphically in Figure 1. As the figure and the preceding discussion suggest, at least two alternatives are possible: one in which only facilities are placed under regime, leaving the flows of plutonium in transit between facilities to be accounted for and protected by other means; and those in which both material contained in facilities and flows are within the custody regime.

\section{Composition}

The nonproliferation credibility of custody, the amount of time needed to establish it, and the level of political capital expended in its implementation and operation, will depend heavily upon the identity of the custody agency and the composition of its membership.

A major choice must be made as to whether the agency should be international or multinational in character." Three options might be considered:

- assignment of this responsibility to the IAEA;

- creation of a new agency of either global composition including at least all the states possessing or using the services of sensitive back-end facilities (such an agency presumably would have a relationship with the IAEA); or

- the establishment of a set of multinational entities, each having an appropriate relationship with the IAEA. 
FIGURE 1

Application of Custody to LMFBR Fuel Cycle

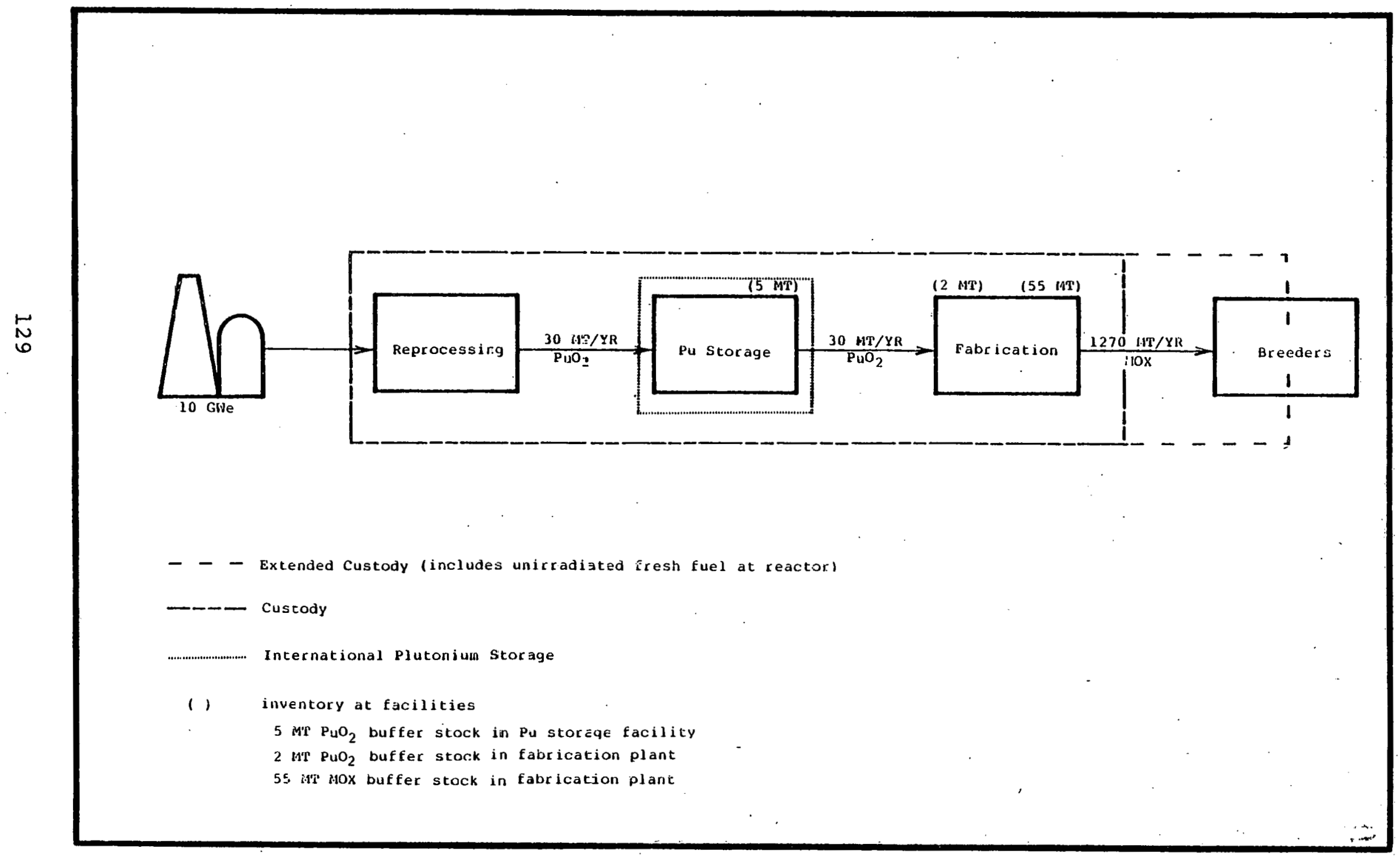


Assignment of custodial responsibility directly and exclusively to the IAEA has several disadvantages and lacks a number of advantages which accompany the multinational approach. The disadvantages include the involvement of the Agency's large membership in a complex enterprise that imposes substantial managerial responsibilities (even though it excludes actual facility ownership and management) and financial resource requirements, and which may further distort the balance between the Agency's promotional and regulatory responsibilities. Perhaps most importantly, the Agency's Board, if not its full membership, would become involved in sensitive issues concerning the disposition and use of national facilities and materials, a result that is likely to bế widely unacceptable.

Some of these difficulties might be overcome by the creation of a single organization, consisting of a subset of the Agency's members either possessing or using the services or products of the back-end fuel cycle facilities in question. This organization, which could be directly linked to the Agency, would have the advantage that all of its members, as producers, users, or both, would have direct interest in the successful operation of the arrangement. Countries would participate in the institution only to the extent to which they have legitimate requirements for sensitive material. Determining membership according to this principle would help reduce the intrusion of extraneous political interests, as might be the case when an organization such as the IAEA, which includes members having no direct interest in the material being supplied, is responsible.

The multinational approach appears preferable to the two previous options on several grounds. Achievement of agreement in one such group would enable the concept to go forward, and could create momentum for the establishment of similar arrangements by other groups, without awaiting universal or near-universal acceptance of the concept. Perhaps most importantly, the selec-. tion of groups of the proper composition would both minimize

\section{Q}


negotiating difficulties and enhance the nonproliferation effectiveness of the arrangement once established. Reduction of the negotiating difficulties could be achieved by selecting potential members with a mutual interest in the effective operation of the endeavor; that is, countries that either own and operate the facilities in question or that plan to use their service. Nonproliferation effectiveness would be enhanced by the selection of members with intimate political, economic, and even security ties, the disruption of which would greatly increase the cost of any violations of the group's mutual nonproliferation undertakings. In general, it is likely that both of these criteria could be met by proper selection of potential membership.

The establishment of a set of such multinational institutions need not derogate from the IAEA's important safeguard and nonproliferation responsibilities and, indeed, could place new and important responsibilities on the Agency. Agency safeguards would, in any event, still be applicable to the group's facilities and materials, and would be essential to extend the assurance of peaceful uses beyond the group's membership to the world community at large. It could also be the Agency's responsibility to satisfy itself and its global membership that each group possessed the requisite technical and political credentials to undertake an effective custodial responsibility, and that the group's charter met appropriate minimum standards ensuring its ability to act as an effective custodian. In effect, the Agency could become the de facto licensor of each multinational custodial group. Such a relationship between the IAEA and the custody agency should overcome potential objections that the multinational approach has a serious potential for leading to discriminatory arrangements that propose different standards among different groups of countries. 
The siting dimension of custody encompasses several considerations of central importance to custody's nonproliferation effectiveness. Among the factors that deserve attention are the number of sites, the nonproliferation credentials of the host countries, and the geographical proximity of reprocessing and fabrication facilities and the scope of transportation requirements. Two basically different siting approaches are possible:

- first, unrestricted siting; that is, to allow each group to decide how many and which of its members will possess sensitive back-end facilities, with no external pressure to minimize the number or to rule out particular locations.

- second, an attempt to limit siting to as few countries as possible, making maximum use of objective criteria such as economic need and scale of nuclear power activities rather than politically discriminatory standards. Colocation of sensitive facilities, regardless of which of the above siting approaches is adopted, might be mandated.

While the second approach would offer greater nonproliferation assurances, it would encounter greater resistance. The definition and application of economic criteria could have a disruptive influence on the institution, and could appear to work as an indirect means for discrimination between industrialized and developing countries.

Custody, however, does not support a presumption of unrestricted siting, either. For both economic and nonproliferation reasons, an unlimited number of sites at which sensitive materials are recovered, stored, or utilized is undesirable. Limitation of the number of sites would reduce the demand upon manpower and financial resources and hence the costs of the undertaking. More importantly, although custody provides a deterrent against misuse, it does not offer an infallible preventative. The strength of that deterrent, moreover, may depend upon the number and 
circumstances of the places where it is applied -- the greater the number and diversity of the situations, the greater potential for a failure of deterrence. As a result, custody is not a complete substitute for measures that reduce the number of locations where sensitive material and facilities are present. Siting restrictions, thus, remain desirable and can form an integral part of a custody institution.

A third approach, which is not an alternative, but an important complement to either siting alternative, is colocation of sensitive facilities, e.g., reprocessing and fabrication. The vulnerability of separated plutonium to seizure while in transit between these facilities strongly suggests that transportation links be minimized. through colocation. Colocation also would enable deliveries of fuel to be closely tied to the scheduled insertion date in reactors in order to avoid sizeable at-reactor inventories of unirradiated sensitive material. While this may not be possible for some existing facilities, colocation could be required at future installations.

The nonproliferation responsibilities of the institutions created to assume custody of sensitive facilities and materials need not and should not be confined to this role. Logical additional responsibilities would include a code of conduct governing such nonproliferation matters as members' policies on export of sensitive technologies, and the siting of new facilities by members. Finally, the custody approach is not inconsistent with, and does not rule out the establishment of, arrangements for multinational ownership and/or management of sensitive facilities by some or all members of a custody institution. Such arrangements would be voluntary, and could be resorted to whenever members saw economic, technical, or other advantages in such cooperation. 
Finally, the custody approach is not consistent with, and does not rule out the establishment of, arrangements for multinational ownership or management, or both, of sensitive facilities by some or all members of a custody institution. Such arrangements would be voluntary, and could be resorted to whenever members saw economic, technical, or other advantages in such cooperation.

\section{3 .5 Deposit of Material}

Basic to the custody institution is its responsibility for material control from "cradle to grave." The sole exception to this principle occurs where the material is rendered inaccessible by a radiation barrier, i.e., inside an operating reactor or contained in spent fuel. Custody would resume once spent fuel entered the reprocessing plant site, as knowledge of the amount of material at the head-end of the plant would be essential to the detectability of diversion at the plant itself. As a technical matter, acceptance of the cradle-to-grave principle lies at the heart of the institution. The sole exception contemplated here is an obvious one based upon highly visible technical facts. Granting exceptions on the basis of less compelling factors could seriously detract from the authority of the inslilutiun.

The cradle to grave approach holds a significant advantage over the alternative approach of requiring deposit of "excess" plutonium, as contemplated in Art. XII A.5 of the IAEA Statute. This provision does not provide sufficient guidance as to what is actually excess and what is legitimately needed, or when plutonium becomes excess. More fundamentally, even if "excess" plutonium is placed under institutional control, that is not excess is not so controlled and, thus, vulnerable to proliferation risk. The cradle-to-grave approach eliminates the potential for differences in interpretation of criteria for excess 
quantities and more clearly establishes the institution's control responsibilities as a central element of the overall nuclear regime.

Since at-reactor stockpiles of unirradiated sensitive material could be vulnerable to proliferation risks, a major objective of the institution should be to avoid stockpiling. Although some working stockpiles might be necessary to ensure orderly reactor operation, the size of these stocks and the time period in which they would be present could be minimized through release criteria that would time release shipment to coincide with refueling schedules.

The policy of minimizing stockpiles would impose certain corresponding obligations upon the institution, among the most important of which would be to explicitly extend assurances that contracted for fuel services and materials produced under the institution's auspices would be available to members complying with all nonproliferation undertakings. It is necessary, however, to distinguish between fuel assurance -- guarantees that existing contracts would be honored and new ones given institutional endorsement to members in good standing -- and the management of fuel cycle operations to ensure the ready-availability of fabricared fuel meeting the user's specitications. 'l'he latter function lies within the normal. responsibilities of the reprocessing or fabrication plant operator and would not be intruded upon by the institution. The institution could, however, develop arrangements by which suppliers agree to back-up each other's contracts to protect the user from such contingencies as plant or transportation failures. Such arrangements would appear to be desirable in order to compensate for the limitation of stockpiles.

One further issue regarding the scope of the institution's control must be considered: the status of plutonium stocks produced before establishment of the institution. Any grandfathering of the significant amounts of civilian plutonium already 
separated would invite charges of discrimination from those whose material would be subject to the institution and would effectively create a two-tier regime that would erode the foundation of the new institution. Although it might prove difficult to win agreement on retroactive extension of the institution to this material, the point appears essential to the success of implementation.

\subsubsection{Release Criteria}

The purpose of release criteria is to provide maximum assurance of legitimate and immediate peaceful need for any material to be transferred and to ensure that appropriate releases take place without hindrance. Within the context of extended custody, final release of the material from custody would occur upon its insertion and irradiation in the reactor, but transfer of material from central or buffer stores would also be subject to approriate release criteria. The criteria would specify:

- the legitimate end-use of the material

- the quantity of material to be released

- the form in which the material is released

- the timinğ of rèlease

- return or other disposition of any material derived from the released quantities.

Implementing these criteria would entail the establishment of procedures for the submission and verification of data regarding the intended end-use, quantities needed, time-frame for use, safeguard and physical security measures, and post-release verification that the material actually was used as intended. The recipient would not be allowed to change the end-use without repeating the release procedure. 
As important as these procedural matters are, a major question. regarding the release criteria is the extent, if any, to which they will define what constitutes a legitimate peaceful use. The principal substantive issue is whether the institution, through its release criteria, specifies what peaceful uses are considered inappropriate or illegitimate. An institution could, for example, rule out use of plutonium for LWR recycle, Iimiting legimitate use to breeder-related work. This more restrictive criterion would provide the nonproliferation benefit of limiting the initial flow of sensitive material, while not inhibiting the development of technology essential to the long-term viability of nuclear power. This benefit, however, must be weighed against the potential political costs of opposing countries interested in recycle and the possibly damaging effect this conflict might have upon implementation. As a result, consideration must be given to whether this restriction on use should be explicitly a part of the release criteria or be addressed outside the framework of the custody institution as a central element of a consensus on fuel cycle policy among the major nuclear countries.

\subsubsection{Critical Facilities and Research}

The principle that custody arrangements are to apply to all sensitive mateidal except where protected by a radiation barrier provides guidance with regard to applying custody to research activities in which no significant radiation barrier is present. Since research activities in which plutonium is present in amounts greater than that necessary for a weapon are subject to proliferation risk if that plutonium is unirradiated, custody measures should be in force to ensure that unauthorized movement of the material does not occur. In this regard, custody applies to a civilian research facility as it would to a fabrication plant -custody personnel would control ingress and egress so long as sensitive material is present at the facility. 


\subsubsection{Operation of the Institution}

The operational role of the institution's personnel would be confined to those functions directly related to maintaining the institution's material control responsibility. This role would not extend to facility operation, even of storage facilities.

Involving institutional personnel in facility operations is undesirable on several grounds. First, proprietary considerations might be affected if such a role were assumed. Second, it is not clear that any new facilities would have to be built specifically for the purposes of the institution. A plutonium storage facility would be necessary to house the inventory at the output end of a reprocessing plant or head-end of a fabrication plant, and there is no compelling reason for the institution's personnel to replace national personnel in an activity the latter would be called upon to perform regardless of the institution. Finally, a facility operation role would dramatically increase the manpower and financial resources required of the institution.

The institution personnel would exercise several responsibilities directly relevant to their material control function. These include:

- authorization and control of access and egress of both material and people

This responsibility lies at the core of the institution, and any systems that seek to accommodate the host-country operator, such as a. "two-key" approach, could not be allowed to detract from the ability of the institution to control access and egress. This power must extend to people, as well as material, in order to deal with all proliferation pathways.

- material accountancy and control functions 
Possession of adequate and accurate information regarding the production, location, and utilization of all peaceful plutonium is critical to the performance of custody, particularly egress control. As the recipient of all such material, the institution would be ideally placed to develop its own material accounting and verification system. This should not lead to reporting requirements duplicating those already in existence for safeguards but might involve establishment of a plutonium registry. Whether there are, in practice, two parallel data systems -- one for safeguards and one for custody -- depends upon whether custody is also performed by the IAEA or by another group.

- physical control

The institution personnel would not perform physical security functions with respect to subnational groups. Its physical control over material vis-a-vis the state itself, however, is the essence of the custody concept as discussed earlier.

- approval of release

The authority to approve release requests would be located in a central dècision-making group, which would also collect and analyze the information necessary to review release requests. This central decision-making organ would communicate its decision to the local custody personnel, who would then authorize movement of the material under the custody of other institution personnel. Once initial approval had been granted, no further release application, say upon completion of fabrication, would be necessary. This would institute a system of "one-time" approvals. The institution could, however, recall the material if fraudulent information or actual violation were suspected of the ultimate recipient or anywhere in the transport system. 


\subsubsection{Candidate Concept}

Based on the foregoing comments, a candidate concept embodying the custody approach could have the following characteristics:

- A set of multinational institutions would be established independently of each other, with composition, technical competence, and institutional ground rules subject to review by and endorsement of the IAEA.

- The membership of each institution would include states possessing the necessary adversity of interest in ensuring compliance with nonproliferation undertakings by other members. At the same time, the maximum degree of political, economic, and security interdependence would be sought. There is no necessary inconsistency between these two criteria, as institutions such as the European Community illustrate. Membership would normally include both suppliers and users of back-end fuel cycle services.

- The essence of the arrangement would be the creation of a multinational entity, with both political direction by the members and multinational staffing, possessing full and irrevocable authority to control ingress and egress of material and equipment to and from sites at which custody is in force, and to undertake, without derogation of the IAEA's verification responsibilities, any verification activity deemed necessary by the institution. Any two-key arrangement with a facility operator, which might be adopted in some cases, must preserve the veto power of the institution.

- Custody arrangements normally would apply only to sensitive material, not spent fuel, and would be initiated once a technical capability to produce such material was established. The same multinational group may also assume responsibility for spent fuel storage and waste disposal, but the existence of custody does not imply or require this.

- Facilities and associated materials within sites at which custody is in force would normally remain under national ownership and management, and the national owners (or their authorized firms) would retain full technical and operational authority over their facilities. Decisions on the timing, degree and nature of expansion of capacity would remain a national responsi- 
bility. However, voluntary association of two or more members of the institution in the ownership, management, or staffing of a facility would not be ruled out and, subject to appropriate limitations on facility siting and technology transfer, might be encouraged.

- The transfer of sensitive material controlled by the group to any country -- whether host nation, other member, or non-member -- would be subject to approval by the institution employing established release criteria acceptable to the institution's membership and to the IAEA. These release criteria would provide maximum assurance of an immediate, legitimate peaceful need for. any material transferred. In particular, these criteria will specify:

-- the end-use of the material;

-- the quantity of material to be released;

- the form in which the material is released;

-- timing of release; and

-- return or disposition of any material derived from the released quantities.

- In the preferred variant of the arrangement, the group's membership would include both suppliers of the service and all or most of their customers, and the institution would develop back-up arrangements to provide assurances of supply to all recipient members.

- The group would also adopt ground rules governing the transfer of sensitive technology by any group member., with the intent to avoid or limit such transfer to the maximum extent.

- The institution would derive funding for the conduct of its activities from its membership, establishing arrangements such as revolving funds based on a surcharge applied to materials or services delivered, which would ensure adequate and uninterrupted funding based upon the extent to which participants call upon the serviccs of the institution.

- The custodial authority of the institution would extend to material up to the time of its insertion into a reactor. This would apply to member and non-member transfers alike, with approval of transfer being conditional 
on acceptance of this arrangement for extended custody. Fuel fabrication would be co-located with reprocessing, and fabricated fuel would be transferred only when immediately needed.

- Alternatively, the institution's custodial authority might not extend beyond the perimeters of controlled facilities, but the institution would require the right to verify the prompt insertion of any transferred sensitive material. In this instance, the material may be required to be shipped in a form considered proliferation resistant by the institution.

Two principal mechanisms for financing -- contribution to a special fund by participants, and user surcharges -- could be. employed. The user surcharges would apportion costs to actual use of the facilities, and, thus, demand for custody operations. While this might appear more equitable, all parties would benefit from the collective security benefit made equally available to minor users. Financing some of the costs through a general fund raised through equal assessments of all parties to the custody arrangement and the balance through user charges might integrate better the full range of private and collective benefits into the financial structure of the operation.

\subsubsection{Concept Evaluation}

\subsubsection{Nonproliferation Assessment}

International custody would strengthen the proliferation resistance of the civilian nuclear fuel cycle in three different ways. Custody will improve capabilities to detect misuse, since custody itself constitutes a surveillance and inspection system operating above and in addition to the current safeguards system, and since transfer of material outside the site perimeter would require approval and release by the institution's authorities. The inclusion of release criteria, as well as control, as the core of a custody arrangement would create a real, although not invincible, physical obstacle to national seizure of weapons- 
usable material or sensitive facilities. Finally, custody, by raising the consequences of violation, may increase the deterrence against use of the civilian fuel cycle for weapon purposes, and would greatly improve the probability that. swift and strong counteraction would be taken in the event of any violation.

National Diversion: The surveillance and containment function of custody would substantially increase the difficulty of diversion by the host country by providing both in-plant and perimeter capabilities for detection and physical restraint of diversion. The special status of the institution's custodial force would enable it to go well beyond the. Iimits of IAEA inspectors in the application of physical search and, if necessary, restraint measures in the event of unauthorized removal of sensitive material from a controlled facility. Independent verification of end-use enables the institution to determine the accuracy of end-use statements contained in release requests, strengthening the institution's detection capabilities vis-a-vis customer states as well. Thus, custody creates an obstacle to diversion which is qualitatively different from safeguards. By placing the release of sensitive material under the control of the institution, custody would add a physical impediment to diversion which would not be present in arrangements where multinational or international responsibility was confined to verification alone.

Seizure: While custodial forces could not withstand a determined national effort to displace the custodial personnel custody could nevertheless contribute significantly to improved resistance against the risk of seizure. This would result from in creasing deterrence against seizure through improving the likelihood and strength of retaliation that seizure would set in motion. Seizure would require expulsion or displacement of custody personnel, which would be a particularly grave offense, capable of providing a juridical and political basis for a swift and effective response. In this respect, custody bears some 
analogy to the presence of defense forces located in areas of risk at a force level that is insufficient to protect against attack or to repel it but sufficient to trigger strong retaliation. Thus, an important element in the proliferation resistance afforded by custody against the risk of seizure is the greater credibility that any violation of that custody lends to an effective response.

The effectiveness of custody as a deterrent to seizure depends to a major extent upon the composition of the membership. If the members are closely interdependent, the political, economic, and security costs of such a grave violation as the expulsion of the custodial force would be exceedingly high. The effectiveness of custody in deterring, seizure also depends upon the nature of siting restrictions, since these determine in some degree where and by whom the institution could be threatened by a seizure attempt.

Abrogation: The nonproliferation importance accorded custody, and its prominence as a major undertaking of the international community, would magnify the political significance of any abrogation and would establish a presumption against withdrawal. The inclusion of nuclear weapons states, other advanced industrial cululsies, and possibly regional rivals as well in the membership would enhance the potential of a custodial arrangement to deter abrogation, since the maqnitude of the consequences that abrogation would invite could significantly elevate the decision threshold of a would-be abrogator. The international political status of an inviolable custody arrangement would provide a guarantee of swift response to abrogation approximating that which is often attributed to group ownership of sensitive facilities.

Technology Transfer: Custody itself does not create any $r$ isks related to technology transfer, since it creates no expectation of or opportunity for access to sensitive technology. By the 
same token, it does not eliminate problems of technology transfer, as the export of sensitive technology or provision of access to it in national plants are not necessarily affected by the custody arrangement. However, in the model under consideration, the overall multinational arrangement would include a code of conduct designed to deal with such issues as technology transfer. Given such ground rules, it is likely that they will be more strictly applied when a multinational institution is monitoring compliance than if compliance were left entirely to national performance.

\subsubsection{Economic/Operational Assessment}

Custody will result in additional costs. However, these would not be substantial in relation to the operating costs of the facilities covered by the arrangement, since the essence of the custodial approach is the political impact of. the presence of custodial personnel, not the physical strength that would derive from their presence in large numbers. A reduction in the number of total sites would help restrain costs by limiting the number of special handling and storage facilities that are needed to secure the sensitive product of reprocessing plants. Most importantly, custody does not directly impede the economic operation of the fuel cycle, nor does it mandate organizational formats that may be less efficient than large-scale national facilities. In light of the potential nonproliferation gains that may be realized through custody, the cost:benefit ratio may be more favorable than under any of the other institutional alternatives considered in this study.

The economic impact of the institution on the participants may be less onerous than for institutions that involve facility operation. The basic costs to the participant would be the surcharge to finance the institution and the foreign exchange expended if the country in question is strictly an importer of sensitive material. However, the latter set of costs are being 
incurred under the present regime. The custody concept, moreover, may provide greater flexibility regarding siting of new plants, and, thus, the possibility of a national plant, than more preclusive concepts such as multinational plants. The participant also would not be required to invest in someone else's plant and incur some of the attendant financial risk, as would be the case in other concepts.

Economically, custody does not make the participant worse off than he would be under the present regime, in which a small number of large national plants is the norm and in which the participant must depend upon the competence of the operators of those plants. The principal economic benefit of custody is that it does not impose any new inefficiencies. Moreover, although it does not promise to create new economic advantages on its own part, it does not preclude these advantages -- such as economies of scale -- if the participants in custody arrangement voluntarily choose to join in larger-scale activities.

\subsubsection{Political Acceptability Assessment}

The custody concept in general and the specific model described in this section clearly involve a major change in the nonproliferation regime as it now exists. Nevertheless, custody represents a less drastic form of institutional arrangement than other approaches that have attracted some support, such as the multinational or regional fuel cycle center, in which ownership, management, and operation, as well as material control, are placed in the hands of an international or multinational institution. While such concepts have not been generally implemented, they have been the object of considerable international discussion and assessment without attracting implacably hostile reactions. Moreover, the custody concept enjoys the not inconsequential advantages of being based upon a principle that is incorporated in the IAEA statute, although in the more limited conlext of Agency storage of separated plutonium. The resurgence of interest and support which international plutonium 
storage and management is now enjoying suggests that the extension of this same concept to international custody of sensitive facilities and sensitive materials may not be an unachievable goal.

While objections will predictably be raised as to the incompatibility of the presence of international or multinational custodians on national soil with the right of the state to exercise authority over internal affairs, particularly those related to security, this same objection will apply to any serious implementation of the plutonium storage regime of Art. XII.A.5. Objections based on this concern, of course, cannot be dismissed lightly. The absence of any national control over the custodyrelated activity of these persons, and the potentially adversary relationship between them and the state, constitutes a significant intrusion into the domain of state authority. This intrusion in some cases may evoke domestic political opposition where the trappings of sovereignty and diplomatic independence have high symbolic meaning and value. However, if custody arouses such opposition, it is highly likely that concepts that involve surrender of national ownership or of advanced fuel cycles, themselves, would arouse considerably more. While treating such complaints as, in the end, philosophical for countries with no intentions to violate nonproliferation undertakings dismisses too easily substantive obstacles to easy acceptance of the institution, custody represents a reasonable effort to reconcile nonproliferation effectiveness with political and diplomatic interests.

A more substantive objection to the custody approach derives from the concern that the custody arrangement gives a multinational authority control over national access to a valuable energy resource and that, even with full compliance by a state with all relevant undertakings, this control entails at least some risk that access to the services and products of the controlled facility might be interrupted. Energy security, thus, may be perceived as reduced by the custody arrangement. 
There are considerations that suggest that, under appropriate conditions, custody might nevertheless gain acceptance and may not disadvantage the energy security interests of some countries as much as may other concepts. The most important of these considerations is that the custody approach can be applied on "a nondiscriminatory basis. Anyone desiring access to a sensitive facility or to its products would have to accept custody as a nonnegotiable condition of that access. No country, including the host country, would have better or more favorable access than any other country. This latter principle predictably would encounter resistance from the host country, since it is access to its own plant that is involved. This potential political obstacle appears unavoidable if the energy security and political concerns of other participants are to be satisfied. At a minimum, this requires that the release requests be processed quickly and with sufficient lead-time before actual shipment to permit utilities to plan refueling schedules with the necessary degree of certainty. It may also require that the criteria be enforced and the release requests processed in such a way that the burden of proof is not upon the customer to convince the custody agency that its needs are valid but upon the agency to successfully challenge these claims. In other words, energy security may be of a sufficiently compelling influence over acceptability that a bias towards approval, and, thus, toward customer needs and interests; should be built into the system.

In this regard, it must be reemphasized that limitations on the siting of sensitive facilities and the use of sensitive materials are not an intrinsic feature of custody, although it is a feature of the specific custody arrangement considered in this study. Even if sensitive facilities were to be sited with few restrictions, their proliferation resistance would be significantly enhanced under a custody regime in comparison with the present safeguard arrangements. 
The need to build consumer confidence also may pose the largest obstacle to a two-key as opposed to autonomous relationship between the agency and host country. Presumably the two-key. approach is dictated by the host country's demand to retain a control over export licensing. Such a double-licensing system as the two-key approach would establish is inherently discriminatory because no third party has a similar power vis-a-vis release to the host country. The way that a two-key approach can be reconciled with nondiscriminatory access is not evident.

Insti,tutional leadership and politics are also particularly important, since a failure of the members to agree on the definition and interpretation of release criteria and conditions of supply or on the appropriate action for particular countries or cases could directly disrupt the fuel supply system. As a result, the composition of the membership may have a decisive influence on the confidence individual participants place in the enterprise. 
The concept of multinational or international ownership and management of sensitive fuel cycle facilities has attracted the attention of nonproliferation policymakers from the outset of the nuclear era. It is a flexible concept, capable of being developed organizationally, managerially, and in respect to terms and conditions in a variety of ways, as such ventures as Eurodif, Eurochemic, and URENCO illustrate. At a time when the dispersion of nationally controlled sensitive facilities is being challenged from a nonproliferation point of view and when the international community is not ready for comprehensive international solutions, arrangements involving multinational ownership and management might be looked to as one way to compromise between the values of nonproliferation, energy security, and involvement in advanced nuclear technologies, and, thus, to diminish perceptions of discrimination and the need for nationally owned and operated facilities. A number of different types of multinational arrangements are discussed in this report. In this section, institutions that have as their dominant characteristic multinational ownership and operation are discussed and analyzed. The term multinational "arrangements" or "institution" as used here refer to multinational ownership arrangements.

From the perspective of countries that, in searching for a comprehensive resolution of fuel cycle risks, emphasize the desireability of institutional arrangements that enhance proliferation resistance through such measures as limiting the number and dispersion of sensitive facilities and the size of plutonium stockpiles to that minimum consistent with identified legitimate needs, multinational ownership alternatives may represent a particularly attractive approach. Other states, who though sensitive to proliferation problems are equally if not more concerned with energy security, may find multinational ownership arrangements a reasonable compromise between purely national systems and more intrusive 
international solutions, especially if their concerns about discriminatory treatment and excessive energy dependence are effectively met.

\subsubsection{Limitations of the Concept}

Multinational ownership arrangements have limitations; some of which result from the environment in which they must operate, others of which are inherent in the concept itself. On the one hand, these institutions, especially those limited to a single purpose only, such as reprocessing, are not panaceas. Alone they will not provide foolproof solutions, and, even collectively, they only can contribute to, but not constitute, a solution to the problem. This is partly due to the complex nature of the proliferation problem. Incentives to proliferate are complex, subjective, and not easily amenablesto reconciliation through institutional innovation. Furthermore, not all countries share the same set of perceptions regarding the proliferation risk of different fuel cycle arrangements or the requirements of energy security. Some states with no interest in nuclear weaponry may still place primary emphasis on maximizing national control over their energy destiny and prefer to manage such things as plutonium production and related activities on a national basis even where participation in a larger multinational enterprise might effect economic savings.

There are other limitations inherent in the concept itself. Managerially and organizationally, multinational ownership enterprises may be less elegant and less efficient than national enterprises. In addition, multinational facilities must confront serious siting issues. The problem of potential host country expropriation exists and must be dealt with. The risk of diver-sion by the host country, other member states, or subnational groups is also not absent in multinational ownership institutions. A problem closely associated with multinational ownership, management, and staffing is the diffusion of technology. While multinational 
ownership organizations have been established in which sensitive technology is intended to be confined to the dominant party (e.g., Eurodif), it is difficult to visualize an institution with significant multinational participation in management and operation that will not involve increased likelihood of dissemination of information. The extent to which a multinational ownership structure intensifies or alleviates these problems depends on specific institutional characteristics.

Despite these limitations, the flexibility of the multinational ownership concept noted above and the benefits attributable to multinational ownership institutions are such that this concept remains prominent in the development of institutional approaches to the reduction of proliferation risks. Among these benefits are:

- The potential for limitation of the number of reprocessing plants, and the confinement of these plants to politically stable locations. While not preventing a state from building a national plant, the existence of a multinational alternative does reduce the justification of building such a plant in order to avoid unacceptable dependence on external sources of supply and raises the threshold of a political decision to proceed with a national facility;

- The improvement of capabilities to detect and deter diversion through the use of multinational staffing, as well as reducing the risk of abrogation or seizure of the facility by the host state;

- The enhanced credibility of assurances of supply of services or fuels, or both, made available through such institutions, in contrast with reliance on an external and independent supplier;

- The generating of greater confidence and stability in affected sectors of the nuclear market through the establishment of higher levels of mutual dependence among participating nuclear suppliers and users.

The potential benefits of multinational ownership institutions, as defined above, will be enhanced by the degree to which: (1) they incorporate adequate arrangements for the management of plutonium; 
(2) they mitigate the sense of discrimination in access to and use of peaceful nuclear energy; and (3) their development avoids the premature diffusion of high-risk technology and facilities and the deployment of sensitive fuel cycles in advance of their actual need. These elements deserve brief elaboration.

Multinationalization of reprocessing facilities alone would offer little in the way of nonproliferation benefit. To be effective, an associated plutonium management arrangement involving storage, release, shipment, use, and disposal of plutonium is necessary. Moreover, for reasons explained in the preceding section, this regime should, incorporate the element of custody, since verification alone would not provide the desired level of nonproliferation resistance. A plutonium custody regime, though coupled to multinational reprocessing, need not be dependent on the same organization that owns and operates the reprocessing plant. It could very well be operated as an international regime under the auspices or control, or both, of an organization such as the International Atomic Energy Agency. From a nonproliferation point of view, international management and custody of plutonium might be reasonable, while international ownership and operation of a reprocessing facility would be a much more radical departure from the present situation and, consequently, more difficult to achieve. It would, of course, also be possible for the multinational ownership institution to apply custody arrangements to the material and services that it distributes. A plutonium custody regime that not only liad the responslbllities identified above, but also included provisions aimed at gearing plutonium production to actual need for breeder and advanced reactor requirements and prohibited plutonium stockpiling on a national basis, would be even more appealing from a nonproliferation standpoint.

Avoidance of discrimination might be accomplished more effectively by providing that multinationalization would not apply only to the building of new facilities themselves. Currently, the French and British commercial facilities provide that purchasers of their 
service pay in advance for the construction of the facilities that will reprocess their spent fuel. Assuming that existing facility owners were prepared to consider the addition of some genuine multinational features extending to management and perhaps operation, the application of multinational arrangements to existing facilities could be significant, for it would immediately place advanced industrial states, including nuclear weapon states, under the same basic regime as would apply to other states. Not only would this weaken the contention of discrimination, but it also would establish a norm for future facilities and increase the political costs to those who would, nevertheless, insist on developing purely national capabilities. Finally, it would offset claims that new facilities must be built now to achieve equalization of opportunity between advanced and both smaller industrial and developing countries and, thus, reduce the risk of premature industrialization of sensitive nuclear activities.

A number of already identified salient features of a possible international ownership institution can be considered against these background considerations.

\section{$4.4 .2 \quad$ Siting}

Careful determination of appropriate sites is particularly important to the ability of an institution to address proliferation risks. A frequently suggested solution to the problem of host country takeover is to confine the institution's facilities to nuclear weapon states. While this would resolve the problem of horizontal proliferation, the price which this restriction is likely to entail in political acceptability among advanced industrial and developing states is self-evident. A possible alternate siting approach is to locate facilities in states with a wellestablished history of neutrality and performance of international undertakings, which makes any violation highly improbable. While this formulation would go far toward resolving the problem of discrimination vis-a-vis most industrial states, it would entail 
potentially difficult political justification and would likely be perceived by the developing world, where there are few obvious such sites, as discrimination against them. A third possible approach would be selection of countries whose small size and high vulnerability deprive them of any realistic means to take advantage of a national takeover. This would involve explicit political judgments similar to those involved in the previous alternative.

An alternative to selective siting might be to disperse complementary (e.g., fuel fabrication) facilities broadly among the institution's members, creating a degree of functional interdependence that could serve to deter national takeover. Such dispersal appears to be sanctioned by Article IX.H of the statute of the IAEA, which provides that "in storing special fissionable materials in its possession, the Agency shall ensure the geographical distribution of these materials in such a way as not to allow concentration of large amounts of such materials in any one country or region of the world." A major difficulty with complementary arrangements of this sort is the volume and frequency of shipments of separated plutonium that it would entail. Transportation of sensitive materials is one of the serious fuel cycle problems. Technical fixes involving spiking and irradiation, while possible additive protective measures, bear potentially heavy economic, health and safety, and industrial burdens that may make their practical utility dubious or even unacceptable.

One additional alternative deserves consideration. Assuming general agreement that the number of reprocessing plants should be limited, and that new construction should be geared to identified -breeder and advanced reactor needs, near-term siting could, in principle, be dealt with by placing existing operating facilities under a multinational ownership regime. This would defer nearterm decisions, which otherwise are likely to raise charges of inadequate site protection and countercharges of discrimination. The opportunity for ownership participation on commercial terms 
would be available to those who required the service, and a plutonium management regime could handle storage, use, and disposal of plutonium.

One problem that would remain unresolved in this framework is the dispersion of plutonium to nationally owned and operated research facilities, even with the existence of an international plutonium management regime. Research facilities are as much a proliferation threat as production facilities. One possible approach to this problem, which would, in effect, complete a comprehensive regime for dealing with plutonium and back-end activities leading to its acquisition without fostering discrimination, would be to incorporate research facilities in a multinational custody regime. This option was discussed at greater length in section 3 of this chapter.

\section{$4.4 .3 \quad$ COMPOSITION}

The national composition of multinational ownership institutions is of particular relevance to their nonproliferation effectiveness. As in the case of custody institutions, a requirement of obvious importance is that genuine adversity of interest with respect to the acquisition of nuclear explosives exists among the membere of the organization. This characteriselc is important not only to the performance of proliferation functions, but to global perceptions of the institution's assurances as well. As in the case of other similar arrangements, adversity of interest can enhance the standards and application of international safeguards; and it can provide added barriers not only to potential misuse of the facility and its material, but also to possible seizure of the plant or abrogation by the host state of its commitments and obligations. This is particularly so if there exists a high degree of interdependence among the members such that breach of commitment by any one of them could have far-reaching and costly effects across a wide range of relationships with the other members. Application of the principle of adversity favors extension of the 
concept of multinationality to operational, as well as managerial functions. This, of course, involves greater access to technology by a larger number of participants, and to the degree that this increases proliferation risks, it represents a negative aspect.

One approach to help establish the characteristic of adversity is the inclusion of one or more nuclear weapons states in the membership of any multinational ownership organization, since the strong interest of these states in avoiding further proliferation is generally accepted. This would be facilitated by having first recourse to existing facilities for purposes of multinationalization. The desireable objective of avoiding early deployment of new reprocessing facilities would simultaneously be served. Another alternative would be to require initial and continuous participation of a supplier state in any multinational ownership organization. While this conceivably might not involve a nuclear weapons state, the only additional suppliers that can be contemplated in the near term are the Federal Republic of Germany and

Japan, both of whom have strong nonproliferation interests.

\subsubsection{Staffing and Technology Transfer}

Clear evidence of technical and managerial competence in the operation of multinationally owned and managed plants would be essential to the economic credibility of the undertaking. This requirement would reinforce the leadership and responsibility of àdvanced industrial and nuclear weapon states within the institution. Their long experience in technical undertakings in general. naturally casts them in the lead role.

The notion of lead roles and the desire to minimize technology transfer and access to sensitive information prima facie suggests limiting the extensiveness of multinational staffing. This consideration requires that explicit attention be given to whether multinationality should be limited to the level of management or whether it should extend to operating levels as well. This raises 
a particularly thorny issue because such limitations invite claims of discrimination and threaten to reduce the political acceptability of the concept. Attention, therefore, must be given to what the relative costs and benefits of technology denial might be and what are some alternative ways of handing this issue.

It is reasonable to assume that multinational ownership arrangements extending to operational activities will entail a potentially wider dispersion of technology than might otherwise be the case. However, unlike the situation with respect to enrichment technology, a considerable amount of scientific and technological information regarding reprocessing was declassified and released at the 1955 Geneva Conference on the Peaceful Uses of Atomic Energy, and subsequently there is little reason to doubt that sufficient information is in the public domain or readily accessible to scientists and engineers to build the kind of facility that would yield adequate material for a number of nuclear explosive devices. Denial of access to all technology in a multinational plant will not change those facts, nor will it prevent the building of a small facility.

Conversely, hands-on commercial level experience in reprocessing and plutonium handing is not widely shared, and actual engineering practices for the successful handling of large quantities of irradiated power reactor fuel are not readily available in the open literature. Design requirements and maintenance information for large-scale facilities tend to be proprietary or classified, or both. If the overall objective of multinational ownership. arrangements is to avoid the dispersion of national facilities even where the technology is known, then it would appear appropriate to seek to design. a multinational ownership arrangement in such a way as to avoid complete denial of technology access while preserving proprietary information.

One alternative might be to differentiate technology functions between design and construction activities and operational 
activities on the one hand, and management functions on the other, and to limit technology sharing on design/construction to those who bring technology in that area to the enterprise while pemitting everything else to be shared on a basis of equity. This arrangement could be coupled to firm undertakings by all parties to the enterprise not to overtly or covertly replicate the technology in question, or any part of the facility in which the technology is employed at commercial, pilot, or laboratory-scale level, and not to participate in any other reprocessing enterprise. States could join the arrangement either as a full-share partner, bringing technology to the enterprise, or as an equity partner only, confining their authority to managerial functions, or by some other variation of this type of formula.

Another alternative might be for a supplier state to provide a turn-key operation in which it remains fully involved, reserving design and construction to itself while sharing as an equal partner with all other members of the enterprise in managerial and even operational decisions. This would be consistent with commercial practices based on protection of proprietary interests other than those to which access is necessary to effectively exercise operational responsibilities. (A turn-key operation in which the supplier of technology served as principal operator and assumed maintenance responsibilities -- something approximating the Eurodif model -- would reduce even further the need for widespread sharing of technology). Of course, provision for access to even this information could be made on appropriate terms and conditions where there was a demonstrated need, as in the case of developing new capacity at new locations to meet increased demand.

The alternative of total exclusion of technology sharing as a matter of principle would appear to have only limited value at the level of commercial-scale activity and would risk being counterproductive in terms of political acceptability. The opportunity to participate in operational activities under specified conditions, furthermore, could provide the added advantage of enhancing 
safeguards by interposing another barrier to diversion or misuse beyond that reflected in IAEA inspection, whether on a continuous basis or not.

\subsubsection{Fuel and Service Assurances}

The long run political viability of a multinational ownership arrangement and, in particular, distinctions among membership would depend in considerable measure upon the multinational plant's ability to meet the economic needs of the participants and the extent to which it met their concern about dependence on nonnational sources of supply. Some states may join in order to avail themselves of reprocessing services, without which their national nuclear program may be impeded for lack of effective means to dispose of spent fuel. Others may require reprocessing to derive needed fuel for breeder and advanced reactor activity. Both would be concerned about assured access to plant capacity and timely provision of the service in question.

The assured supply function of a multinational plant may be more credible than that of basically national plants confined to advanced countries and offering services to the international community, where assurances are based solely upon contractual commitments made in the open market. Equity participation would strengthen the claim on timely supply and give equity customers greater confidence that intervention by the plant operator in the supply system would be less capricious than if they were nonequity customers of the plant. On the other hand, the decisionmaking influence of equity participants would be less than that of operator participants and, in particular, of the host country. Differentiated treatment of the different types of participants with regard to assured supply could be damaging to the credibility of the enterprise and lead to decisions to undertake alternative national arrangements. Hence, not only reliability, but evenhanded and equitable treatment of all participants is essential to an effective multinational ownership arrangement. 
Intervention in the supply of service or fuel could arise as a result of changing political perspectives on nuclear activity in the host country. The risk of such changes leading to interruption, delay, or dilatory performance would be reduced, but not eliminated, by linking multinational participation to some form of guaranteed licensing in the case of mixed oxide fuel or plutonium production services, ensuring delivery of the material in question unless it is demonstrated that the recipient has defaulted on a nonproliferation obligation, or to some form of guaranteed import of spent fuel where reprocessing for waste disposal purposes only is involved.

Insofar as the risk of overburdening plant capacity is concerned, the credibility of the arrangement would be enhanced to the degree that it was either a closed-end arrangement serving only member requirements or one that though open for service contracts to outsiders, gave absolute priority to member state needs. Assured supply of service and access could be an important ingredient affecting a state's decision whether to seek to develop nationally controlled reprocessing facilities or to foresake that alternative in favor of a multinational ownership approach. This could be particularly important in situations of regional rivalry, where such rivalry could encourage competitive indigenous reprocessing. The availability of regional alternatives that could reduce incentives to develop national facilities and remove justification for the same while meeting supply concerns, would be an important nonproliferation contribution.

\subsubsection{Rights and Privileges, Including Physical security}

Proposals for the establishment of multinational ownership institutions give rise to two important issues. They are the juridical status of the institution, particularly the relationship between plant autority and host country for defining responsibility for the security of its sites and facilities, and the rules and conditions governing the distribution of sensitive materials. 
As observed earlier, siting may be the single most important means of dealing with the possibility of host country takeover. It is important that such an action be made an unambiguous violation of the host country's obligations, as well as an act that would trigger a strong response from both the members of the institution and the world community as a whole.

The charter of the institution, which should have treaty status, should remove explicitly any right by the host country to eject the institution's personnel or expropriate the facilities or materials of the institution. It should also provide that withdrawal by the host country could only occur with the acquiescence of all member states. Careful specification of the circumstances within which this could occur and what measures might be taken by the other participants to protect nonproliferation objectives would be necessary.

The limited sort of physical control over the plant sites and facilities, as described in the section dealing with custody, could be vested in a multinational custody force directly responsible to the multinational organization. While this custody force clearly could not be endowed with sufficient force to resist a determined host country takeover, its presence, and the need of the host country to use force for its removal, would make the act of takeover a highly visible and exceptionally serious offense. This, in turn, would make much more likely a determined response on the part of the institution's members. The need for this arrangement underscores an important point made in the discussion of custody; it is the multinational responsibility for control over use of material and facilities, rather than any proprietary responsibility, which is central to nonproliferation effectiveness.

\subsubsection{Joint Management and Multinational Ownership}

The discussion on staffing and assured supply raises questions regarding the structural characteristics of a multinational 
ownership arrangement. The economic and operational liabilities of the multinational approach, which were discussed in the chapter dealing with the assessment framework, demand that careful attention be paid to devising ways in which, consistent with nonproliferation, national political and economic preferences can be prevented from detracting from the economic efficiency of the enterprise. Assignment of responsibility for economic and political decisions to different levels of the institution, possibly through the creation of a two-tier board, would be necessary to achieve this.

A two-tier arrangement has a number of potential benefits. More than likely, a multinational arrangement would involve a government-to-government agreement, probably in the form of a treaty that establishes all of the terms and conditions, rights, and obligations of participation, and a subsidiary industrial ( agreement relating to construction and operation of the facility. A two-tiered structure reduces the risk that decisional activities in one realm of responsibility will interfere with or complicate decision activities in another realm, and it helps to maintain the integrity of the distinction between partial and full-fledged participants. Arrangements of this type have been utilized in Intelsat as well as in URENCO.

If a multinational ownership facility is structured in such a way as to distinguish between equity participants who are involved in technology-related activities and decisions and those who are not, there are strong arguments for separating normal operating and standard managerial decisions from those relating to political questions. Two-tiered systems help to accommodate this need. Furthermore, the distinction between equity and full-scope participants entails loss of the enhanced detection capabilities that might be achieved through multinational staffing. However, involvement of equity participants in a decision tier dealing with policy questions, such as the terms and conditions of access to plant products by members or outside parties contracting for 
services, or the application of international safeguards including surveillance and containment techniques, can contribute to political deterrence of misuse by those charged with operational responsibilities. Thus, two-tiered systems not only contribute to efficiency of plant operation, but also help to mitigate class distinctions among participants by facilitating meaningful involvement of non-operational members in policy and managerial decisions and, thereby, partially offsetting the loss of safeguards benefits that might accrue from total participant involvement.

\subsubsection{Candiate Concept}

Based on the preceding discussion, the multinational institution could be organized to incorporate the following features:

- Siting of sensitive facilities would be confined in the first instance, if feasible, to an existing plant. Alternatively, siting would be limited to participating states that were either nuclear weapons states or states in stable regions and not involved in sharply adversary relationships with one or more neighbors. Location of non-sensitive activities such as LEU (but not MOX) fabrication facilities in other participating states could be contemplated to help increase interdependence and reduce apparent economic inequities.

- While multinational management and staffing at one or more operating levels would be employed, necessitating varying degrees of access to technical information and technological know-how, basic design and construction technology of sensitive facilities would be supplied by participating nuclear weapons or other advanced states and would not be shared with other participants. The possibility for broader sharing of reserved technologies would be taken under consideration on a case by case basis and would be geared to the need for expanded capacity or in response to new developments in the context of the multinational regime and associated international controls.

- The institution would extend assured supply of services and, where appropriate, fuels to participants in the institution. Release of materials would be subject to the terms and conditions of an international plutonium custody regime if such exists, or the terms and conditions of the multinational institution as agreed in advance by participants. In the enterprise, such a 
regime should govern acceptance, storage, release, transport, use, and disposal of special fissionable material. A regional orientation may be given to the plant if that appears to contribute to the political acceptance of the institution and does not derogate from the level of international confidence in the nonproliferation effectiveness of the arrangement.

- Unless located in a nuclear weapons state (and even in this instance the arrangements to be described might be desirable for reasons of precedent and equity) the institution's facilities would be under the custodial authority not of the host nation but of custody forces under the aegis of the institution itself. These forces, although obviously incapable of withstanding armed host country takeover, would exercise material control within the boundaries of the institution's site(s) and would possess permanent rights of control not subject to termination or suspension by the host country for any reason. Their removal could therefore be accomplished only by a clear-cut violation of treaty accords and the use of force by the host country.

- Operational authority would be separated, to the maximum possible extent, from political control consistent with the objective of nonproliferation by establishment of a two-tier organization in which management responsibility would be vested in a multinational, but technically qualified, staff, while political responsibility would reside in a board of governors representing the participant states.

- The institution would be subject to IAEA safeguards, and participants would obligate themselves to adhere to agreed nonproliferation commitments. Participation in the institution would entail commitments to not engage in similar activities elsewhere; including national development, and not to replicate facilities on an industrial, pilot, or laboratory scale, as well as to consult with regard to the adequacy of capacity with a view to agreeing on the need, timing, and relevant conditions of any capacity expansion.

\subsubsection{Concept Evaluation}

The multinational plant described above would not provide absolute assurance against diversion or takeover, but it would interpose higher barriers to these eventualities than does the existing IAEA safeguards-based regime. It would not ensure prevention of the 
building of nationally owned and operated reprocessing facilities. It would, however, significantly reduce justification for countries to argue the case for purely national facilities rather than entering a multinational arrangement based on concerns with assured supply or excessive external dependence. In any event, it would contribute to limiting the total number of national facilities and foster norms and precedents that bear importantly on the character of the international nuclear fuel cycle in the coming years. The concept should also increase the likelihood that prompt and strong counteraction would be taken against any violation, since any diversion, seizure, or abrogation would involve the taking of property and the contravening of treaty commitments against a number of states. The deterrent effect of this response capability is a major nonproliferation rationale for multinational arrangements, and may be somewhat greater for multinational ownership than for custody alone.

The concept is strengthened to the extent that it draws, in the first instance, on an existing facility. In the first place, this removes one basis for charges of discriminatory treatment between weapons states and non-weapons states or between advanced industrial and developing states by placing the former under the same regime and conditions as would apply to any newly constructed plant. It also could help avoid the dispersion of unnecessary new capacity for the near and medium term, and thereby reduce the risk of implying that widespread reprocessing is a legitimate and timely activity, and help avoid the premature industrialization of this element of the nuclear fuel cycle. Finally, it provides a practical and working basis from which to evolve toward nonnational sensitive fuel cycle facility development in the future.

Establishment of multinational ownership of reprocessing facilities alone will not contribute significantly to containing proliferation. The multinational plant must be linked to a plutonium custody regime that governs the use, transfer, storage, release, 
and disposal of plutonium. Rules relating to the timing of shipment of plutonium for legitimate and agreed purposes, as well as to the insertion and removal of such materials from critical facilities, research reactors, or power reactors, are essential components of such a regime. Additionally, multinational ownership arrangements should include provisions regarding non-replication, non-participation in other enterprises and the like on the part of the members, above and beyond their normal safeguards and nonproIiferation undertakings. The regime would be further enhanced to the extent that members agreed to carry out research and development activities in the framework of multinational or international facilities developed to accommodate their needs.

4.4.9.1 Nonproliferation Assessment

National Diversion: A major advantage of the multinational structure vis-a-vis the alternative of nationally owned and operated facilities is its enhanced ability to deal with national diversion. Much of this advantage would also be present in a custody arrangement that included strong verification, as well as material control authority. Multinational staffing and adversity of interest could increase substantially the probability and timeliness of detection at the reprocessing plant itself. Although the nationals of a larger number of countries could have access to sensitive material, they could be expected to be more disposed to closely watch each other and less likely to enter into a conspiracy to divert. These expectations could be strengthened by explicit understandings with regard to the obligation to observe and report diversions or suspicions of such activity. A multinationally owned plant in which one lead country operated the plant while others shared only in the financing and decisionmaking would not possess this safeguard advantage unless the multinational institution also exercised custody over the facility. It would, thus, likely diminish international confidence in the proliferation-resistant nature of the arrangement if the plant, or any probable additional ones, were located in a 
non-nuclear weapon state.. Eurochemic and URENCO are more appropriate models than is Eurodif in this regard. This applies, as well, to considerations regarding seizure and abrogation.

Seizure: Overt takeover would be a less serious threat in most cases, particularly in view of the fact that seizure likely would disrupt relations with a number of states across a potentially broad range of activities. The exception may be that in which the host country also acts as the lead country operating the plant. In such an instance, the resistance offered by the institution would depend upon the ability of the other members to respond quickly. Multinational staffing might provide an additional line of defense. It would be more difficult to conceal preparations and to prevent security leaks if the would-be proliferator's personnel constantly interact. with other nationals.

Abrogation: Multinational ownership and management of sensitive facilities would make abrogation by a host country tantamount to seizure of group-owned property. The vesting of ownership rights in the multinational group would, thus, change the legal standing of abrogation, as compared to what it might be where the facility was owned by the host country. Although the implications of expropriation have become modified over recent years, particularly when compensation is offered, nevertheless, abrogation in the context of multinational ownership would possibly incur greater consequences because of its equivalence to seizure. The deterrence against abrogation similarly could be higher than in the case of national ownership under multinational custody, since the other owners of the facility could be expected to be more forthright in their response. The credibility of the penalties and willingness to involve them would depend upon the composition of the group.

It bears emphasis with regard to abrogation, and seizure as well, that nuclear facilities are in many respects sui generis. The risk of nationalization of property, which has become more common 
in the past several decades, is reduced in the nuclear arena to the extent that violation of solemn undertakings and the attendant threat of proliferation are related in a very fundamental way to international peace and security and regarded as unacceptable to the international community. Hence, it may not be appropriate to extrapolate from conventional multinational activity to the nuclear sector and to conclude that abrogation risks are as likely to occur there as in other industrial or resource sectors. Conventional measures, such as providing just, adequate, and prompt compensation for expropriation, would be far short of providing satisfaction to the expropriated partners in this arena. Punitive measures alone would be regarded as appropriate responses to such action. $\circ$

At the same time, as this argument makes clear, it is not ownership per se that imparts a special status to the nonproliferation undertakings of a multinational arrangement, but the very nature of those undertakings, themselves. For this reason, the inviolability of these undertakings can be assured in ways that do not depend on ownership.

Technology Transfer: The proliferation problems associated with technology transfer would not disappear and, in most cases, would be intensified with the multinational concept. Demands for transfer of technology might dominate the politics of the institution. Regional siting may not substitute for transfer, since it could stimulate interest in sensitive technology in areas where it is not yet extensively deployed. Access to technical data and handson experience with the technology, however, is an unavoidable concommitant of multinational staffing, although the degree of transfer could be controlled in some measure by limitations on the number, location, and duties of personnel from countries not already in possession of sensitive technology, as is the practice in Eurodif. The information and experience derived could be utilized in a clandestine plant, and this could lead to the conclusion that multinational arrangements are less desirable than reliance on a 
small number of large national plants sited in weapons states or other stable countries.

On the other hand, as pointed out, at least with regard to reprocessing, the basic technology necessary for a small-scale plant dedicated to deriving modest amounts of material for weapons purposes is widely known. Technology denial will in no way change those facts. The hands-on experience derived from operational activities in a large-scale commercially oriented facility can help in the acquisition of information and experience necessary to operate a comparable facility, and it could also contribute to the speed and certainty of the would-be proliferator's clandestine small-plant effort. This problem might be more effectively addressed through commitments and undertakings by the parties to the multinational arrangement not to replicate or apply any information derived from multinational participation, directly or indirectly. It also might be controlled by considering design/ construction phases as part of reserved technology to be disseminated only when expansion of capacity has been determined to be necessary and a new facility serving the needs of some more advance states is decided upon. Access to research opportunities in multinational or international facilities, or both, would provide appropriate technology participation opportunities in the meantime. Total denial of access, however, focuses on the wrong issue and is very likely to be interpreted as an effort to maintain discriminatory policies in access to and participation in the benefits of peaceful nuclear energy.

In summary, the multinational plant may offer definite advantages in combatting diversion at the reprocessing plant, itself in comparison with the base case of national plants under IAEA safeguards. It could significantly handicap, though not absolutely prevent, overt takeover or seizure. Problems in the transfer of technical information exist and appear to be inherent in the concept of multinational staffing, although the scope and implications of those difficulties must carefully be weighed against 
the political costs of total technology denial efforts in view of the fairly widespread dissemination of reprocessing technology. information. The linkage of a multinational reprocessing plant to an international plutonium custody regime would appear essential to providing effective control over the multinational arrangement. In the absence of such a relationship, the concept would be deficient from a nonproliferation point of view.

\subsubsection{Economic/Operational Assessment}

The multinational concept may offer significant economic advantages, particularly to states with anything less than a very substantial nuclear program. It broadens the financial base of the operation and enables the sharing of investment and technological risk. As URENCO illustrates, where competitive technological development exists, the multinational structure allows the incorporation of different projects under the same roof, although with a significant departure from the concept of total integration of ownership, management, and operation. The inclusion of several parties in the same enterprise also might provide the market base to make the project commercially feasible and to facilitate the achievement of economies of scale. with a plant larger than would otherwise be the case. The opportunity to manufacture components with a relatively guaranteed customer could attract countries concerned about infrastructure development. The attractive power of these advantages has an empirical base in the events leading to the formation of both Eurodif and URENCO. Indeed, it bears noting that strong commercial considerations, based on recognition that collaboration was likely to contribute to the establishment of viable industries in this sector of the nuclear fuel cycle, as well as more purely political interests encouraged establishment of URENCO.

Dependence upon foreign sources of supply, regardless of whether the particular customer owns a share in the plant, entails potentially significant economic costs. Jobs that otherwise would 
have been created by an indigenous project would be lost, as would the foreign exchange necessary to pay for the imported fuel. However, for small countries with relatively marginal nuclear industries, an indigenous project may well represent an inefficient allocation of effort and funds. Access to the possibly greater technical competence and financial support of a multinational project could, for some countries, outweigh these economic costs.

The major a priori objection on economic grounds to a multinational structure of the inter-governmental sort envisioned here rests upon the inefficiencies often attributed to the management and operation of joint projects. These inefficiencies were enumerated in the section of Chapter Two dealing with acceptability assessment. What is more important here than the individual problems encountered in multinational management and operation is the encouragement that frustration with such problems has given to the concept of a lead-country approach, or even single operator. Such an approach could be more efficient, but at the expense of some gain in nonproliferation effectiveness in comparison with multinational staffing and operation. A lead-country approach also might result in some loss in acceptability to potential participants that could enjoy ownership and management responsibilities only as partners in a multilateral venture.

These inefficiencies are not of small significance. Unacceptable costs, construction delays, or down-times in plant operation would discourage. support for the institution. At the same time, and importantly, the existence of two enrichment ventures and other fuel cycle enterprises that have significant elements of multinationality suggests that important countries can be persuaded of the concept's advantages, especially if it is seen as serving nonproliferation interests and helping to preserve the nuclear power option. Furthermore, past experience would seem to underscore the need for a flexible approach capable of accommodating the ultimate specific project and specific participants and of taking acccount of the prevailing political environment in which the enterprise must function. 
Particularly in view of the changed political climate in the nuclear arena and the elevation of nonproliferation considerations to their current level of prominence, the most significant economic question may be not whether a multinational ownership arrangement offers identifiable economic advantages not otherwise attainable, but whether it entails acceptable economic costs in relation to its incremental nonproliferation advantages over custody alone. This question, in the final analysis, can only be given a political answer.

\subsubsection{Political Acceptability Assessment}

There may exist compelling political reasons to join a multinational project. A country might regard the denationalization of certain fuel cycle activities as a condition precedent to a viable nuclear industry worldwide, or it might consider participation preferable to political, technical, and economic isolation in the nuclear area. The opportunity to engage in an activity that otherwise would attract opposition from other countries could be particularly persuasive for countries in sensitive political circumstances. The West German decision to conduct its enrichment activities in a multilateral framework and, at least initially, at a site outside Germany was due, in large part, to the sensitivity. such activity within Germany would have had in the late 1960 s.

Another political factor leading to the same result is domestic opposition to indigenous siting of operations to which health or environmental problems are attributed. The domestic controversy over waste disposal and interim spent fuel storage might encourage some governments to seek international solutions to their political dilemmas. Coupling the availability of multinational storage and disposal to multinational reprocessing could offer a way in which political interest in some operations could be exploited to expand the scope of participation. However, as noted in an earlier section, while these reasons might make participation attractive to a non-host country, they are likey to make the arrangement less popular to a host country than it might otherwise 
be. While opportunities to use waste disposal and spent fuel storage as an incentive to the establishment of multinational ownership arrangements should not be overlooked, it would clearly be undesirable to make a multinational solution of these problems a condition of such arrangements.

The most obvious political cost in joining a multinational undertaking, and one which could seriously limit its acceptability, is loss of national control and discretion. Depending upon how voting. is structured, some countries with low voting shares could be reduced effectively to the level of observers. Since the level of energy dependence on such facilities might be high, this could prove intolerable to them, for reduction of dependence on external supply sources may have been one of the major reasons for their joining in the first place. Political control by the group can also have an impact on a country's interest in nuclear export markets. The Netherlands' reluctance to agree to URENCO exports of enriched uranium to fuel reactors to be supplied by the Federal Republic of Germany to Brazil reportedly was a source of considerable dissatisfaction to the latter parties.

Two points deserve emphasis here. First, this political cost must be compared to the costs of the alternatives. An entirely indigenous undertaking might arouse substantial foreign opposition and evoke strong pressures against the activity. Such a decision could intensify domestic debate on all nuclear issues. Failure to successfully carry through, for technical or other reasons, an indigenous program once begun could seriously damage the political fortunes of a government and, thus,deter it from doing so. This possibility must be included in political calculations, as does the possibility that an arrangement such as custody could overcome much of the international opposition to a particular activity while preserving the national program. 
Second, perceived political costs of joining multinational ownership institutions can be mitigated to the extent that the most technologically advanced and politically influential states subscribe to the same regime. This is the basis for concluding that existing national facilities should be considered as first candidates for establishing and demonstrating the multinational ownership concept. Involvement of such facilities in a multinational ownership undertaking at least limits the claim that there is overt discrimination between states in the peaceful nuclear arena, and it establishes a norm for future development of sensitive fuel cycle facilities. The flexibility of the multinational ownership concept nevertheless leaves room for some differentiation between multinational undertakings, and could allow adequate room for the most advanced nuclear states to effectively meet their programmatic requirements on a timely and unimpeded basis. This consideration, of course, applies with at least equal force to custody arrangements.

Regionalization of multinational structures might enhance their political attractiveness in some instances. Since total elimination of discrimination between weapon and nonweapon or advanced and developing states is quite likely unobtainable, the regional structure could minimize distinctions among a country's more immediate peers. This could be a particularly powerful argument in favor of the project to the extent that regional competition motivates efforts to achieve autonomy. A major political cost of autonomy -- spurring on others to keep pace -- would be avoided as a result.

Loss of national control in many circumstances would be the principal 'argument against multinational ownership. National control, however preferable it may appear, is not in every case the politically and economically optimal course. Whether the multinational ownership concept can prove acceptable to politically ambitious states is one of the major uncertainties of the concept. Ambition, however, would not neressarily make such countries unmindful of the cost of unilateral action. Incorporation of such 
countries into responsible positions in the organization could give them a stake in its success. In view of the serious political sacrifices that participation would entail, enlisting their participation may demand the use of incentives and disincentives largely external to the concept. Extensive use of such "incentives," however, could create an organization whose support is not tied to the concept itself. Any change in the incentives, as a result, could undermine even a reasonably efficient project. This suggests that considerable care must be taken to utilize the attractive powers of the concept itself as much as possible. 


\subsection{INTERNATIONAL (GLOBAL) INSTITUTION}

A global authority could be established to perform one or more institutional functions, ranging from improved safeguards at one extreme, through ownership, management, and operation of sensitive facilities at the other. The distinguishing feature of the global authority is its composition -- as opposed to regional or multinational institutions, all users and suppliers of reprocessing services and sensitive material would participate in a single international institution. Although there might exist multinational or regional bodies performing functions other than those performed by the global authority, the global authority would possess exclusive jurisdiction and responsibility for the conduct of its assigned tasks.

There exists a spectrum of global institutional arrangements that can be defined by the functions that the institution performs. Although the responsibility of the global authority might be confined to the back-end of the fuel cycle, inclusion of front-end responsibilities as well might impart to the global institution an attractiveness from a fuel assurance standpoint, which could prove compelling in enlisting the broadest possible participation.

\subsubsection{Functions}

Code of Conduct: An international institution with responsibility for defining and implementing a code of conduct could take one of two forms. The institution would be composed of either: 1) all suppliers and customers of reprocessing services; or 2) regional or multinational institutions. In the first case, the institution would establish a code carried out directly by the member states. In the second, the institution would provide an international framework for the harmonization of the rules and undertakings of the member institutions. Both of these cases have already been defined and analyzed under the general concept of Association. 
Improved Safeguards: There already exists a global institution for the performance of safeguards: the IAEA. As a result, the principal task in connection with the performance of improved safeguards by a global institution is not to establish the organizational framework for the task, as this already exists, but to determine how safeguards will be improved. The concept of improved safeguards developed at the start of this chapter (Candidate Concept 4.2 - Improved Safeguards) describes changes in the relationship between the safeguards agency and the recipient state, in the areas of rights of access and frequency of inspection, etc., which would be central features of an improved safeguards system. The concept of an international institution performing improved safeguards can be considered equivalent to Candidate Concept 4.2, and subject to the same analysis as for that concept.

Custody: Rather than establish a multinational custody institution(s), as was contemplated in Candidate Concept 4.3 - Custody, this responsibility could be vested exclusively in a single international authority, either an arm of the IAEA established for the purpose or a new global organization. This international authority would perform the same functions as the multinational authority. However, the same arguments developed under Candidate Concept 4.3 in support of a multinational approach to custody can be reiterated here. Custody may impose new responsibilities upon the IAEA that that organization may not be able to handle and that would tilt the balance between the IAEA's promotional and regulatory roles even more in the latter direction than is presently the case. There are also potential problems in maintaining the necessary commitment to nonproliferation among an international, as opposed to multinational, group and in developing the momentum essential to implementation if the support of a very large number of countries must be enlisted before the institution can begin to function. 
Operation: The one functional case that has not yet been discussed as an institutional option of another concept is that in which the global authority operates sensitive facilities. Unlike the functional cases above, in which ownership, management, and staffing have remained in national hands, in the case of facility operation the international group is involved at one or more of these levels. Although international operation appears to be a variation of multinational operation, with an obvious major change in the composition of the institution, the concept of an international fuel authority presents a sufficiently different set of problems and opportunities as to merit more detailed discussion.

The global Euel authority would:

- Combine the functions of fuel assurance, reprocessing, and possibly front-end services.

- Control fissile material and own the fuel facilities.

- Offer assurance of continuous supply of fuel in return for the relinquishing of national control over fuel cycle activities.

The global authority might contribute to controlling the spread of nuclear capabilities in three primary ways. First, technology could be controlled to some extent in the short run, and perhaps in the long run, too, if the authority develops such close working relationships with national nuclear engineers and companies that construction of even covert plants would be more difficult to conceal. Second, the reduction of discrimination in this approach could improve its political acceptability and, perhaps; open the way for integrating the nuclear programs of even the most adamantly nationalist countries into the international structure, though at the expense of greater technology transfer. Third, the supply function of the global authority may inspire greater confidence than does the current regime, by supplementing market transactions with more institutionally based claims upon services via shareholding or other concrete 
forms of participation. By tying claims to fuel supply to the level of participation in the institution, the global authority might address equity issues better than relationships in which a country had no means of influence over price setting.

A major supposition of this concept is that it can extend to sensitive facilities a level of proliferation resistance equivalent to that of multinational institutions and, through its wider array of fuel services, attract broader participation than might be achievable in the multinational approach. At the same time, the international composition of the membership may aggravate several disadvantages found in multinational ownership and operation.

\subsubsection{Ownership and Management}

International ownership and management of sensitive facilities offers many of the same advantages and disadvantages as cited in the case of multinational plants. The major gain achievable through the global authority is the strengthening of the concept that sensitive facilities belong in international rather than national hands. The authority's duty to build new facilities as needed, together with the broadest participation possible, may intensify the political pressure against autonomous national plants.

At the same time, the need to parcel out votes to a larger and more diverse set of countries would seriously detract from managerial efficiency. Moreover, the politicization of business decisions may be greater in the global authority. The much wider range of economic, political, and energy circumstances in the membership may promote conflict over key issues such as prices and terms of fuel supply. Existing cleavages between advanced and less developed consumer and supplier countries would be internalized within the organization. The managerial and decision-making liabilities of the multinational concept 
likely would be far more serious in the global authority: This probability strongly argues for a lead-country approach for the management and operation of internationally owned plants, but such an'approach may be more difficult to implement by such a large and diverse group of states in which the distribution of economic benefits may be a dominant issue. International staffing would be particularly unattractive because of the potential difficulty of recruiting a competent and cohesive staff. The experiences of existing international organizations with recruitment suggest that the probability that politically determined national quotas might be imposed would be high.

The initial step in the implementation of the institution would be the acquisition of existing facilities. Not only would this require relatively large amounts of capital to purchase these facilities, but it would also necessitate highly visible political sacrifices on the part of the countries operating those facilities. On both accounts, this feature of the global fuel authority can be considered disadvantageous. On the other hand, such a step could go far in mitigating the discriminatory character of any institution that otherwise made distinctions regarding who could own or operate plants based upon economic or political criteria. Construction of future facilities by a single international authority could help insure that more proliferation-resistant designs and technologies would be employed, if such additional measures were deemed necessary, by eliminating economic competition.

\subsubsection{Fuel Assurances}

Although the option of diversifying suppliers and the benefits of competition would be lost, the global authority would eliminate the possibility of collusive pricing and substitute in its place a regulated enterprise whose costs and rate of return would be open knowledge to the participants. Furthermore, the participants themselves, through periodis governing board 
meetings, would determine supply and price policy. It does not follow from this, however, that pricing policy would necessarily be favorable to users of the service, as compared with producers. The relative weight given to these two sectors would depend on complex relationships within the organization, and could well change with time, as has been seen in the case of regulated utilities in the United States. Moreover, the economic consequences of the loss of competition would never be known, but could well be very high. The authority also might better rationalize the supply system linking all stages of the back-end.

The major attraction of the global institution is its ability to offer integrated front-end/back-end fuel services on terms that make it clear that assured supply is contingent upon honoring nonproliferation commitments. Such integrated assurances would not be available from other institutions confined solely to back-end operations. If full universal membership is achieved, the emergence of a two-tier market, differentiated by substantial disparities of nonproliferation undertakings, would no longer be possible, as it might be in the other concepts that have less comprehensive membership or that leave the variety of nonproliferation conditions applied to front-end supply unaffected.

The fact that all sensitive facilities would be owned exclusively by the global authority, however, would constitute direct and highly visible intrusion of an international institution upon the right and ability of states to determine their own fuel cycle policies. This characteristic could have even greater negative consequences for political acceptability than does multinational ownership, since the voting power of any individual state would be diluted to a proportionally greater extent among the much larger membership of a global organization. 


\subsubsection{Candidate Concept}

The broad outlines of a global authority for the back-end of the fuel cycle include:

- Provision of services in the areas of reprocessing, fabrication, and transportation, together with front-end services. In particular, integrated front-end/back-end fuel assurances are a major incentive to participate and are a principal point distinguishing international from those multinational arrangements that are confined to the back-end.

- International ownership of all sensitive facilities, but management and staffing left in hands of lead countries.

- Purchase of existing national back-end facilities and construction of all subsequent ones. This is to firmly establish a political presumption against national facilities.

- Provision of materials and services on a full costrecovery basis subject to rate of return or rate-base regulation in order to ensure that consumer interests are protected. The authority would have pricing and marketing responsibility, with strong commitment, as in the case of regulated utilities, to meet all demand.

\subsubsection{Concept Evalulation}

\subsubsection{Nonproliferation Assessment}

In most respects, the nonproliferation effectivness of the global authority resembles that of the multinational institution. International ownership is the principal foundation for deterrence of misuse of the facility, and every effort is made to employ proliferation-resistant technologies and designs. A major gain afforded by the global authority concept is that its inclusion of both front- and back-end fuel services increases the incentives to participate in such an arrangement, as well as the political isolation of countries refusing to join. As in other cases considered, the global authority does not eliminate the risks of diversion or national takeover, as was recognized as early as 1945 in the Acheson-Lilienthal study. 
National Diversion: Under the global authority, the principal diversion threat would come from either agents of national governments acting within the plant or elsewhere in the back-end, and from the host country. Theoretically, the global authority concept would appear to possess greater deterrent power, since the authority is explicitly the representative of the international community. Any attempted diversion would be a particularly serious act involving what would likely be direct and immediate response. However, the ability of a global institution to act may be handicapped by uneven levels of commitment among the members to nonproliferation and a diffusion of authority and responsibility. This could result in a serious constraint upon the capacity of a global authority to deter abuse through the certainty of penalties against misuse. Moreover, unless the institutional arrangements included measures for the physical control and custody of sensitive material, the primary bulwark against diversion in this specific concept would be safeguards. The composition of the institution itself would not have any impact on the difficulty or detectability of misuse, unless international staffing was employed.

Seizure: Seizure by the host country would remain a problem for the global authority concept as it does for the others discussed here. For several reasons (to be discussed under political acceptability below.) confinement of sensitive facilities to NWSI or advanced industrial states will be very difficult in his concept. This may reduce the availability of siting restrictions as a nonproliferation instrument and increase the potential for seizure. The guard force at the plant would not be sufficient to repel a national force attempting to seize the plant, while the potential political weaknesses of an institution with an international composition, discussed later, may limit the deterrent capacity of the institution.

Abrogation: International ownership would have a legal and political effect on abrogation analogous to that of multinational ownership. However, the possibly diluted ability of 
the institution itself to respond to host country abrogation could seriously detract from the deterrent political of international ownership. As a result, deterrence may rest upon the ability and willingness of individual countries to take it upon themselves to respond to an abrogation.

Technology Transfer: The same risks of technology transfer attendant in multinational composition are potentially present, or more so, in the global authority. They, in fact, could be aggravated if voting control shifted towards LDCs that would demand access to technology as the price for their participation. The maintenance of two classes of membership would be even more difficult that in a multinational institution. The potential for misuse of experience of competence gained through international participation at the operating level of a sensitive facility could be reduced through hiring a permanent staff or relying upon the national staffing in the lead-country approach, as opposed to accepting international personnel seconded from their respective national agencies. A more serious risk results from the likelihood that substantial technology transfer would be officially sanctioned by a global institution, such that a serious potential for misuse would almost be inherent in the concept. A major consequence of this potential is the need for greater obtrusiveness on the part of the institution, possibly extending to monitoring national R\&D and related technological activity. This necessary obtrusiveness could easily create serious problems in the area of acceptability.

\subsubsection{Economic/Operational Assessment}

The economics of the global fuel authority may differ in degree, but not in kind, from those of a multinational institution with responsibility for plant operation. The global fuel authority would involve international financing and, like its multinational counterpart, would be vulnerable to national inability or unwillingness to meet new financial requirements. Whether the 
broader participation would tend to dilute this effect or exacerbate it by minimizing each participant's sense of resposibility for the overall outcome is difficult to forecast. A major potential liability of the global authority operating an the intergovernmental level is that decisions normally guided by business criteria could be seriously and irremediably politicized. Although this potential is present in the multinational facility as well, the politico-economic diversity of the participants in an international authority of the sort described, and thus, the potential severity of the problem here would be greater. As a result, claims for job quotas, politically determined allocation of procurement contracts, etc., could be more serious and difficult to deal with than in the multinational authority. Neither the international nor the multinational authorities compare favorably with an institution in which such proprietary matters are left in the hands of a national owner-operator.

A major difference between the international authority and the concept of the multinational facility is the absence in the form of competition among suppliers and, thus, of a competitive price system. Instead, the price of fuel, or fuel services, is administered by the global authority. The determination of price levels, as a result, might be the result of political bargaining that could easily lead to discord within the institution, since the divergent energy and economic circumstances could lead to incompatible policy positions. Most importantly, most countries would probably favor higher prices than would those who are only consumers, leading to permanent tension.

A lead"country approach to management and operation could reduce the magnitude of economic and operational inefficiencies. Such an approach also would accomodate better the economic interests of the host country, insofar as it insulates the procurement process from political quotas and results in more employment opportunities and contracts for the host country/ manager-operator. However, it is difficult to envisage circumstances in which the lead-country approach could significantly 
reduce such political pressures on economic decisions or even be acceptable in the first place, since the presumption that economic benefits would be broadly distributed among the membership would likely be a prominent factor in the prospective participant's evaluation of the concept's acceptability. A twotiered decision-making structure may reduce political interference with everyday managerial affairs but not with major questions of economic and commercial policy. The international composition of the global fuel authority, coupled with the operational nature of its primary function, may well intensify the seriousness of these problems. The smaller number of countries in a multinational institution may make economic problems more manageable by comparison. Minimizing the intrusion on proprietary matters altogether by leaving them in national hands would reduce them further still.

\subsubsection{Political Acceptability Assessment}

The creation of any powerful new international organization that infringes upon traditional national prerogatives would encounter political opposition. The presumption of the global fuel authority approach, however, is that broader scale recognition of the dangers of proliferation can be transformed into a solid political base in support of such an institution. Nevertheless, the questionable extent of the gain in nonproliferation effecitveness through the global fuel authority concept, as opposed to other concepts, together with several problems of a political acceptability nature described below, suggest that such a political base may not be forthcoming.

The implications of the global fuel authority for energy security are a highly visible aspect of the institution. The concept makes a radical departure from the others discussed in this chapter on a very fundamental point. Under the global authority there is no longer a competitive market within which the customer is free to contract with a diversity of independent suppliers. Instead, assurance of supply is based upon capacity of 
the authority to allocate services and materials from the facilities under its control. Inclusion of enrichment services, and possibly uranium, in the authority's fuel assurance scheme might, when combined with back-end services, offer a particularly attractive package of services to prospective participants, but the means of allocation of such services may be less acceptable. There would be a major incentive for supply to be always adequate to meet all demand, but the ability of the institution to achieve this objective would be subject to many uncertainties.

Substantial objections against such a mechanism might exist regardless of whether the authority is able to demonstrate that it is capable of managing the supply system. Customers may still feel that a competitive market offers the best protection against abrogation of contracts and the most effective guarantee of acceptable prices and contract terms. In the case of a single global authority, the customer would have no recourse to an alternative supplier short of abrogating its commitments to the institution should it be disatisfied with the authority's performance. Inclusion of uranium supply would be particularly problematical in view of the present opposition of uranium suppliers to any institutional infringement on the market, let alone its replacement.

There exists other energy security-related objections. The concept involves surrender of national authority over fuel cycle policy to the institution. That authority would now reside in an institution with a highly diffuse and disparate membership, over which individual states, save for the very largest, would have little influence. Thus, in exchange for what many states consider to be a significant political sacrifice, the concept offers an institutional alternative to national policy control that may appear to states as placing them close to the opposite extreme of having no influence over fuel cycle matters at all. 
Not all the political implications of the concept are uniformly negative, however. Some states, particularly LDCs, may view the global authority as a forum for advancing claims for a redistribution of economic wealth through more extensive sharing of technology and as a means of diluting the power of advanced states over nuclear policy issues. These very same effects, which might be counted by some as beneficial, might be viewed in the exact opposite light by some advanced countries.

The diametrically opposed nature of these perspectives points in the direction of what may be the post serious political liability of the concept: its politics. The liability may be more a function of the international composition of the membership as much as its functional responsibilities.

The inclusion of countries of divergent commitment to nonproliferation or at least divergent views of how to ensure nonproliferation, would dilute the ability of the institution to establish the necessary arrangements to enhance the proliferation resistance of its activities and to act in the case of violation.

Restrictive siting, even though justifiable on nonproliferation grounds, and constraints on technology transfer may be politically impossible in the global institution. Moreover, countries of lower nonproliferation commitment may dominate the organization because of their greater number. The more egalitarian decision-making arrangements that could prove necessary to win their support may seriously restrict the influence of those countries most strongly committed to nonproliferation. Whereas the composition of a well-constructed multinational institution may considerably enhance its ability to both deter and react to misuse, the unavoidable inclusion of a widely divergent range of political, economic, and energy interests and commitments among the members of an international institution may seriously detract from its nonproliferation effectiveness. 
There is a far greater chance in such an institution that a violation would be treated on the basis of which country committed it, than on the basis of the severity of the offense. 
5. IMPLEMENTATION OF INSTITUTIONAL CONCEPTS

The implementation of multinational or international institutional arrangements for the purpose of reducing proliferation $r$ isks in the civilian nuelear fuel cycle involves selection of the particular types of arrangements that are to be deployed, identification and enlistment of participating countries, and determination of where in the fuel cycle the arrangements are to be in force. Assumptions and conclusions drawn from the analysis of the previous chapters regarding institutional means of.satisfying both nonproliferation effectiveness and political, economic, and operational acceptability can provide a guide as to how these tasks should be carried out, and the analysis here relies very heavily upon the preceding chapters.

While the implementation process is continuing one that requires in its later stages the formulation and application of detailed negotiating tactics, these detailed actions are not an appropriate matter for consideration in this study.

There are several major considerations that must be taken into account in developing institutional packages, which will occupy much of the rest of this report. Careful specification of the criteria that implementation must satisfy is particularly important as both a guide to action and a measure of "success" in the eventual outcome. In keeping with the approach to implementation identified here, analysis of potential participating countries is necessary to identify dominant objectives and needs among leading actors in order to provide a basis for determining what kinds of institutional arrangements would be compatible with those objectives and needs and at the same time would satisfy the requirements of proliferation resistance. Likewise, careful definition of the proposed institutional arrangements that the conceptual analysis of the preceding chapter indicate as promising must be undertaken with a particular view towards defining the 
rights and obligations of the members and the potential benefits of participating. Lastly, the potential leverage and incentives for developing consensus in support of the institution must be identified and evaluated. Having addressed these considerations, it is then possible to develop specific institutional packages that could be implemented by particular groups of countries.

\subsection{IMPLEMENTATION CRITERIA}

Two basic sets of criteria guided the assessment of the candidate institutional concepts in the previous chapter: nonproliferation effectiveness; and political, economic, and operational acceptability. Those same criteria obviously retain their validity for the analysis of implementation. An institutional outcome for implementation that inadequately dealt with proliferation or whose establishment required heavy doses of coercion would be undesirable. There are, however, additional criteria that, while derived from these two basic considerations, are particularly germane to implementation. These include:

- Early implementation

- Applicability to existing facilities

- Maximum involvement of sensitive facilities

- Expansion without stimulation

- Appropriate composition

Early Implementation: Of particular importance is the interest in early implementation, not simply to deal with proliferation risks as they materialize in the near-term, but to impart to the process of institution building a momentum which that carry it through more difficult cases. This interest places a premium upon enlisting the participation of at least some major customers and suppliers of sensitive fuel cycle services in the initial effort in order to maximize the encouragement that institutional operation involving such countries might have upon other prospective participants. As will be discussed shortly, however, this general 
interest in an early start does not imply that any institution will do for the sake of getting agreement on something, since the belief that the initial institution can subsequently be strengthened is not well-founded.

Applicability to Existing Facilities: A second criterion is that implementation effectively address the problems and opportunities inherent in the application of the institutional arrangements to existing facilities. Although institutional or even technical modifications, should those be determined to be necessary in new plants, may not be retrofitable in all aspects to existing facilities, as a general principle, implementation should not allow "grandfathering" of existing civilian facilities. Not only would a two-tier regime in which some facilities or countries are subject to more stringent controls than others be viewed as less legitimate, a differentiated approach, as "grandfathering" entails, would fail to deal adequately with some of the world's major sensitive facilities. Eventually such an approach could pose practical problems, as international trade in sensitive materials and services would be subject to different controls based upon the origin of the commodity. Existing facilities offer an opportunity to proceed with implementation at an early date and to develop precedents and political momentum necessary to impose the institution upon future facilities when built.

Maximum Involvement of Sensitive Facilities: Implementation must also strive to achieve maximum involvement of sensitive countries. The rationale for this criterion is self-evident -- failure to include those countries in which sensitive facilities or materials might be particularly subject to proliferation threats would make the institution largely irrelevant to the real risks of proliferation. This is not to say that failure to include all such countries would render the institution worthless. The proliferation problem in some countries may be beyond institutional solutions. Nonetheless, there exists some lower bound to the number and nature of the countries whose participation is crucial 
for success. This criterion recognizes, however, that at the outset some countries may stand aside and. wait to see whether the institution is successful and tolerable.

Expansion Without Stimulation: Implementation also must result in institutional arrangements capable of accommodating additional facilities while not artificially stimulating their construction. The establishment of an institution will tend to have a legitimizing effect on decisions to build sensitive facilities or use their services. Indeed, this effect may be a powerful incentive to participate in the institution. At the same time, the existence of the institution must not be allowed to give the impression that construction of sensitive facilities, regardless of economic or technical justification, is now acceptable. Given the nonproliferation interest in minimizing the overall number of facilities and the economic interest in avoiding facilities of inefficient size, implementation may also have to develop consensus on some objective guidelines for addition of new capacity if it is to satisfy these two criteria.

Appropriate Composition: Finally, implementation must result in groupings of appropriate composition. This means not only that sensitive countries be included, but that the membership be stable and balanced in terms of economic, political, and nonproliferation interest. The adversity of nonproliferation interests and politicoeconomic interdependence cited in Chapter Two as important characteristics of appropriate composition are vital to the stability and long-term viability of the grouping.

\subsection{EVOLUTION AND EXPANSION}

One crucial point about implementation remains to be made. Institutional evolution and institutional expansion must be care- . fully dealt with in the course of implementation. It is sometimes thought that, in the interest of attracting the widest possible participation, it may be advantageous to settle initially for a 
weaker regime than is considered adequate, in the expectation that once in place both the authority and functional scope of the regime will increase. This "incremental" approach to implementation views the implementation process as a continuous one in which not simply the membership but the institution itself changes over time.

Although this approach may appear enticing if resistance to more strenuous institutions blocks implementation, the premises upon which it rests are dubious. Once established, international organizations and regimes tend to resist change. Having developed vested interests in a particular configuration of the institution or the distribution or power within it, the members frequently resist any significant redefinition of its instrumentalities, functions, or purpose that would threaten those interests. The history of the IAEA supports this contention. Since its inception in 1957, the Agency has acquired no new functions. While the Agency's safeguard system has grown in scope and scale to match developments in nuclear power itself, it should be recognized that the adoption of the IAEA safeguard system represents a restriction on rights that the Agency was accorded by its statute, not an enlargement. It should also be noted that the major institutional developments in recent years -- the NPT, the London Suppliers Group -- were initiated outside the confines of the Agency.

Institutional expansion is to be kept carefully distinct from incremental institutional evolution. The focus of institutional expansion is upon membership rather than functional scope or authority. Demonstration by the institution that it can perform its tasks to the satisfaction of its original members, together with whatever leverage may be exercised through bilateral or multilateral diplomacy, may subsequently attract more members. The ability of the institution to achieve this, of course, depends upon its initial composition. An initial coalition behind an institution that fails to include at least some major suppliers, customers, or sensitive countries likely would not be able to generate the momentum necessary for institutional expansion. 
The institutional expansion approach, it must be kept in mind, places great weight upon the institutional outcome of the early implementation effort, as it implies that there may be no second chance to get something better at a later date. Rather than weaken the institution to attract the largest initial membership, it may be more productive to narrow the original membership in order to establish the stronger institution that is the ultimate objective in the first place. This does not mean there must be an absolute correspondence between the actual outcome and the ideal form of the institution, but it does require that the initial charter be sound with regard to the essentials of the institution.

Finally, indefinite expansion is not necessarily a desirable outcome. As indicated in earlier chapters, the ability to respond effectively to violations may be weakened in groups that are too large.

\subsection{POTENTIAL PARTICIPATING COUNTRIES}

As the preceding discussion of implementation criteria makes clear, the composition of the membership is crucial to the overall prospects for implementation. This is true not only from the rather obvious standpoint that the proliferation risks posed by sensitive countries and facilities must be effectively addressed, but also from the standpoint of the implementation process itself. The composition of the group is important in relation to both the performance of the institution and the momentum of the implementation process.

On the basis of these considerations one can identify three factors that must be taken into account with regard to the participation of a particular country:

- the interests in, need for, and programs for sensitive fuel cycle materials and facilities; 
- the country's potential role in the implementation process, especially whether it is an active or passive participant or a member of the founding core group; and

- the consequences of its participation or non-participation for the success of implementation and for the achievement of the institution's objectives.

The interests in, need for, and programs for sensitive materials and facilities provide an indication of the demands potential participants may make of the institution, the degree of compatibility between the features of the institution and the policies and programs of the members, and their contributions to the technical competence or political stability of the institution. These factors influence not only the kind of institution that is established, but the logic behind the composition of the groupings as we 11 .

Not all countries share a common role in the implementation process. Central to implementation is the organization of an initial supporting coalition that in turn has the momentum and the leverage to attract more participants. This initial coalition need not include all the major participants whose eventual participation is sought. While there exists some minimum size that is sufficient to establish the institution, there may be an upper limit, too, which is the point at which the price of bringing in additional members is a dilution of the institution in order to accommodate more divergent interests. This proposition is related to the previously mentioned matter of institutional evolution and expansion, in that priority must be given to the adequacy of the institution rather than maximizing the membership at any cost.

The third consideration regarding participating countries -- the consequences of participation or nonparticipation for the success of implementation -- follows, in part, from the second. As a general principle, serious dilution of the authority and responsibilities of the regime is a price that should not be paid in order to maximize participation. However, in considering whether support from a particular country is essential to the success of 
implementation, specific attention must be paid to how much compromise within the bounds set by institutional effectiveness is possible, and to whether the institution would continue to provide significant nonproliferation benefits in the face of nonparticipation or withdrawal by that country. The non-participation question may be only a matter of timing -- an initially reluctant country may simply join at a later date. The more serious possibility is that the country or countries in question can successfully establish a supply system totally outside the grasp of the institution and subject to much weaker nonproliferation controls. such a two-tier system could undermine the institution and possibly aggravate proliferation risks. Thus, this ability to undermine the institution by staying out is a major test of whether implementation can afford to accept withdrawal or nonparticipation by a particular country.

\subsection{INSTITUTIONAL CONCEPT}

The evaluation of candidate concepts in Chapter Four reached several conclusions regarding the efficacy and acceptability of different institutional arrangements. Prominent findings were:

- that institutional arrangements applied to sensitive facilities but not sensitive materials are insufficient from a nonproliferation standpoint;

- that institutional arrangements that unnecessarily infringe upon proprietary responsibilities, especially where such arrangements are established on an exclusive basis, can become serious obstacles to acceptability; and

- that responsibility for the control of sensitive material has direct relevance to the proliferation resistance of the fuel cycle activity, and that, at a minimum, international or multinational institutional arrangements must be established for this purpose.

These conclusions were reached on the basis of careful assessment of the costs and benefits of institutional concepts and evaluation 
of how the acceptability of these institutions might be perceived by prospective participants.

The institutional analysis of Chapter four drew attention to three points in particular:

- the position of custody as the core of any effective institution;

- the role of a code of conduct (which, when considered as a separate institution in Chapter Four, was referred to as the "association") as an additional feature of an institution; and

- the importance of, and political basis for, measures for joint ownership and management of sensitive facilities.

One important aspect of implementation is to ascertain to what extent these concepts are compatible with each other and capable of being established. This is not simply an organizational matter, but one of the correspondence between institutional features and the needs, interests, and objectives of the participants.

The focus of the analysis of institutional implementation that follows is upon custody. This choice is a deliberate one based upon the importance of custody to the reduction of proliferation risks through institutional means and upon its broad applicability to both sensitive facilities and sensitive materials. Within a nuclear regime with custody at its core, individual facilities might have varying institutional arrangements -- multinational, as well as probably predominantly national. The following analysis, however, will not address the implementation of those arrangements.

\subsubsection{Additional Institutional Arrangements}

Although custody would be at the center of a new international nuclear regime, additional sorts of arrangements may be desirable to address problems for which custody is not the appropriate means 
or is incapable of dealing with. Two such additional arrangements merit attention: multinational ownership: and management; and an association of suppliers. The former arrangement, as envisioned here, is a voluntary measure taken largely for the purpose of spreading commercial and financial risks among a number of countries. Custody itself does not deal with this possible economic interest but leaves it to national authorities to take the measures they regard as appropriate. Multinational ownership, approached in this manner, would have the desirable nonproliferation benefit of reducing the overall number and location of sensitive facilities, but it would not be the exclusive basis for building new facilities.

Moreover, multinational ownership is not the only means by which the number and location of sensitive facilities could be limited. Similar limitations could be achieved through formal agreements to the effect, restrictions on technology transfer, and the exercise of leverage vis-a-vis particular countries. Although the nonproliferation benefits of multinational ownership may in some cases be considerable, the acceptability problems associated with multinational ownership do not warrant the expenditure of political capital necessary to implement this as an exclusive arrangement. This is a major conclusion that emerges from Chapters Three and Four.

An association of suppliers, however, incorporating a code of export policy conduct, could make a very important contribution to the effectiveness of custody. An association could standardize the nonproliferation conditions governing nuclear exports, provide a mechanism for organizing back-up arrangements among the suppliers for the purpose of strengthening fuel assurances, and establish controls to limit the export of sensitive technology.

Restraints on sensitive technology transfers, however, are very important if custody is not to artificially stimulate the acquisition of such technology by appearing to legitimize its wide- 
spread use. An association limited to suppliers of sensitive nuclear technology would provide a more ready vehicle for implementing restraints on technology transfer than a custody institution whose membership might be more diffuse. The association could offer a better means of dealing with the discriminatory aspects (i.e., Iimitations on the location of sensitive facilities) of the nuclear regime than custody itself. Explicitly discriminatory provisions, moreover, could seriously detract from custody's acceptability to a broad range of participants, supplier and non-supplier alike. Careful consideration must be given to whether an association with restraint on technology transfer as one of its principal functions should be grafted onto the custody institution. As an alternative to an institution performing both custody and code of conduct functions, an association of suppliers could be established in parallel to, but separate from, the custody arrangements.

\subsection{LEVERAGE AND INCENTIVES}

The pace at which implementation proceeds, as well as its actual outcome, will depend to a great extent upon the incentives offered as a reward for participation and the leverage exercised to persuade countries to join. Clearly, the strength of the incentives and leverage needed to bring about participation is related to the overall acceptability of the institution and those considerations. regarding participation that are paramount in the decision making of potential members. The more acceptance is achieved through external incentives and leverage, the greater is the danger of a decline in support if those incentives are removed.

There are two broad classes of incentives and leverage. First, there are those that are intrinsic, or based upon or derived from participation in the institution. Second, there are non-institutionally based extrinsic incentives and leverage, involving benefits and costs whose source is outside the institution. Prominent examples of incentives in each category are listed below: 
- Intrinsic

- nonproliferation benefits

- fuel assurances (to the extent offered by the institution itself)

- legitimization of fuel cycle policy

- Extrinsic

- nuclear assistance

- non-nuclear economic assistance

- diplomatic support

- security cooperation

The disincentives, and the leverage that is based upon them, would involve the conscious withholding or loss of the above benefits. The proposition that acceptability should be rooted in the institution places particular weight upon intrinsic incentives and leverage.

Reduction of proliferation risks through the institution could be a particularly powerful incentive for some countries, but for many countries this benefit may be insufficient by itself to attract participation. Countries may rank reduction of proliferation risk quite differently, depending upon their perceptions of the immediacy. of this threat, as compared to other threats to national security, such as insecure energy supply. Moreover, since reduction of proliferation $r$ isk has the character of a collective good, soime countrles may be less willing to accept the constraints inherent in participation if they believe other countries will establish an effective institution. This might encourage passive participation or even nonparticipation if a country feels it can benefit from the reduction of proliferation risks while not having to pay for this good. Consequently, other incentives, from whose enjoyment nonparticipants can be excluded, must exist if some countries are not to be tempted into such a "free rider" strategy.

Assured availability of fuel services and materials, implemented in a way that clearly excludes non-members, might help discourage 
free riders by raising the costs of nonparticipation. A coupling of back-end with front-end assurances, which might be possible insofar as the major suppliers of back-end services are also the major front-end suppliers, could further reinforce the strength of this incentive. The fuel assurance incentive might be particularIy important in dealing with the numerous countries that perceive energy security as being at least as important as nonproliferation.

A third major incentive is legitimization of fuel cycle policy. This incentive has two aspects -- demonstration of peaceful intent to countries that otherwise might suspect military motivation of a sensitive project and take countervailing action; and reduction of external (and possibly even domestic) pressure against a sensitive fuel operation. The question of policy legitimization is a sensitive one, and what is said here does not contradict what was said earlier about minimizing the spread of sensitive technology. There are important distinctions to be made between appropriate use of sensitive material, as determined by criteria set by the group, and who actually conducts reprocessing or fabrication operations, and also between reduction of diplomatic pressure and artificial stimulation of premature sensitive fuel cycle operations.

Although sensitive fuel cycle operations carried out under the institution's auspices will acquire political legitimacy, this does not mean that a blanket approval would be given to such operations anywhere. The institution may still incorporate criteria governing when, and on what scale, sensitive operations are appropriate within the context of the institution. The legitimizing effect described here may be one of the most powerful incentives, especially where it involves removal of foreign opposition, to development of sensitive fuel cycles or assurance that controls possessed by particular supplies over sensitive activity will be exercised affirmatively. This incentive might he especially effective where the alternative is possible escalation of 
political conflict with major political, economic, or military partners.

There undoubtedly will be cases in which intrinsic incentives and disincentives provide insufficient or ineffective leverage in encouraging participation. Thus, the question of which category of incentives is relied upon is not an either-or choice, but one of proportion. Obviously, the greater the role of intrinsic incentives, the stronger will be the foundation of support for the institution.

Bilateral nuclear assistance, such as access to loans for nuclear power facilities, could be made contingent upon participation. Its effectiveness as a source of leverage would appear to require multilateral understanding among other suppliers of technical assistance, another reason for considering an association as part of the overall nuclear regime. One of the major advantages of nuclear assistance as an instrument of persuasion is the visibility of its relationship to the issues addresssd by the institution and its lower potential for being influenced by other cross-cutting non-nuclear issues and interests.

The same advantages cannot be claimed for the remaining extrinsic incentives -- economic assistance, diplomatic pressure, and security cooperation -- and especially for their use as a source of leverage. Unless nonproliferation were accorded the highest foreign policy priority, the utilization of these sources of leverage could be constrained by conflicts with non-nuclear policy objectives. Serious credibility problems in the use of such leverage would result. For example, the leverage afforded by withholding security assiatance would be limited if the target of this leverage realized that there was a point beyond which other competing foreign policy interests might not permit denial of assistance to go. This does not mean that in specific instances a country could not be pushed hard to participate. What it does mean is that a 
wider range of policy interests might come into play where this sort of leverage is involved, as compared to nuclear assistance.

\subsection{INSTITUTIONAL GROUPINGS}

Both the nature of the institutional arrangements described here and the criteria established to guide implementation place great weight upon the composition of the group(s) of countries comprising the membership of the institution. Composition has direct relevance to the institution's nonproliferation effectiveness, its organizational cohesion, and the time necessary to implement the institution. The ensuing discussion of institutional groupings is organized around four broad points: who the countries are; what facilities are involved; the rationale for the structure of the group; and the incentives and leverage available to help establish it.

The analysis presented in this chapter has emphasized the importance of establishing an institution that is adequate for its tasks from the very start, rather than relying upon institutional evolution to achieve. this. A corollary to this is the imperative of not compromising the institution in order to encourage broader participation. These considerations raise a fundamental issue regarding the implementation strategy. Should the implementation strategy be to:

- establish a single institution of international composition, possibly by organizing an initial coalition to which additional members arè subsequently added; or

- establish a number of multinational groupings, taking care that the first such grouping includes enough major suppliers and sensitive countries to develop sufficient momentum to carry the implementation process forward?

In view of the worldwide scope of nuclear trade and cooperation and the complex interrelationships among countries -- not just suppliers and customers of reprocessing services, but also suppliers of uranium and enrichment and of reactor technology and 
equipment -- a comprehensive international approach to composition would appear to have merit. Nuclear trading patterns at present are not drawn along regional lines, and a single international grouping would not encounter potential jurisdictional problems if a supplier in one multinational group sold material to a customer in another group. Moreover, the inclusion of suppliers of a range of nuclear materials and equipment in the same group could broaden the range of incentives available to attract members, especially if comprehensive front-end/back-end supply assurances could be developed.

Such an institution, however, may be impractical, especially at the start. Achieving an agreement on an institution that would be acceptable on both nonproliferation and energy security grounds would become progressively more difficult as the number and diversity of participants in the negotiations increased. An attempt to found the institution upon a membership of truly international composition from the start would run serious risk of violating the basic principle that the authority and responsibilities of the institution should not be compromised for the sake of achieving the widest possible participation.

If other than a broad international institution is the objective of implementation, the basis for establishing the resulting mutlinational structures would be the need to fit the institution to the location and scale of the reprocessing operations and resulting patterns of sensitive material flows to customers. Although a regional basis for the composition of a multinational institution has frequently attracted attention. in the study of multinational institutions, the current situation with regard to the supply of reprocessing services, in which Japan is a major customer of BNFL and Cogema, and of uranium enrichment, to which rights of control over retransfer and reprocessing are attached by some countries, clearly does not follow regional lines and would appear to make a regional approach to composition impractical. 
A more productive approach would be to base composition upon certain affinities among the members, which could be the scale of their reprocessing operations, supplier-customer relationships, or, in some cases, avowedly political interests in ensuring that regional rivals operate under the same institutional restrictions. These affinities would provide a basis for organizing an initial group for the sake of early implementation and for subsequent expansion of this group or the establishment of other multinational groups. Regardless of how the groups are constituted, however, a primary interest must be in getting an early start on implementation.

Moreover, given a choice between the international and multinational approaches, the multinational approach may retain several advantages. First, the interdependence of economic, political, and possibly security interests, as well as adversity of proliferation interests, would be more visible and immediate in a multinational group. This would enhance both the deterrence of violation and the leverage necessary for implementation. Second, there would be less potential for fundamental nonproliferation and energy security interests to be subordinated to issues drawn from other political areas (e.g., North-South relations) than would be the case in an international institution. Third, fewer special interests and national. situations would have to be accommodated in a smaller group, thus reducing the danger of serious institutional compromise for the sake of attracting members. Finally, the multinational approach imparts greater flexibility to implementation. Countries unwilling to join an international group can be accommodated if a multinational alternative is made available, and the unwillingness of a number of countries to join the multinational group will not foreclose its establishment.

Obviously, the major consideration governing the choice between the international and the multinational approach is the relative likelihood of each to result in successful establishment of an 
effective institution. If a single international group is the more likely outcome, then there is no compelling a priori reason to foreclose this outcome. Nevertheless, the preference here is for the multinational approach, for the reasons just expressed.

\subsection{AN IMPLEMENTATION STRATEGY}

Although there are several large reprocessing plants currently in operation, or planned to come into operation by the mid- to late1980s, there are numerous facilities of smaller size that are located in a number of major nuclear countries. Several of these countries are non-nuclear weapon states and have plans, in varying stages of consideration, for larger commercial facilities. At the same time, these countries share concern for both nonproliferation and energy security. For reasons developed below, these characteristics make these countries a potentially attractive starting point for implementation.

The logic of extending custody arrangements to these facilities is not based primarily upon the amount of material that would come within the domain of this particular institution. Given the sizes of the facilities, the quantity would not be particularly large. Furthermore, spent fuel sent by these countries for reprocessing elsewhere might not be subject immediately to this institution.

Extending the institution to small and medium facilities would provide a valuable demonstration of the custody concept, as well as a precedent that if sensitive activities, including smallscale operations, are to continue or be initiated, they must be conducted under the auspices of the custody institution. The strength of the precedent would be reinforced by the fact that: 1) a range of plant capacities are involved in this grouping, thus, minimizing any possible impression that there is a threshold below which a facility could be kept outside custody; 2) the product of these facilities, in some cases, is of importance to 
advanced fuel cycle development, so that the institution's noninterference with energy security-related projects can be demonstrated; and 3) major nuclear countries are involved, such that politically, if not technically (given the plant capacities involved), the institution will be a central element of the international nuclear regime.

In some respects, demonstration of the custody concept by application to some or all of these facilities would be analogous to the early demonstrations of IAEA safeguards at several U.S. reactors. These demonstrations played a valuable role both in the development of safeguards techniques and in gaining wider acceptance of safeguards by demonstrating their effectiveness and nonintrusiveness.

The primary purpose for proceeding to implement custody at these facilities first, however, is to get a head start on implementation. The small scale of the facilities is directly relevant to the achievement of this objective. Commercial scale plants may. be characterized by factors more unique to those plants that could retard implementation and complicate the organization of the initial coalition supporting early implementation. First, agreement would have to be reached with existing customers of these plants on retroactive application of a new nonproliferation condition--acceptance of custody. The untried nature of the institution, if applied to major quantities of plutonium, especially if that plutonium is destined for use in developing advanced fuel cycles to which enegy security priority is attached, could be a source of serious concern to customers. Second, the operators of those facllities might regard significant commercial interests to be at stake if custody is applied first to their operations. Potential considerations on the part of these suppliers might be loss of customers if the latter take exception to the institution and turn to other sources of supply and the protection of proprietary information and maintenance of imooth operations once custody personnel with access to all parts 
of the plant site are on station. Finally, all parties, supplier and customer alike, might be reluctant to make a major political and economic commitment to an untried institution, as would be the case if it were first implemented at commercial facilities, without first attempting to see if it could function acceptably on a smaller scale.

The facilities possessed by the small-scale group of countries could provide a testing ground for establishment and operation of custody. The commitment of resources that would be required would be smaller, and the political commitment could be more tentative. : With a long-term commitment being contingent upon actual. experience with the institution, commercial interests would be avoided, and the relatively small amounts of plutonium involved would not be indispensible for the ability to conduct an advanced reactor development program. Consequently, in terms of the scale of operations affected, there may be greater willingness to carry out an institutional experiment with these facilities than with the larger commercial ones.

At the same time, the composition of the group is such that achievement of agreement on the institution among such countries, and satisfactory experience with its operation, could have a very positive impact on the momentum of implementation and the prospects of establishing similar arrangements elsewhere. The group encompasses a full range of interests related to reprocessing and, thus, to any institutional arrangements for that part of the fuel cycle. The group would include a major customer of reprocessing, reactor operators, potential commercial reprocessors fast breeder developers, an existing commercial reprocessor, and a front-end supplier with control over reprocessing of much of the spent fuel in the non-communist world. Forging agreement among such countries, and satisfaction of these interests in the course of the institution's operations, would be a major step in the implementation of custody. 
The inclusion of the available civil plutonium separated at west Valley could be a major contribution on the part of the United States and would give the U.S. material, as well as political standing as chief advocate for the institution and as an organizer and leader of the negotiations. In the absence of comparable civil facilities, this plutonium would constitute the U.S. submission to the institution. This submission also would reiterate the important point that the institution is not limited to countries with sensitive facilities but extends to anyone producing or using sensitive material. The inclusion of a plant devoted to reprocessing breeder fuels would provide evidence that the institution need not interfere with advanced fuel cycle development and would also provide practical experience in accommodating the needs of such work within the framework of the institution.

It is anticipated, however, that this group would not remain a permanent fixture, but could well be expanded through the inclusion of large-scale facilities. There would be little sense over the longer term in separating out rather minor segments of national and international reprocessing operations. Moreover, several of the countries with small facilities are already customers of commercial reprocessors, and it is difficult to conceive of their remaining simple customers of those organizations, with no participation in the custody institution that might apply to commercial facilities. Rather, the purpose of this group is to demonstrate the viability of custody at the earliest possible date, with either merger with a commercial-scale group or simply expansion to include those facilities and countries.

There are several sources of leverage available to the U.S. that could be instrumental in establishing this group. One is the U.S. right to approve retransfer and reprocessing of spent fuel, as well as return of the separated plutonium to the owner (rights that are referred to here by the term MB-10 approval). The present case-by-case approach to MB-10 approval could be replaced 
by, and unilateral U.S. controls over SNM suspended in favor of, the institution's controls. Regardless of how favorably the other countries may react to such a change, though, the limited amounts of material subject to U.S. reprocessing approval that are involved with operation of the small facilities in question would restrict the incentive power of this development. The fact that, at present, the U.S. has no reprocessing approval right over material supplied to the European Community would also sharply restrict application of this leverage in connection with small facilities there, which, in general, do not perform reprocessing services for fuel from third countries.

However, if progress were made towards implementing custody in this group, a more positive attitude could be taken towards MB-10s for reprocessing at existing commercial facilities, too. Implementation of custody at the small facilities could be regarded as an instance of significant cooperation regarding nonproliferation and could be explicitly taken into account in reviewing MB-10s for reprocessing at the larger facilities. At some stage, however, approval of reprocessing at these larger facilities would be keyed to progress in extending the custody regime to incorporate them as well. The leverage effect of MB-10 rights could be sharply diminished if the U.S. readily approved return of SNM, regardless of institutional context. At a minimum, relating approval for return of plutonium to the owner, prior to the extension of custody to commercial facilities, to at least temporary measures to protect SNM during its return to the sender would be desirable.

The prospect of simply reducing U.S. pressures regarding the development of sensitive fuel cycles by joining the custody institution might, itself, be a particularly powerful inducement. Although the issuance of MB-10s could be the most immediate manifestation of this reduction of pressure, U.S. Offers to share the costs of and participate in development of advanced fuel policy that would define the legitimate uses of plutonium and the purposes (waste management, production of fuel for breeder development, etc.) that reprocessing would serve. 
The implementation strategy analyzed in this chapter might have significant advantages in getting an early start on implementation and in providing a base of experience with the institution at the small plants. This might facilitate establishment of custody elsewhere, but it also creates a potentially serious problem, in that large amounts of plutonium separated at commercial facilities initially would not be subject to the institution. However, this difficulty would be mitigated to the degree that recovered plutonium remained at these reprocessing locations and return made subject to further approval. Nevertheless, the central premise of the strategy described in this chapter is that there are factors associated with large-scale plants that while they may not differ in kind from those encountered with any sensitive facility or fuel cycle, may differ sufficiently in degree as to counsel approaching implementation in two distinct tracks.

The reprocessing of $5600 \mathrm{MTU}$ of spent fuel at existing commercial facilities has been contracted for, of which 400 MTU has been reprocessed. Although this is a substantial amount of material, the main problem in terms of implementation would arise when return of the material is requested by the owner. Unless custody were in force at these facilities, there would be no institutional means for controlling this material. The U.S. right to approve return of this material to non-European Community customers, and the conditions under which it would occur, would provide a practical basis to encourage extension of the regime to these larger facilities.

As was the case with regard to implementing custody at the small plants, a principal source of U.S. leverage in encouraging its extension to commercial facilities is the U.S. Fight of approval for reprocessing of U.S.-origin spent fuel. The approval could be exercised in two ways for the purpose of encouraging implementation. Approval of the return of separated plutonium produced from spent fuel reprocessed under already approved subsequent arrangements could be made contingent upon establishment of custody at 
the two facilities in question. The possibility that substantial amounts of their material could be tied up if commercial reprocessors did not agree to custody could prompt customer states to bring pressure to bear on these countries to participate.

Conditioning U.S. willingness to consider new subsequent arrangement requests upon progress in the negotiation of custody arrangement offers a second means of using the approval power to encourage implementation. This particular exercise of reprocessing appoval power would use the threat of loss of business to directly pressure commercial reprocessors.

Another major incentive for participation would be the prospect of reduced American pressure against reprocessing if custody were adopted. The effect of this potential incentive would be enhanced if implementation of custody was accompanied by development of some common understandings regarding fuel cycle policy and the legitimate purposes of reprocessing and plutonium utilization. The positive impact of the the small plant group moving ahead would also be helpful.

An obvious corollary of efforts to bring large scale plants into a custody arrangment is for the U.S. to undertake to accept the same arrangement with respect to U.S. commercial reprocessing facilities, if and when they ate completed, without regard to whether this is done under private or government ownership.

It should be recalled that the decision to approach implementation in two tracks -- small and large plant groups - was based upon tactical considerations. There is no significant reason to maintain two separate groups. The administrative problems resulting from the difference in the locus of institutional responsibility for plutonium coming out of the small plants of the first institution and that for plutonium from spent fuel sent to large facilities by some countries in the small plant group could detract from acceptability. The two groups could either merge or, more simply, 
the larger facilities could be brought into the small plant group to form a single comprehensive multinational entity concerning all facilities in these countries.

Although the nucleus of a custody institution might be the countries operating small and commercial scale reprocessing facilities, it may also be the case that the particular regional political circumstances of some countries may necessitate the establishment of separate institutional groupings, with custody as their core. This might more explicitly address the requirements of nonproliferation and energy security where those countries are involved. For a number of reasons, with nonproliferation commitment and technical competence being foremost among them, the inclusion of outside countries may be advisable. This would strengthen the credibility of the nonproliferation assurances offered by the institution in this case, and possibly improve its acceptability to the countries in question by reducing the impression that they had been singled out for special attention.

At the same time, it must be recognized that there are regions in which the threat of proliferation, and the underlying forces motivating it, are too advanced to encourage any belief that under the present circumstances custody could be implemented or that, if established, it would significantly reduce the risk of proliferation. Other approaches to reducing proliferation risk, drawn from more traditional areas of arms control, security assistance, and so forth, may hold more promise of being effective. This is not to rule out completely the utility of institutional measures, especially at some later date, but important and fundamental changes in the politico-military relations of the region may be a prerequisite for such measures to be possible.

The role of countries that are strictly customers of sensitive fuel cycle services is somewhat indefinite in a regime of institutions whose key membership is necessarily countries operating sensitive facilitics. Nonetheless, countries utilizing sensitive services will be unavoidably affected by the institution. 
The ranks of customer countries include both industrialized and industrializing states. Such countries include Sweden, Switzerland, the Netherlands, Spain, Taiwan, South Korea, and the Philippines.

The choice facing these countries is whether to join an existing group or to passively accept custody as a condition of access to sensitive services without acquiring any standing within the institutional group. Although from a nonproliferation standpoint either outcome is acceptable, for acceptability purposes the existence of a group of countries that regard themselves as powerless to affect the institution might be undesirable.

There are several reasons to believe that these countries would ultimately join a group. First, they would be affected by the institution in any event; as members they might have some say in its operation. Second, the intrinsic incentives for participating, such as fuel assurances and policy legitimization, might be particularly attractive to some of these countries. Finally, development of political momentum behind implementation could make staying out a difficult diplomatic proposition, if for no other reason than that non-participation could induce strains in alliance or regional relationships.

As was argued earlier in this chapter, expansion of membership is distinct from an evolutionary approach to development of the institution's powers and responsibilities. Renegotiation of the institution's charter would not, and should not, occur except where the participants in an already satisfactory institution choose to take on additional functions, such as facility operation. Indeed, there would appear to be little need to adjust the institution to accommodate new members, as a comprehensive range of interests (front-end suppliers, reactor operators, reprocessors, etc.) would have been represented in the membership, and 
their respective needs addressed, from the start. The requirements of nonproliferation effectiveness would be factors of critical importance in determining whether additional expansion of a particular group, and the resulting inclusion of additional energy and politico-economic circumstances in the membership, would be desirable. The possible existence of an upper limit on the desirable membership of a particular group may reinforce the preference shown in the study for a multinational approach.

It would be necessary for each group to have clear criteria for the acceptance of additional host-country members. Such criteria should limit new facilities to locations where national needs have grown to proportions sufficient to support an economically efficient facility. It is highly desirable, moreover, that rules for acceptance of new host-countries be uniform among the custody organizations to avoid "shopping" by potential reprocessors for the most liberal arrangement. 